TULIA ISABEL MARTINEZ AGUILAR

DINÂMICA SAZONAL DO ICTIOPLÂNCTON EM UMA ÁREA COSTEIRA SUBTROPICAL - UBATUBA, SÃO PAULO

Tese apresentada ao Instituto Oceanográfico da Universidade de São Paulo, como parte dos requisitos para obtenção do título de Doutor em Ciências, programa de Oceanografia, área de concentração Oceanografia Biológica.

Orientador: Prof. Dr. Mario Katsuragawa

São Paulo 
UNIVERSIDADE DE SÃO PAULO

INSTITUTO OCEANOGRÁFICO

\section{DINÂMICA SAZONAL DO ICTIOPLÂNCTON EM UMA ÁREA COSTEIRA SUBTROPICAL - UBATUBA, SÃO PAULO}

\section{TULIA ISABEL MARTINEZ AGUILAR VERSÃO CORRIGIDA}

Tese apresentada ao Instituto Oceanográfico da Universidade de São Paulo, como parte dos requisitos para obtenção do título de Doutor em Ciências, programa de Oceanografia área de concentração Oceanografia Biológica.

Julgada em 1

Prof. (a)

Prof. (a)

Prof. (a)

Prof. (a)

Prof. (a)
Conceito

Conceito

Conceito

Conceito

Conceito 


\section{Sumário}

Agradecimentos

Lista de figuras iii

Lista de Tabelas ix

Resumo $\mathbf{x}$

Abstract xi

1. Introdução 1

2. Objetivos 5

2.1 Objetivo geral _ـ 5

2.2 Objetivos específicos 5

3. Hipótese 5

4. Contextualização do projeto 6

5. Área de estudo 7

6. Material e métodos 11

6.1 No campo 11

6.1.1 Hidrografia 11

6.1.2 Amostragem do plâncton 14

6.1.2.1 Clorofila $a$ - Fitoplâncton 14

6.1.2.2 Microzooplâncton 14

6.1.2.3 Mesozooplâncton 14

6.1.2.4 Ictioplâncton 14

7. Análise de amostras 15

7.1 Clorofila $a$ 15

7.2 Biomassa do plâncton 15

7.3 Ictioplâncton 16

8. Análise dos dados 17

8.1 Massas de água 17 
8.2 Zona de mistura e zona eufótica 18

8.3 Densidade de ovos e larvas de peixes 18

8.4 Frequência de ocorrência das famílias 19

8.5 Análise estatística 19

9. Resultados 21

9.1 Variáveis ambientais 21

9.1.1 Massas de água 21

9.2 Dados biológicos 27

9.2.1 Clorofila $\mathrm{a}$ 27

9.2.3 Biomassa do zooplâncton 30

9.2.4 Ictioplâncton 31

9.2.4.1 Composição taxonômica 31

9.2.4.2 Densidade total 33

9.2.4.3 Frequência de ocorrência de larvas de peixes (\%) 34

9.2.4.4 Densidade mensal das famílias mais frequentes 36

9.2.4.5 Densidade das espécies das famílias predominantes 40

9.2.4.6 Estágio de desenvolvimento larval 50

9.3 Análise estatística 63

10. Discussão 65

10.1 Variáveis ambientais 65

10.1.1 Massas de água 65

10.2 Dados biológicos 69

10.2.1 Biomassa do zooplâncton 70

10.2.2 Ictioplâncton 72

11. Considerações Finais 75

12. Referências bibliográficas 76 
Minha jangada vai sair pro mar

vou trabalhar, meu bem quever se Deus quiser quando eu voltar do mar um peixe bom eu vou trazer

Meus companheirros também vão voltar

E a Deus do céu vamos agradecer

Adeus, adeus

Pescador não esqueça de mím vou rezar pra ter bom tempo, meu nêgo Pranãoter tempo ruim vou fazer sua caminha macia Perfumada com alecrim 


\section{Agradecimentos}

Esse trabalho é o resultado de uma árdua jornada, que só foi possível com o apoio de muitas pessoas e instituições.

Ao Prof. Mario Katsuragawa, agradeço a orientação e todo o apoio dado para a realização desse trabalho, assim como, a confiança, oportunidades de crescimento profissional e de muitos ensinamentos. Para mim, é uma imensa honra e orgulho tê-lo como orientador e também, por ter me permitido ser parte da equipe do Laboratório de Biologia e Ecologia do Ictioplâcton Marinho - LABEIM.

Dona Lourdes, meu mais sincero muito obrigado, trabalhar ao seu lado foi sensacional e todo um "sucesso" você vai além de tudo, tenho certeza que não acharei uma pessoa tão competente no seu trabalho como técnica do laboratório, pois ao mesmo tempo consegue ser amiga, irmã, mãe, conselheira e companheira. Você é realmente maravilhosa. Sem seu apoio incondicional esse trabalho não seria o mesmo

A toda equipe do Projeto ANTARES, sou completamente grata por todo o apoio ao desenvolvimento desse trabalho, pela amizade e cumplicidade, assim como, para o meu crescimento profissional, pois fizeram parte dessa inolvidável experiência embarcada. Em especial, agradeço ao Prof. Salvador Airton Gaeta do IOUSP, por permitir-me desenvolver este projeto como um subprojeto da rede ANTARES, assim como pelo fornecimento dos dados de temperatura, salinidade, densidade e clorofila $a$. Ao Prof. Milton Kampel do INPE pelo apoio logístico e financeiro para o curso Spatial and Temporal Patterns in physical-biological oceanic process realizado no Institut de Ciéncies del Mar - ICM em Barcelona - Espanha, a Maysa Pompeu pelo apoio logístico, técnico e muitas vezes emocional; ao pessoal do IO que enfrentou as ondas do Antares, Mateus Chuqui, Giulia Campos, Pedro Guy, Henrique Amato Peres e do INPE Gabriel Moiano, Aline de Mattos Valerio, Natalia Rudoff.

A todos os funcionários da Base Clarimundo de Jesus, do IOUSP, gostaria de agradecer todo o apoio logístico. Em especial, agradeço ao Manoel e Airton; aos funcionários do Véliger II, Daíco, Oziel e Xen; Seu Silvio e Adriano pelos ensinamentos e auxílios durante as coletas, e as queridas Donas Cida, Vânia e Beth, por me tratarem como se fosse parte de família em todos os momentos. Sou muito grata à vida por ter colocado pessoas tão especiais no meu caminho.

Aos Profs. Thais Navajas Corbisier e Frederico Pereira Brandini, agradeço as considerações durante a etapa de qualificação. Sou grata ao Prof. Rubens Mendes Lopes e Mario Katsuragawa pelo apoio e empréstimo de material de coleta e aos Profs. June Ferras Dias e Mario Katsuragawa, agradeço os ensinamentos durante meus estágios como bolsista PAE.

A Dra. Mônica Angélica Varella Petti, curadora da Coleção Biológica Prof. Edmundo F. Nonato do IOUSP - ColBIO e a Dra. Maria Luiza Flaquer da Rocha, agradeço pelo empréstimo do material para utilização na identificação das larvas desse trabalho.

Aos técnicos do IOUSP, agradeço imensamente todo o convívio e apoio dado durante a execução de todas as etapas desse trabalho. Em especial, meu muito, muito 
obrigada é para Tomás, Luizinho e Davi, agradeço pela imensa ajuda durante as etapas experimentais e de campo; Valter e Airton obrigada por entender meu Windows em espanhol e ter resolvido meus problemas de BIOS.

Aos funcionários da Biblioteca do IOUSP, quero agradecer a eficiente contribuição quando me senti completamente perdida em meio as estantes e volumes de revistas a serem revisados. Em especial, gostaria de agradecer a Claudinha, Cidinha e Marta, por toda simpatia e competência fazendo da biblioteca do IO um lugar maravilhoso.

A secretaria da pós-graduação, Ana Paula, Leticia e Daniel e, Marlene do DOB, muito obrigada pela ajuda em resolver tantas situações burocráticas e acadêmicas.

Amigos, são a família que escolhemos, muito obrigada às pessoas que fui conquistando ao longo destes anos em repúblicas, corredores do IOUSP e diferentes laboratórios. Obrigada pela força, sem a presença de vocês na minha vida teria sido muito complicado terminar bem esse trabalho, em particular as queridas Giulia, Mariana, Marilia, Natascha Bergo, Natasha Hoff, Silvia e, também, aos queridos Pedro, Mauricio, Mateus.

Aos amigos do LABEIM, muito obrigada pela ajuda em todos os momentos. Todos e cada um contribuíram para o seguimento desse trabalho. Camilla, obrigada pela identificação dos Pleuronetiformes e puxar minha orelha quando foi necessário; Claudia, muito obrigada pela ajuda em estatística e por compartilhar comigo seu vasto conhecimento em icitioplâncton o apoio moral em momentos difíceis foi de enorme ajuda; Erico, obrigada nas medições das larvas; Henrique, obrigada pelos gráficos e interpretações oceanográficas além das conversas e bandejões; Jana, obrigada pela ajuda acadêmica e pessoal; Marcio, mesmo à distância, a sua ajuda na identificação via whatsapp foi fundamental. Sinto-me privilegiada por ter participado deste grupo tão especial.

Ao pessoal do cafezinho MK, cada momento foi essencial, mais do que importante para me dar energia na finalização desse trabalho com sucesso.

Por fim, agradeço em especial àqueles que sempre me apoiaram incondicionalmente, apostando em mim mais do que ninguém: meus pais Cecilia e Luis e minha irmã Angela Sofia, obrigada por ficarem sempre ao meu lado, mesmo a quilômetros de distância. E, o que seria do meu último ano de doutorado sem você ao meu lado, meu gato bandido, muito obrigada Rogerio por tudo, especialmente pelo amor e apoio incondicional.

A Universidade de São Paulo, ao Instituto Oceanográfico e ao Conselho Nacional de Desenvolvimento Cientifico e Tecnológico CNPq processo CNPq 141623/2014-4, agradeço pelo apoio logístico e financeiro durante estes anos. 


\section{Lista de figuras}

Figura 1. Localização das estações fixas da rede ANTARES 7

Figura 2. Área de estudo. Localização da estação de amostragem. Estação fixa rede Antares - Ubatuba.

Figura 3. Duas das três embarcações utilizadas para o trabalho de campo.

Figura 3. Instrumentos de amostragem de água e de plâncton e método de fixação das amostras do zooplâncton e do ictioplâncton.

Figura 5. Variação temporal dos percentuais de massas de água presentes no período de coleta de fevereiro/2014 a fevereiro/2015 na estação fixa da rede - Antares localizada em Ubatuba-SP Brasil. AC - Água Costeira; AT - Água Tropical; ACAS Água Central do Atlântico Sul....

Figura 6.Variação vertical dos percentuais de massas de água presentes na estação fixa rede Antares localizada em Ubatuba-SP Brasil: As linhas pontilhadas horizontais destacam as profundidades em que houve coleta de clorofila $a$. Linha pontilhada vertical ressalta o percentual de $50 \%$. + - meses com alta influência da ACAS; $\Delta$ - meses com baixa influência da ACAS. AC- Água Costeira; AT - Água Tropical; ACAS - Água Central do Atlântico Sul; Zm = Zona de mistura e Zeu = Zona eufótica. 23

Figura 7. Variação vertical da temperatura $\left({ }^{\circ} \mathrm{C}\right)$ na estação fixa da rede Antares, localizada em Ubatuba-SP Brasil. + - meses com alta influência da ACAS; $\Delta$ - meses com baixa influência da ACAS. Zm = Zona de mistura e Zeu = Zona eufótica.

Figura 8. Variação vertical da salinidade na estação fixa da rede Antares, localizada em Ubatuba-SP Brasil. + - meses com alta influência da ACAS; $\Delta$ - meses com baixa influência da ACAS. Zm = Zona de mistura e Zeu = Zona eufótica. 25

Figura 9. Diagrama TS espalhado mensal no período de fevereiro/2014 a fevereiro/2015 na estação fixa da rede Antares. Estão representados os índices termohalinos das massas de água (Amor, 2004). + - meses com alta influência de ACAS; $\Delta$ - meses com baixa influência de ACAS. AC- Água Costeira; AT - Água Tropical; ACAS - Água Central do Atlântico Sul. 26

Figura 10. Variação vertical da clorofila $a\left(\mathrm{mg} \mathrm{m}^{-3}\right)$ no período de fevereiro/2014 a fevereiro/2015 na estação fixa da rede Antares, localizada em Ubatuba-SP. As linhas pontilhadas representam: preta $=$ limite inferior da zona de mistura e cinza $=$ limite da zona eufótica. 28 
Figura 11. Variação temporal da clorofila $a$ em estação fixa da rede Antares localizada em Ubatuba-SP. A. Interpolação temporal das coletas discretas de clorofila $a$. B. Clorofila $a$ integrada

Figura 12. Variação da biomassa total de zooplâncton em termos de peso seco (g $100 \mathrm{~m}^{-3}$ ), em estação fixa da rede Antares localizada em Ubatuba-SP. * - Meses com alta influência de ACAS. 30

Figura 13. Densidade do ictioplâncton (ovos ou larvas $100 \mathrm{~m}^{-3}$ ) em estação fixa da rede Antares localizada em Ubatuba-SP. * - meses com alta influência da ACAS. ...... 34

Figura 14. Representação do percentual da frequência de ocorrência (FO \%) e da densidade (larvas $100 \mathrm{~m}^{-3}$ ) das famílias coletadas no período de fevereiro/2014 a fevereiro/2015 em estação fixa da rede Antares localizada em Ubatuba-SP. A linha pontilhada representa $50 \%$ de frequência de ocorrência.

Figura 15. Distribuição percentual mensal da densidade das larvas de peixe Distribuição mensal do número de larvas nos estágios de desenvolvimento pré-flexão, flexão e pós-flexão coletadas em estação fixa da rede Antares localizada em Ubatuba-SP. A. Densidade das famílias com frequência de ocorrência maior ou igual a 50\%, e outras famílias; B. Detalhamento de "outras famílias”. Categoria "outras famílias" inclui aquelas com frequência de ocorrência inferior a 50\%.* - meses com alta influência da ACAS. 38

Figura 16. Distribuição mensal da densidade (larvas $100 \mathrm{~m}^{-3}$ ) da espécie de Engraulidae - Engraulis anchoita - versus a clorofila $a$ integrada $\left(\mathrm{mg} \mathrm{m}^{-2}\right)$ e a biomassa do

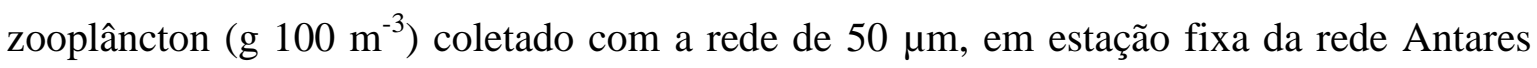
localizada em Ubatuba-SP. • - a sua posição no gráfico indica o peso seco.

Figura 17. Distribuição mensal da densidade (larvas $100 \mathrm{~m}^{-3}$ ) das espécies de Clupeidae - Harengula jaguana, Opisthonema oglinum e Sardinella brasiliensis - versus a clorofila $a$ integrada $\left(\mathrm{mg} \mathrm{m}^{-2}\right)$ e a biomassa do zooplâncton $\left(\mathrm{g} 100 \mathrm{~m}^{-3}\right)$ coletado com a rede de $50 \mu \mathrm{m}$, em estação fixa da rede Antares localizada em Ubatuba-SP. • - a sua posição no gráfico indica o peso seco.

Figura 18. Distribuição anual da densidade (larvas $100 \mathrm{~m}^{-3}$ ) da espécie de Synodontidae - Trachinocephalus myops - versus a clorofila $a$ integrada $\left(\mathrm{mg} \mathrm{m}^{-2}\right)$ e a biomassa do zooplâncton $\left(\mathrm{g} 100 \mathrm{~m}^{-3}\right.$ ) coletado com a rede de $50 \mu \mathrm{m}$, em estação fixa da rede Antares localizada em Ubatuba-SP. - a sua posição no gráfico indica o peso seco.42

Figura 19. Distribuição mensal da densidade (larvas $100 \mathrm{~m}^{-3}$ ) das espécies de Ophidiidae - Lepophidium brevibarbe e Ophidion holbrookii - versus a clorofila $a$ 


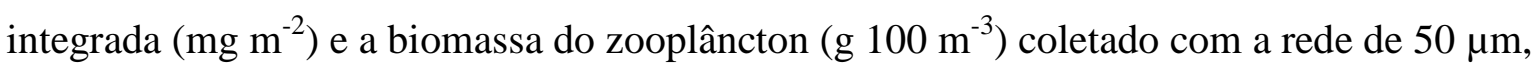
em estação fixa da rede Antares localizada em Ubatuba-SP. - a sua posição no gráfico indica o peso seco.

Figura 20. Distribuição mensal da densidade (larvas $100 \mathrm{~m}^{-3}$ ) das espécies de Carangidae - Caranx sp., Chloroscombrus chysurus, Selene setapinnis, S. vomer $e$ Trachurus lathami - versus a clorofila $a$ integrada $\left(\mathrm{mg} \mathrm{m}^{-2}\right)$ e a biomassa do zooplâncton $(\mathrm{g}$ $100 \mathrm{~m}^{-3}$ ) coletado com a rede de $50 \mu \mathrm{m}$, em estação fixa da rede Antares localizada em Ubatuba-SP. - a sua posição no gráfico indica o peso seco.

Figura 21. Distribuição mensal da densidade (larvas $100 \mathrm{~m}^{-3}$ ) das espécies de Paralichthyidae - Cyclopsetta fimbriata, Etropus crossotus e Syacium papillosum - versus a clorofila $a$ integrada $\left(\mathrm{mg} \mathrm{m}^{-2}\right)$ e a biomassa do zooplâncton $\left(\mathrm{g} 100 \mathrm{~m}^{-3}\right)$ coletado com a rede de $50 \mu \mathrm{m}$, em estação fixa da rede Antares localizada em Ubatuba-SP. • - a sua posição no gráfico indica o peso seco.

Figura 22. Distribuição mensal da densidade (larvas $100 \mathrm{~m}^{-3}$ ) das espécies de Cynoglossidae - Symphurus tessellatus e S. trewavasae - versus a clorofila $a$ integrada (mg

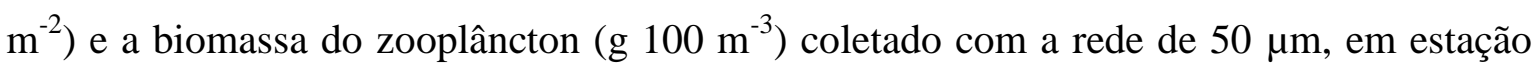
fixa da rede Antares localizada em Ubatuba-SP. • - a sua posição no gráfico indica o peso seco.

Figura 23. Distribuição mensal da densidade (larvas $100 \mathrm{~m}^{-3}$ ) das espécies de Serranidae - Diplectrum sp., Epinephelus sp. e Serranus sp. - versus a clorofila $a$ integrada

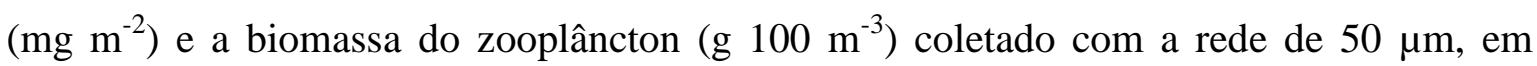
estação fixa da rede Antares localizada em Ubatuba-SP. - - a sua posição no gráfico indica o peso seco.

Figura 24. Distribuição mensal da densidade (larvas $100 \mathrm{~m}^{-3}$ ) das espécies de Sciaenidade - Cynoscion sp., Isopisthus parvipinnis e Menticirrhus americanus - versus a clorofila $a$ integrada $\left(\mathrm{mg} \mathrm{m}^{-2}\right)$ e a biomassa do zooplâncton $\left(\mathrm{g} 100 \mathrm{~m}^{-3}\right)$ coletado com a rede de $50 \mu \mathrm{m}$, em estação fixa da rede Antares localizada em Ubatuba-SP. • - a sua posição no gráfico indica o peso seco. 48

Figura 25. Distribuição mensal da densidade (larvas 100m-3) das espécies de Sciaenidae - Micropogonias furnieri, Stellifer sp., S. rastrifer e S. stellifer - versus a clorofila $a$ integrada $\left(\mathrm{mg} \mathrm{m}^{-2}\right)$ e a biomassa do zooplâncton $\left(\mathrm{g} 100 \mathrm{~m}^{-3}\right)$ coletado com a rede de $50 \mu \mathrm{m}$, em estação fixa da rede Antares localizada em Ubatuba-SP. • - a sua posição no gráfico indica o peso seco. 49 
Figura 26. E. anchoita - Distribuição mensal do número de larvas nos estágios de desenvolvimento pré-flexão, flexão e pós-flexão coletadas em estação fixa da rede Antares localizada em Ubatuba-SP.

Figura 27. Harengula jaguana - Distribuição mensal do número de larvas nos estágios de desenvolvimento pré-flexão, flexão e pós-flexão coletadas em estação fixa da rede Antares localizada em Ubatuba-SP.

Figura 28. S. brasiliensis - Distribuição mensal do número de larvas nos estágios de desenvolvimento pré-flexão, flexão e pós-flexão coletadas em estação fixa da rede Antares localizada em Ubatuba-SP. .52

Figura 29. O. oglinum - Distribuição mensal do número de larvas nos estágios de desenvolvimento pré-flexão, flexão e pós-flexão coletadas em estação fixa da rede Antares localizada em Ubatuba-SP.

Figura 30. O. holbrookii - Distribuição mensal do número de larvas nos estágios de desenvolvimento pré-flexão, flexão e pós-flexão coletadas em estação fixa da rede Antares localizada em Ubatuba-SP. .53

Figura 31 C. chrysurus - Distribuição mensal do número de larvas nos estágios de desenvolvimento pré-flexão, flexão e pós-flexão coletadas em estação fixa da rede Antares localizada em Ubatuba-SP.

Figura 32. S. setapinnis - Distribuição mensal do número de larvas nos estágios de desenvolvimento pré-flexão, flexão e pós-flexão coletadas em estação fixa da rede Antares localizada em Ubatuba-SP. 55

Figura 33. T. lathami - Distribuição mensal do número de larvas nos estágios de desenvolvimento pré-flexão, flexão e pós-flexão coletadas em estação fixa da rede Antares localizada em Ubatuba-SP.

Figura 34. E. crossotus - Distribuição mensal do número de larvas nos estágios de desenvolvimento pré-flexão, flexão e pós-flexão coletadas em estação fixa da rede Antares localizada em Ubatuba-SP.

Figura 35. S. tesselatus - Distribuição mensal do número de larvas nos estágios de desenvolvimento pré-flexão, flexão e pós-flexão coletadas em estação fixa da rede Antares localizada em Ubatuba-SP.

Figura 36. Diplectrum sp. - Distribuição mensal do número de larvas nos estágios de desenvolvimento pré-flexão, flexão e pós-flexão coletadas em estação fixa da rede Antares localizada em Ubatuba-SP. 
Figura 37. Cynoscion sp. - Distribuição mensal do número de larvas nos estágios de desenvolvimento pré-flexão, flexão e pós-flexão coletadas em estação fixa da rede Antares localizada em Ubatuba-SP.

Figura 38 M. americanus - Distribuição mensal do número de larvas nos estágios de desenvolvimento pré-flexão, flexão e pós-flexão coletadas em estação fixa da rede Antares localizada em Ubatuba-SP. 61

Figura 39. . Stellifer sp. - Distribuição mensal do número de larvas nos estágios de desenvolvimento pré-flexão, flexão e pós-flexão coletadas em estação fixa da rede Antares localizada em Ubatuba-SP.

Figura 40. S. stellifer - Distribuição mensal do número de larvas nos estágios de desenvolvimento pré-flexão, flexão e pós-flexão coletadas em estação fixa da rede Antares localizada em Ubatuba-SP.

Figura 41. Analise de Componentes Principais para as variáveis ambientais coletadas em estação fixa da rede Antares localizada em Ubatuba-SP. Os dois primeiros componentes explicam 92\% da variância total. T_m: Temperatura média; S_m: salinidade média; Clo-a_In: Clorofila $a$ integrada; Clo-a_m: Clorofila $a$ média; BM50: Biomassa

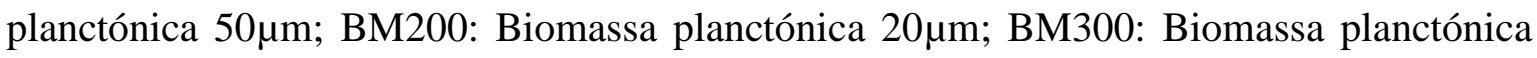
300 $\mu \mathrm{m}$; F14: fevereiro/2014; M14: março/2014; AB14: abril/2014; JN14: junho/2014; JL14: julho/2014; AG14: agosto/2014; S14: setembro/2014; OT14: outubro/2014; N14: novembro/2014; D14: dezembro/2014; JA15: janeiro/2015; F15: fevereiro/2015 Me.

Meses com baixa influência de ACAS. $\square$ Meses com alta influência de ACAS 63

Figura 42. Analise de Componentes Principais para as espécies das famílias predominantes coletadas em estação fixa da rede Antares localizada em Ubatuba-SP. Os dois primeiros componentes explicam $57 \%$ da variância total. E.an: E. anchoita; T.my: $T$. myops; L.br: L. brevibarbe; O.ho: O. holbrooki; C.ch: C. chrysurus; T.la: T. lathami; C.sp: Caranx sp.; S.se: S. setapinnis; S.vo: S. vômer; E.cr: E. crossotus; C.fi: C. fimbriata; S.pa: S. papillosum; S.te: S. tessellatus; S.tr: S. trewavasae; DI.sp: Diplectrum sp.; SE.sp: Serranus sp.; EP.Sp: Epinephelus sp.; CY.sp: Cynoscion sp.; I.pa: I. parvipinnis; M.am: M. americanus; M.fu: M. furnieri; ST.sp: Stellifer sp.; S.ra: S. rastrifier; S.st: S. stellifer. F14: fevereiro/2014; M14: março/2014; AB14: abril/2014; JN14: junho/2014; JL14: julho/2014; AG14: agosto/2014; S14: setembro/2014; OT14: outubro/2014; N14: novembro/2014; D14: dezembro/2014; JA15: janeiro/2015; F15: fevereiro/2015. - Meses com baixa influência de ACAS. $\square$ Meses com alta influência de ACAS. 
Figura 43. Imagem de satélite do 14/junho/2014 da concentração superficial de clorofila $a \mathrm{mg} \mathrm{m}^{-}{ }^{3}$ é possível identificar os vórtices anticiclônicos perto da Ilha de São Sebastião (fonte: MODIS-Aqua L2A base de dados: https://oceancolor.gsfc.nasa.gov/)... 67

Figura 44. Imagem de satélite do 14/julho/2014 da concentração superficial de clorofila $a \mathrm{mg} \mathrm{m}^{-}{ }^{3}$ é possível identificar os vórtices anticiclônicos perto da Ilha de São Sebastião (fonte: MODIS-Aqua L2A base de dados: https://oceancolor.gsfc.nasa.gov/)... 68 


\section{Lista de Tabelas}

Tabela 1. Países e instituições participantes da rede ANTARES. 6

Tabela 2. Produtividade primaria integrada $\left(\mathrm{g} \mathrm{C} \mathrm{m}^{-2} \mathrm{dia}^{-1}\right)$ da área de Ubatuba descrita por Gaeta et al., 1999.

Tabela 3. Data de realização das campanhas oceanográficas da Rede Antares e embarcações utilizadas de janeiro/2014 a fevereiro/2015.

Tabela 4. Índices termohalinos utilizados para o cálculo dos percentuais de massa de água (Amor, 2004)

Tabela 5. Valores da profundidade $(\mathrm{m})$ da Zona de Mistura $(\mathrm{Zm})$ e da Zona eufótica (Zeu) em estação fixa da rede Antares localizada em Ubatuba-SP. No mês de abril não há densidade já que não foi registrada a salinidade. Em cinza são ressaltados os meses com alta influência de ACAS.

Tabela 6. Peso seco da biomassa do plâncton coletado com diferentes malhas no período de fevereiro/2014 a fevereiro/2015 em estação fixa da rede Antares localizada em Ubatuba-SP

Tabela 7. Composição taxonômica das larvas de peixes coletadas no período de fevereiro/2014 a fevereiro/2015 em estação fixa da rede Antares localizada em UbatubaSP. Classificação baseada em Nelson et al., 2016.

Tabela 8. Número de indivíduos ( $\mathrm{N}$ ), densidade (ovos ou larvas $\mathrm{m}^{-3}$ ), porcentagem da densidade total (\%), densidade média (Média) e desvio padrão (dp) dos ovos e larvas de peixes coletados em estação fixa da rede Antares localizada em Ubatuba-SP. Realce cinza indica meses com alta influência de ACAS

Tabela 9. Número de indivíduos (N), densidade total (larvas $100 \mathrm{~m}^{-3}$ ), porcentagem (\%), densidade média (Média), desvio padrão (dp), das famílias coletadas no período de fevereiro/2014 a fevereiro/2015 em estação fixa da rede Antares localizada em Ubatuba-SP. 


\section{Resumo}

Os estudos sobre a ecologia de ovos e larvas de peixes em áreas costeiras desempenham um papel relevante para o entendimento da biologia das espécies, visto que essa fase de desenvolvimento é o mais crítico do seu ciclo de vida. Este trabalho tem como objetivo principal descrever a variação temporal da comunidade ictioplanctônica em estação fixa localizada em Ubatuba-SP $\left(23^{\circ} 36,79^{\prime} \mathrm{S} ; 4^{\circ} 53,46^{\prime} \mathrm{W}\right)$, e analisar sua relação com a hidrografia local, entre fevereiro/2014 e fevereiro/2015. Para o melhor entendimento da área de estudo foi realizado: análise de percentuais de massa de água, composição, densidade, distribuição temporal das larvas de peixes e uma análise multivariada de componentes principais (ACP). Os principais resultados mostram a alta influência da Água Costeira ( $\geq 50 \%$ ) nos primeiros $10 \mathrm{~m}$ de profundidade em todos os meses de coleta. A Água Tropical não foi identificada com altos percentuais $(\geq 50 \%)$, com exceção de junho e julho . A Água Central do Atlântico Sul (ACAS) comparece com altos percentuais ( $\geq 50 \%$ ) em fevereiro, outubro, novembro e dezembro/2014. A concentração média de Clorofila $a$,

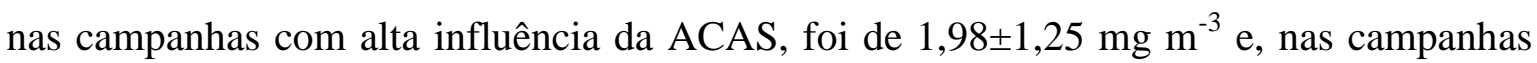
com baixa influência da ACAS, foi de $1,04 \pm 0,71 \mathrm{mg} \mathrm{m}^{-3}$. A biomassa total do zooplâncton foi maior na rede de malha $50 \mu \mathrm{m}$ e menor na de $200 \mu \mathrm{m}$. Foram coletadas 2.446 larvas de peixes, sendo que 1.906 foram identificadas em 17 ordens, 25 famílias, 23 gêneros e 26 espécies. Paralichthyidae e Sciaenidae tiveram frequência de ocorrência (FO) superior a $80 \%$ e densidade superior a 40 larvas $100 \mathrm{~m}^{-3}$; a FO de Ophidiidae e Carangidae foi de $58 \mathrm{e}$ $67 \%$, respetivamente. A análise de PCA evidenciou a formação de três grupos de espécies, cuja densidade e frequência de ocorrência variam no decorrer do ano, especialmente em função da maior ou menor influência da ACAS. 


\begin{abstract}
Studies on the ecology of fish eggs and larvae in coastal regions are important to understand the biology of species, since this developmental stage is the most critical in its life cycle. This study aims to describe the temporal variation of ichthyoplankton community in a fixed sampling station at Ubatuba-SP (23 $\left.36.79^{\prime} \mathrm{S} ; 4^{\circ} 53.46^{\prime} \mathrm{W}\right)$, and to evaluate its relation with the local hydrographical regime along a year, February/2014 to February/2015. To better understand the study area, we performed: an analysis of water masse percentages, composition, density and temporal distribution of larval fishes and a principal component analysis (PCA). The main results show the high influence of Coastal Water ( $\geq 50 \%)$ in the first $10 \mathrm{~m}$ depth on all sampling months. The Tropical Water was not recognized with high percentages ( $\geq 50 \%$ ), with exception on June and July. ACAS occurs with high percentages $(\geq 50 \%)$ on February, October, November and December $/ 2014$. Chlorophyll-a was $1.98 \pm 1.25 \mathrm{mg} \mathrm{m}-3$, in campaigns with high ACAS influence, while under low ACAS influence the average chlorophyll-a was $1.04 \pm 0.71 \mathrm{mg} \mathrm{m}-3$. Total biomass was highest for $50 \mu \mathrm{m}$ zooplankton and lowest for $200 \mu \mathrm{m}$ ones. A total of 2,446 larvae were collected and 1,906 were identified, totaling 17 orders, 25 families, 23 genera and 26 species. Occurrence frequency of Paralichthyidae and Sciaenidae was superior than $80 \%$ and density higher than 40 larvae $100 \mathrm{~m}-3$. For Ophidiidae and Carangidae, occurrence frequency was 58 and 67\%, respectively. According the PCA, three groups of species were formed, whose occurrence frequence and density vary during the year, especially in light of the greater or lesser influence of the ACAS
\end{abstract}




\section{Introdução}

Ecossistemas costeiros são alguns dos mais vulneráveis ambientes terrestres, visto que são susceptíveis à degradação por impacto antrópico pois aproximadamente mais da metade da população mundial habita essas áreas (Nicholls \& Small, 2002; Hinrichen, 1998; WOR, 2010) que também são locais de atividades recreativas e comerciais (Boerseth, 2016). Esses sistemas são, ecologicamente, um dos mais valiosos devido ao fornecimento de habitat, abrigo, alimento e também condições físicas e hidrodinâmicas favoráveis para os estágios iniciais de organismos marinhos (Nagelkerken et al., 2014; Sheaves et al., 2015).

Os estudos sobre a ecologia de ovos e larvas de peixes em áreas costeiras desempenham um papel relevante para o entendimento da biologia das espécies, visto que essa fase inicial de desenvolvimento é o mais crítico do seu ciclo de vida. Os padrões de distribuição espacial e temporal, bem como a abundância dos ovos e larvas de peixes, são influenciados pela interação de vários processos bióticos e abióticos. Os fatores biológicos incluem o local, momento e tipo de desova, a abundância dos adultos, a duração do estágio larval, o comportamento larval, a presença de predadores potencias e a disponibilidade de alimentos adequados (Llopiz et al., 2014).

A importância do estudo das comunidades ictioplanctônicas está no fato de que através delas é possível entender a biologia, ecologia e a evolução da ictiofauna, aumentando o conhecimento sobre interações entre espécies e ambiente. Conjuntamente a ciência pesqueira também se vê favorecida, já que estratégias reprodutivas de peixes, crescimento, mortalidade, alimentação e deriva das larvas fazem parte do conjunto de assuntos que abrange o estudo do ictioplâncton (Tanaka 1973; Hempel, 1979; Moser \& Smith, 1993; Matsuura \& Olivar, 1998; Garbini, 2012).

As primeiras pesquisas sobre o ictioplâncton foram realizadas na segunda metade do século XIX, quando o cientista norueguês Geord Ossian Sars foi designado para estudar a biologia do bacalhau, no sentido de entender as flutuações que ocorriam na captura anual desse peixe; em 1865, ao encontrar ovos de bacalhau flutuando próximo à superfície, apresentou os ovos como sendo uma das etapas mais importante do ciclo de vida de peixes marinhos (Bonecker et al., 2017).

No Brasil, os primeiros estudos realizados sobre ictioplancton são os de Matsuura (1971, 1972) sobre a distribuição e abundância dos ovos e larvas da sardinha-verdadeira Sardinella brasiliensis, entre cabo de São Tomé (RJ) e cabo de Santa Marta (SC). Vale 
ressaltar que a maioria das pesquisas sobre ictioplâncton marinho aborda a análise da estrutura da comunidade e dá ênfase aos recursos pesqueiros pelágicos (Matsuura, 1977).

Entre os estudos baseados nas possíveis causas das variações da dinâmica populacional das espécies estão: Scombridae (Matsuura \& Sato, 1981; Katsuragawa et al., 1993), Engraulidae (Nakatani, 1982; Kraus \& Bonecker, 1994; Favero et al., 2014), Carangidae (Katsuragawa, 1990, 1997; Saccardo \& Katsuragawa, 1995), Sciaenidae (Porcaro, et al., 2014) Fistulariidae (Barros et al., 2007), Pleuronectiformes (Garbini, 2012). Aspectos como crescimento, mortalidade, condição nutricional e alimentação do ictioplâncton foram abordados por Yoneda (1987), Dias (1995), Freire (1995), Fiadi (2008) e Namiki et al. (2015), e seguindo uma tendência mais ecológica e de relações e repostas a fatores ambientais, Katsuragawa et al. (2014), Namiki et al. (2017), assim como as variações interdecadais das condições oceanográficas dos ovos de Engraulis anchoita Favero et al. (2017a, b).

São frequentes os estudos de ictioplâncton realizados no Brasil que abrangem regiões bastante extensas tanto na área costeira como oceânica, como por exemplo, a costa sudeste do Brasil, entre Cabo Frio (RJ) e Cabo de Santa Marta Grande (SC). Essas pesquisas têm como objetivo principal a distribuição, composição e abundância, tanto espacial como temporal (Katsuragawa et al., 2006; Brandini et al., 1997). Entretanto aqueles desenvolvidos na plataforma continental, especificamente sobre águas costeiras, são pouco usuais (Matsuura et al., 1992; Katsuragawa et al., 1993; Katsuragawa et al., 2011; Namiki et al., 2007; Katsuragawa et al., 2008, 2014; Porcaro et al., 2014).

A composição taxonômica, abundância, assim como a distribuição sazonal do ictioplâncton são influenciadas pela interação entre fatores físicos e biológicos como: temperatura, salinidade, profundidade, clorofila a (Katsuragawa et al., 1993; Lopes et al., 2006; Garbini, 2012). Sabe-se que as larvas de peixes são organismos biologicamente frágeis e por isso altamente sensíveis às variações ambientais da coluna de água, e que qualquer impacto ou mudança poderia ter consequências catastróficas a estas populações (Katsuragawa et al., 2011). Dessa maneira é fundamental que se conheça a dinâmica das massas de água, a fertilidade dessas águas, a composição e distribuição dos componentes bióticos do sistema, e seu inter-relacionamento com as variáveis físicas, químicas e sedimentologias atuantes (Pires-Vanin, 1993).

Processos físicos tais como advecção induzida por ventos, marés e vórtices podem afetar a distribuição e abundância das populações de animais marinhos especialmente da 
comunidade planctônica (Harrison \& Parsons, 2001; Katsuragawa et al., 2014; Namiki et al., 2017). Em águas costeiras bem misturadas, esses fatores são tidos como os mais importantes nas mudanças de curto e médio prazo nas comunidades zooplanctônicas (Mann \& Lazier; 1991). A penetração de águas ricas em nutrientes na região costeira estimula uma variedade de efeitos ecológicos através de sua influência nos processos metabólicos dos produtores primários (Longhurst \& Pauly, 2007).

A concentração de clorofila $a$ em áreas costeiras depende diretamente do tipo de produtor primário em desenvolvimento. Portanto é importante mencionar que grande parte da variabilidade da riqueza de clorofila $a$ está relacionada com a circulação oceânica e aos processos físicos de mesoescala (Simpson \& Shapler, 2012). Segundo Santos (2015), o transporte de parcelas de água ricas em nutrientes para a zona eufótica é o processo chave para o desenvolvimento do fitoplâncton. Em condições onde a radiação solar é suficiente e a camada de mistura coincide com a zona eufótica, processos físicos, como a ressurgência costeira provocada pelo transporte de Ekman ou meandramentos causados por instabilidades das correntes, podem ser responsáveis pelo transporte de nutrientes para a camada de mistura. O resultado é o aumento da biomassa fitoplanctônica, que favorece a transferência de energia para os níveis tróficos superiores e o fluxo de carbono para o leito marinho.

Regiões costeiras tem maior interesse para os pesquisadores devido a duas situações: primeira, o contato direto que tem com comunidades humanas e, a segunda, o papel fundamental que exercem na bomba biológica. Há estimativas que $47 \%$ da exportação global de carbono para o leito marinho ocorra em plataformas continentais proveniente de águas costeiras (Jahnke, 2010), o que equivale a uma proporção de exportação/produção cinco vezes maior que as regiões oceânicas. Vale ressaltar que do ponto de vista pesqueiro é extremadamente produtiva, contribuindo com cerca de $90 \%$ da pesca mundial (Pauly et al., 2002).

Uma vez que a região de estudo está localizada no litoral norte do estado de São Paulo, município de Ubatuba, é necessário destacar que as águas oligotróficas (Aidar et al., 1993; Gaeta et al., 1995; Melo Júnior, 2016) são enriquecidas periodicamente pela Água Central do Atlântico Sul (ACAS), geralmente entre os meses de dezembro a março, devido às mudanças no regime de ventos (Castro Filho et al., 1987; Castro et al., 2006). Além dessa massa de água ainda são características a Água Costeira (AC), e a Água Tropical (AT). A sazonalidade de intrusão da ACAS influencia não apenas a estrutura 
oceanográfica, mas também a distribuição sazonal dos organismos e a dinâmica do ecossistema da região (Pires-Vanin et al., 1993). Essa massa de água afeta a estrutura da comunidade do ictioplâncton na plataforma continental ao largo da região Sudeste do Brasil (Katsuragawa et al., 2014; Soares et al., 2014; Lopes et al., 2006, Freitas \& Muelbert, 2004; Katsuragawa et al., 1993; Katsuragawa \& Matsuura, 1990). Todos os estudos realizados até o momento na região consideram uma escala temporal associada às estações sazonais mais características (por exemplo: verão e inverno, ou primavera e verão). Até o momento não foi realizada nenhuma pesquisa com maior frequência temporal de amostragem para o grupo do ictioplâncton, entretanto, dentro dos trabalhos realizados no mesmo ponto de coleta estão os de Marcolin et al. (2015) Melo Júnior et al., (2016) para o grupo de mesozooplâncton.

Esse estudo visa obter uma descrição da variação sazonal de ovos e larvas de peixe na região de Ubatuba (SP), principalmente em relação à densidade, integrando estes resultados a temperatura, salinidade, clorofila $a$ e biomassa planctônica. Desta maneira, espera-se contribuir para o conhecimento da comunidade ictioplanctônica, visto que dentro da dinâmica do ecossistema da costa sudeste do Brasil, o percentual da ACAS na coluna de água deve representar uma importante influência na densidade do ictioplâncton. Para tal, serão analisadas amostras de ictioplâncton coletadas mensalmente na estação fixa $\left(23^{\circ}\right.$ $\left.36,79^{\prime} \mathrm{S}-44^{\circ} 53,46^{\prime} \mathrm{W}\right)$ da rede ANTARES - Brasil. 


\section{Objetivos}

\subsection{Objetivo geral}

Descrever a variação temporal da comunidade ictioplanctônica em estação fixa localizada em Ubatuba-SP ( $\left.23^{\circ} 36,79^{\prime} \mathrm{S} ; 4^{\circ} 53,46^{\prime} \mathrm{W}\right)$, e sua relação com a hidrografia local, entre fevereiro/2014 e fevereiro/2015.

\subsection{Objetivos específicos}

- Descrever a variação temporal das massas de água presentes em estação fixa de Ubatuba-SP.

- Quantificar a biomassa fitoplanctônica, em termos da concentração de clorofila $a$, e do microzooplâncton (organismos $\leq 50 \mu \mathrm{m})$ e do mesozooplâncton $(50 \mu \mathrm{m}<$ organismos $\leq$ $200 \mu \mathrm{m})$ em termos de peso seco.

- Identificar a composição taxonômica das larvas de peixes e estimar sua densidade.

- $\quad$ Descrever a variação temporal da comunidade ictioplanctônica.

- Descrever a variação temporal das espécies das larvas de peixes predominantes quanto ao seu estágio de desenvolvimento.

- Avaliar a relação entre a densidade das espécies de larvas de peixe predominantes com as variáveis temperatura, salinidade, clorofila $a$ e biomassa do microzooplâncton e do mesozooplâncton.

\section{Hipótese}

Como o ponto de coleta se encontra numa área costeira e possui alta variação hidrodinâmica, foram investigadas as seguintes hipóteses científicas:

- A densidade das larvas de peixe é maior nos meses com alta porcentagem de Água Central do Atlântico Sul.

- A composição taxonômica assim como a densidade do ictioplâncton na região costeira de Ubatuba-SP estão relacionadas com a quantidade de biomassa planctônica, considerando que as condições de temperatura e salinidade mudam no período de um ano de coleta. 


\section{Contextualização do projeto}

O presente trabalho estabelece-se no projeto ANTARES, o qual está composto por uma rede de laboratórios de pesquisa localizados em vários países da América do Sul e o Mar Caribe (Tab. 1; Fig. 1). A finalidade deste projeto é estudar e compreender a variabilidade dos ecossistemas costeiros da região, assim como suas condições oceanográficas, com relação as flutuações das alterações climáticas e atividades humanas; considerando uma larga escala temporal. A união internacional de esforços, deste projeto procura: intercâmbio de ideias, desenvolvimento de infraestrutura para a logística da coleta de amostras, apoio e mutuo conhecimento, e finalmente fornecer um veículo eficaz para treinamento e capacitação para os profissionais da região. Visando o enlace entre os dados de satélite e observações in situ, a rede ANTARES foi criada em 2003 e contou com o apoio do IOCCG (International Ocean-Color Coordinatin Group) e do POGO (Partnership for the Observation of the Global Oceans) (Dogliotti et al., 2005).

O recurso humano deste projeto, tem como base pesquisadores sul-americanos de várias áreas da ciência, capacitados na análise e interpretação de dados de satélite, distribuição de fitoplâncton marinho e produtividade primaria nos oceanos, assim como medidas de longo prazo da dinâmica do fitoplâncton e estrutura da comunidade. No entanto esta equipe é complementada por especialistas dos EUA e do Canadá, os quais tem apoiado o projeto, na capacitação especialmente no campo da óptica, cor do oceano, dinâmica do fitoplâncton e da produção primaria.

Tabela 1. Países e instituições participantes da rede ANTARES.

\begin{tabular}{cll}
\hline \multicolumn{1}{c}{ Pais } & \multicolumn{1}{c}{ Instituição } & \multicolumn{1}{c}{ Estação } \\
\hline México & UABC & Ensenada \\
Argentina & CONICET/INIDEP & EPEA \\
& INIDEP & \\
& CONICET/IAFE & \\
Venezuela & FLASA & Cariaco \\
& FLSCN/EDIMAR & \\
Brasil & USF & \\
Colômbia & IOUSP/INPE & Ubatuba \\
Peru & CIOH/DIMAR & Cartagena \\
Equador & IMARPE & IMARPE \\
& INOCAR & La libertad \\
& & Manta \\
\hline
\end{tabular}




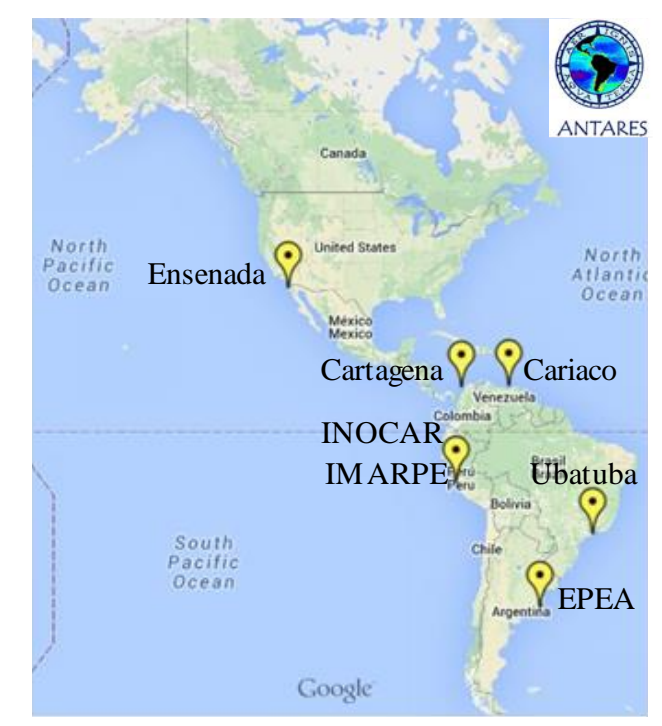

Figura 1. Localização das estações fixas da rede ANTARES.

\section{5. Área de estudo}

A região de Ubatuba, localizada no litoral norte do estado de São Paulo, entre a ilha de São Sebastião a enseada de Ubatumirim e as isóbatas de 10 e 100 m, compreende uma área $3.800 \mathrm{~km}^{2}$, aproximadamente. Vale ressaltar que essa área na sua região centrosul, da costa até a isóbata de $50 \mathrm{~m}$, difere fisiogeograficamente da porção norte, pois apresenta obstáculos físicos representados pelas ilhas Anchieta, Vitória, Búzios e, principalmente, pela ilha de São Sebastião. Estas características geográficas fazem com que tanto o impacto de mar aberto como o hidrodinamismo sejam menos intensos (PiresVanin et al., 1993).

$\mathrm{Na}$ região de Ubatuba é possível encontrar três diferentes massas de água: Água Costeira (AC), Água Tropical (AT) e Água Central do Atlântico Sul (ACAS). As características principais destas massas de água estão descritas por Emilsson (1961), Miranda (1985), Castro et al. (1987), Castro \& Miranda (1998), Castro et al. (2006) e Castro (2014). A AC resulta da mistura da descarga continental de água doce com as águas da plataforma continental e apresenta temperaturas entre 21 e $27^{\circ} \mathrm{C}$, que variam de acordo com a época do ano. Possui os menores valores de salinidade $(<35)$ devido ao aporte dos pequenos e médios rios presentes na região. Ocupa a parte mais interna da plataforma continental e apresenta pequena estratificação vertical em função dos processos de mistura causados pelas tensões de cisalhamento do vento na superfície e de cisalhamento das correntes de maré no fundo. A AT é caracterizada por ser uma massa de água quente, salina e pobre em nutrientes, com temperatura maior que $20{ }^{\circ} \mathrm{C}$ e salinidade acima de 36 . 
Essa massa de água é transportada para sul-sudoeste $(0-200 \mathrm{~m})$ pela corrente do Brasil (CB), por volta da quebra de plataforma continental. Sua influência geralmente se limita à plataforma continental média e externa.

A ACAS é uma massa de água relativamente fria e rica em nutrientes, com temperatura entre seis e $20^{\circ} \mathrm{C}$ e salinidade variando entre 36,4 e 36 . Ela também é transportada na direção sul-sudoeste ao longo do talude continental, na camada inferior da CB (200-500 m), próximo à quebra da plataforma continental. No inverno, a ACAS tende a permanecer mais restrita às áreas mais extremas da plataforma e ao largo do talude fazendo com que a coluna de água na plataforma interna e média apresente homogeneidade térmica, enquanto na primavera e no verão ela tende a penetrar em direção à costa. A intrusão da ACAS em direção à costa ocorre em decorrência dos ventos NE que favorecem o transporte de volume na camada de Ekman em direção ao largo, enquanto abaixo da camada de Ekman o transporte de ajuste induz a penetração da água subsuperficial (ACAS) em direção à costa. A presença sazonal da ACAS na plataforma interna de Ubatuba é a principal característica oceanográfica estruturando o ecossistema na região (Pires-Vanin \& Matsuura, 1993).

Estudos quali-quantitativos e fisiológicos tendo como base o fitoplâncton natural levaram à caracterização da área de Ubatuba como oligo a mesotrófica (Sassi \& Kutner, 1982; Teixeira, 1982, 1986; Vieira \& Teixeira, 1982; Teixeira \& Gaeta, 1991; SusiniZillmann, 1990; MetzIer, 1991) especificamente nas massas de água AC e AT devido à ausência de uma fonte externa de nutrientes (Aidar et al., 1993).

A produção primária representa a capacidade de um ambiente de fixar carbono inorgânico dissolvido em moléculas orgânicas de alto potencial energético, dessa forma pode-se estimar o potencial pesqueiro de um ecossistema aquático (Ryther, 1969). Na costa brasileira, a produção primaria aumenta devido ao acontecimento de sistemas frontais, que ocorrem simultaneamente em tempo e espaço, fertilizam a plataforma continental e substituem o sistema oligotrófico antigo por um sistema de produção nova (Dugdale \& Goering, 1967), incrementando a média anual de produção primaria. Tornando a bacia sudeste do Brasil a mais produtiva dentre as províncias da margem costeira brasileira (Brandini et al., 2018).

$\mathrm{Na}$ área de estudo, embora as frentes frias sejam comuns em todas as estações do ano, ocorrem em média duas a três passagens de sistemas frontais em fevereiro e cinco a seis em outubro (Oliveira, 1986). Estes sistemas representam condições desfavoráveis para sustentar a intrusão da ACAS e são responsáveis pela intensa mistura da coluna de água, 
favorecendo a entrada de nutrientes na zona eufótica devido à remobilização do substrato rico em compostos nitrogenados. Assim tanto os ventos de NE, característicos de verão, como a passagem de frentes frias, recorrentes no inverno, podem estar relacionados ao aumento da produtividade primária (Gaeta et al., 1999; Oliveira, 2009; Santos, 2015)

A região estudada, em condições de mistura, está caracterizada pelo domínio de nanoflagelados em superfície e, entre 50 e $1 \%$ de intensidade luminosa, as diatomáceas respondem por mais do $50 \%$ da biomassa fitoplanctônica; em razão disto a média de produção primária em condições normais é de $0,5 \mathrm{~g} \mathrm{C} \mathrm{m}^{-2} \mathrm{dia}^{-1}$. Alterações como a descrita anteriormente, de entrada de nutrientes, ou de chuvas intensas que causam entrada de material continental, incrementam em mais de duas vezes o valor de produção primaria (Gaeta et al., 1999) (Tab. 2).

$\mathrm{Na}$ área de estudo, o valor de produtividade primária varia com o estado da coluna de água, conforme tabela a seguir (Gaeta et al., 1999):

Tabela 2. Produtividade primaria integrada $\left(\mathrm{g} \mathrm{C} \mathrm{m}^{-2} \mathrm{dia}^{-1}\right)$ da área de Ubatuba descrita por Gaeta et al., 1999.

\begin{tabular}{ccc}
\hline Estado da coluna de água & Produtividade primária integrada da zona eufótica \\
\cline { 2 - 3 } & Média \pm Desvio padrão & $\begin{array}{c}\text { Amplitude de variação } \\
\mathrm{g} \mathrm{C} \mathrm{m}^{-2} \text { dia }^{-1}\end{array}$ \\
\hline Mistura $\rightarrow$ Estratificação & $0,40 \pm 0,11$ & 0,21 a 0,59 \\
\hline $\begin{array}{c}\text { Durante e depois de fortes } \\
\text { chuvas }\end{array}$ & $1,24 \pm 0,28$ & 0,63 a 0,86 \\
\hline $\begin{array}{c}\text { Estratificação depois de } \\
\text { chuva }\end{array}$ & $0,74 \pm 0,10$ & 0,63 a 0,86 \\
\hline Estratificação $\rightarrow$ Mistura & $0,90 \pm 0,27$ & 0,45 a 1,2 \\
\hline $\begin{array}{c}\text { Estratificação depois de forte } \\
\text { mistura }\end{array}$ & $0,63 \pm 0,28$ & 0,26 a 1,07 \\
\hline
\end{tabular}

O comportamento da biomassa do fitoplâncton na área de estudo, em termos de clorofila $a$, segundo Aidar et al. (1993), pode ser explicado em cada massa de água: na AC no verão varia entre 0,31 a $0,82 \mathrm{mg} \mathrm{m}^{-3}$ e no inverno entre 0,53 a $1,07 \mathrm{mg} \mathrm{m}^{-3}$; na AT varia de 0,06 a $0,25 \mathrm{mg} \mathrm{m}^{-3}$ no verão e de 0,31 a $0,37 \mathrm{mg} \mathrm{m}^{-3}$ no inverno.

A comunidade planctônica tem necessidades nutricionais bem definidas que, identificadas, podem auxiliar o entendimento da sua dinâmica de crescimento no oceano (Eppley \& Holm-Hansen, 1986). Tendo em vista esta situação, na área de estudo o Nitrato pode atingir valores máximos de $1,58 \mu \mathrm{M}$. Na AT os valores máximos chegam a $0,5 \mu \mathrm{M}$, porem valores iguais a zero são frequentes. Durante verão na $\mathrm{AC}$ as concentrações se encontram entre 0,15 a $0,38 \mu \mathrm{M}$ maiores dos que na AT que estão entre 0,06 a $0,34 \mu \mathrm{M}$; no 
inverno os valores na $\mathrm{AC}$ se encontram entre 0,29 a $0,77 \mu \mathrm{M}$, menores do que os encontrados na AT 0,44 a 1,24 $\mu \mathrm{M}$. abaixo da termoclina e portanto, sob o predomínio da ACAS, a variação nas concentrações de nitrato dissolvido ocorre numa escala maior do que na $\mathrm{AC}$ e na $\mathrm{AT}$, principalmente nas época de intensa penetração daquela massa de água sobre a plataforma continental. Quando a ACAS se aproxima da superfície, atingindo a camadas superiores da zona euf6tica (verão), as concentrações de nitrato se tornam frequentemente indetectáveis variando entre 0,27 a $\mathrm{O}, 80 \mu \mathrm{M}$ (Aidar et al., 1993).

Outro nutriente limitante para o metabolismo dos organismos marinhos é o fósforo. $\mathrm{Na}$ área de estudo a distribuição deste nutriente, em formato de íon fosfato, se assemelha muito a do íon nitrato. As concentrações na camada de mistura (predominância de $\mathrm{AC}$ ou da $\mathrm{AT}$ ), assim como no verão, variando entre 0,09 a $0,23 \mu \mathrm{M}$ na $\mathrm{AC}$ e 0,09 a $0,15 \mu \mathrm{M}$ na AT, e no inverno, 0,23 a $0,42 \mu \mathrm{M}$, na $\mathrm{AC}$ e 0,14 a $0,38 \mu \mathrm{M}$ na AT, são baixas. $\mathrm{Na}$ ACAS o fosfato variou entre 0,23 a $0,65 \mu \mathrm{M}$ valores significativamente mais elevados que nas outras massas de água (Aidar et al., 1993). 


\section{Material e métodos}

Para o desenvolvimento do presente estudo foram utilizados dados hidrográficos e biológicos coletados na estação fixa localizada na região de Ubatuba. Nesta estação é desenvolvido o projeto ANTARES-Brasil, o qual tem como objetivo estudar as mudanças de longo período nos ecossistemas costeiros da América do Sul (http://www.dsr.inpe.br/antares/).

\subsection{No campo}

As coletas foram realizadas em estação fixa da rede Antares na plataforma interna de Ubatuba, aproximadamente a 10 milhas náuticas do continente $\left(44^{\circ} 58^{\prime} 52^{\prime \prime} \mathrm{W}, 23^{\circ} 37^{\prime}\right.$ 19"S), sobre a isóbata de 40 m (Fig. 2). Doze campanhas oceanográficas, de fevereiro de 2014 a fevereiro de 2015, com exceção de maio de 2014, foram realizadas a bordo do B/Pq. Alpha Delphini, B/Pq Veliger II ou o barco de pesca Vulcano (Fig. 3; Tab. 3). Em janeiro de 2014 foi realizado um trabalho de campo piloto com o objetivo de ajustar o tempo de realização das coletas.

\subsubsection{Hidrografia}

Os dados de profundidade, temperatura $\left({ }^{\circ} \mathrm{C}\right)$ e condutividade foram obtidos a partir de registros verticais contínuos obtidos com auxílio do CTD (Condutivity, Temperature, Depth) Seabird ${ }^{\circledR}$. A partir dos dados do CTD foi calculada a salinidade e a densidade da coluna de água.

Para estimativa da zona eufótica foram realizadas medidas de profundidade de transparência da coluna de água com auxílio de um disco de Secchi. 


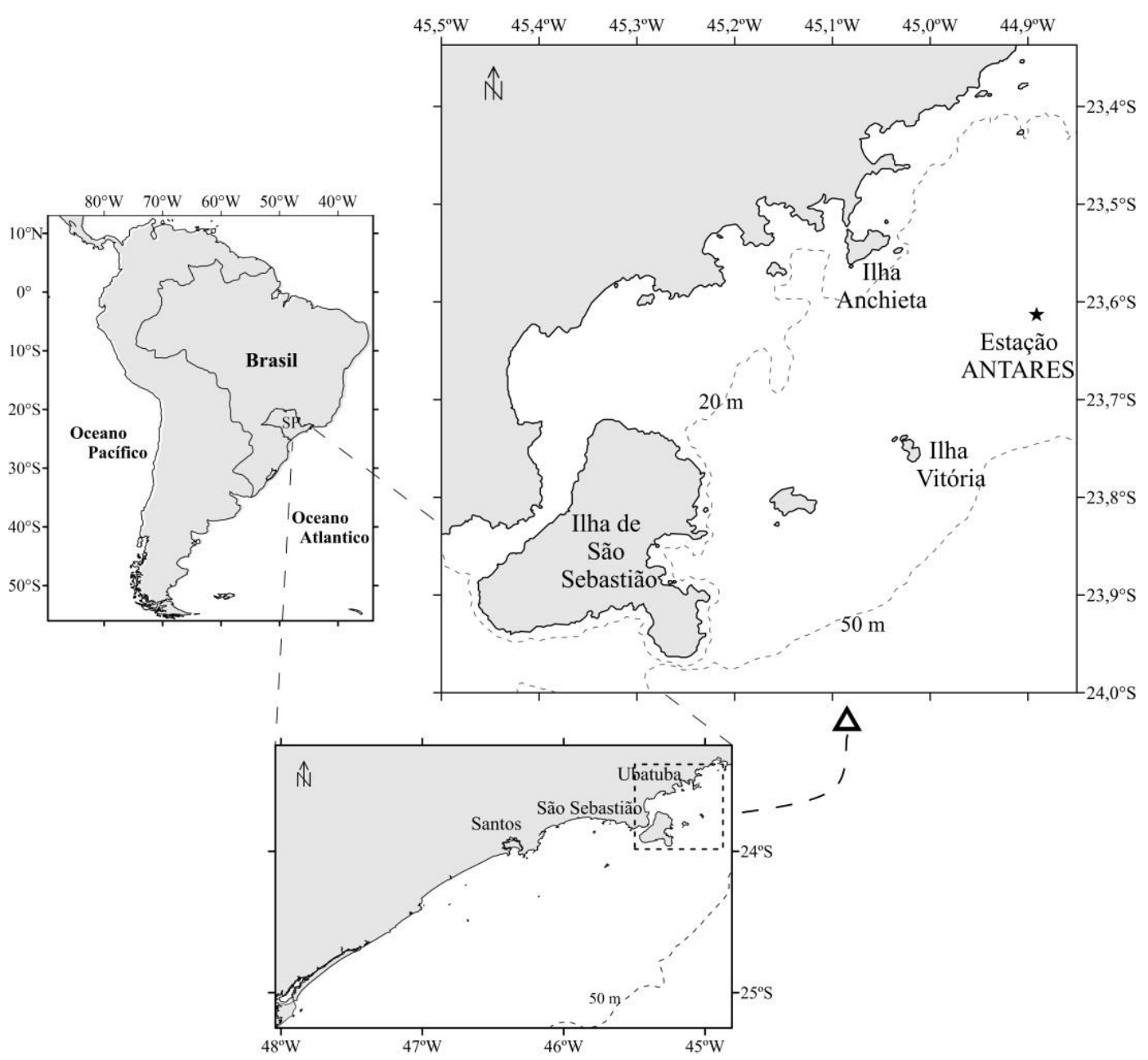

Figura 2. Área de estudo. Localização da estação de amostragem. Estação fixa rede Antares - Ubatuba.

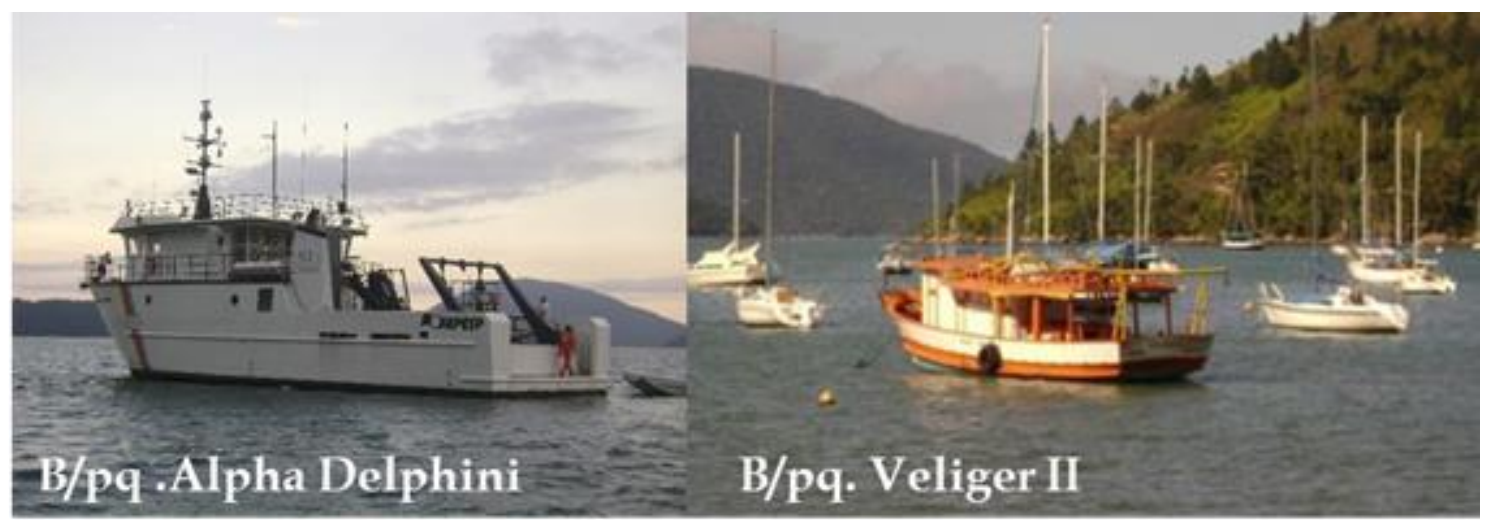

Figura 3. Duas das três embarcações utilizadas para o trabalho de campo. 
Tabela 3. Data de realização das campanhas oceanográficas da Rede Antares e embarcações utilizadas de janeiro/2014 a fevereiro/2015.

\begin{tabular}{|c|c|c|c|c|c|c|}
\hline Data & $\begin{array}{c}\text { Sigla } \\
\text { ANTARES }\end{array}$ & Código amostra & Fixador & Malha - Tipo de rede & $\begin{array}{l}\text { Profunidade } \\
\text { máxima de } \\
\text { arrasto (m) }\end{array}$ & Embarcação \\
\hline $21 / 01 / 2014$ & UBA107 & Piloto & Formol 4\% & $300 \mu \mathrm{m}$ bongô & 35 & Alpha Delphini \\
\hline \multirow{4}{*}{$25 / 02 / 2014$} & \multirow{4}{*}{ UBA108 } & L- 4965 F1 & Formol 4\% & \multirow{2}{*}{$300 \mu \mathrm{m}$ bongô } & 35 & \multirow[t]{4}{*}{ 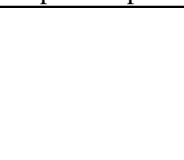 } \\
\hline & & L- 4965 F2 & Formol $4 \%$ & & 35 & \\
\hline & & Z- 287-200 & Formol $4 \%$ & $200 \mu$ m cónico simples & 35 & \\
\hline & & Z- 287-50 & Formol $4 \%$ & $50 \mu \mathrm{m}$ cónico simples & 35 & \\
\hline \multirow{4}{*}{ 24/03/2014 } & \multirow{4}{*}{ UBA109 } & L- 4966 F1 & Formol 4\% & \multirow{2}{*}{$300 \mu \mathrm{m}$ bongô } & 35 & \multirow{16}{*}{ Veliger II } \\
\hline & & L- 4966 F2 & Formol $4 \%$ & & 35 & \\
\hline & & Z- $288-200$ & Formol $4 \%$ & 200 ㅆm cónico simples & 35 & \\
\hline & & Z- $288-50$ & Formol 4\% & $50 \mu \mathrm{m}$ cónico simples & 35 & \\
\hline \multirow{4}{*}{ 23/04/2014 } & \multirow{4}{*}{ UBA110 } & L- 4967-F1 & Formol 4\% & \multirow{2}{*}{$300 \mu \mathrm{m}$ bongô } & 35 & \\
\hline & & L- 4967-F2 & Formol 4\% & & 35 & \\
\hline & & Z- 289-200 & Formol $4 \%$ & 200 ㅆm cónico simples & 35 & \\
\hline & & Z- $289-50$ & Formol 4\% & $50 \mu \mathrm{m}$ cónico simples & 35 & \\
\hline \multirow{4}{*}{ 17/06/2014 } & \multirow{4}{*}{ UBA111 } & L- 4968-F1 & Formol 4\% & \multirow{2}{*}{$300 \mu \mathrm{m}$ bongô } & 35 & \\
\hline & & L- 4968-F2 & Formol 4\% & & 35 & \\
\hline & & Z- 290-200 & Formol 4\% & 200 ㅆm cónico simples & 35 & \\
\hline & & Z- 290-20 & Formol 4\% & $50 \mu \mathrm{m}$ cónico simples & 35 & \\
\hline \multirow{4}{*}{$16 / 07 / 2014$} & \multirow{4}{*}{ UBA112 } & L- 4969-F1 & Formol 4\% & \multirow{2}{*}{$300 \mu \mathrm{m}$ bongô } & 35 & \\
\hline & & L- 4969-F2 & Formol $4 \%$ & & 35 & \\
\hline & & Z- 291-200 & Formol $4 \%$ & $200 \mu \mathrm{m}$ cónico simples & 35 & \\
\hline & & Z- 291-50 & Formol $4 \%$ & $50 \mu \mathrm{m}$ cónico simples & 35 & \\
\hline \multirow{4}{*}{$14 / 08 / 2014$} & \multirow{4}{*}{ UBAA113 } & L- 4970-F1 & Formol 4\% & \multirow{2}{*}{$300 \mu \mathrm{m}$ bongô } & 35 & \multirow{4}{*}{ Alpha Delphini } \\
\hline & & L- 4970-F2 & Formol $4 \%$ & & 35 & \\
\hline & & Z- 292-200 & Formol $4 \%$ & $200 \mu \mathrm{m}$ cónico simples & 35 & \\
\hline & & Z- $292-50$ & Formol $4 \%$ & $50 \mu \mathrm{m}$ cónico simples & 35 & \\
\hline & & L- 4971-F1 & Formol 4\% & & 35 & \\
\hline & & L- 4971-F2 & Formol $4 \%$ & $300 \mu \mathrm{m}$ bongo & 35 & \\
\hline 16/09/2014 & UBA114 & Z- $293-200$ & Formol $4 \%$ & $200 \mu \mathrm{m}$ cónico simples & 35 & Vulcano \\
\hline & & Z- 293-50 & Formol $4 \%$ & $50 \mu \mathrm{m}$ cónico simples & 35 & \\
\hline & & L- 4972-F1 & Formol 4\% & 300 um bongô & 35 & \\
\hline & & L- 4972-F2 & Formol $4 \%$ & $300 \mu \mathrm{m}$ bongo & 35 & \\
\hline 14/10/2014 & UBA115 & Z- 294-200 & Formol $4 \%$ & $200 \mu \mathrm{m}$ cónico simples & 35 & \\
\hline & & Z- 294-50 & Formol 4\% & $50 \mu \mathrm{m}$ cónico simples & 35 & \\
\hline & & L- 4973-F1 & Formol 4\% & 300 um honô̂ & 35 & Alpha Delphını \\
\hline $25 / 11 / 2014$ & UBA116 & L- 4973-F2 & Formol $4 \%$ & $300 \mu \mathrm{m}$ bongo & 35 & \\
\hline $25 / 11 / 2014$ & ОВАІІО & Z- 295-200 & Formol $4 \%$ & $200 \mu \mathrm{m}$ cónico simples & 35 & \\
\hline & & Z- 295-50 & Formol $4 \%$ & $50 \mu \mathrm{m}$ cónico simples & 35 & \\
\hline & & L- 4978-F1 & Formol 4\% & & 35 & \\
\hline & & L- 4978-F2 & Formol $4 \%$ & $300 \mu \mathrm{m}$ bongô & 35 & \\
\hline 14/12/2014 & UBA117 & Z- 296-200 & Formol $4 \%$ & $200 \mu \mathrm{m}$ cónico simples & 35 & \\
\hline & & Z- 296-50 & Formol $4 \%$ & $50 \mu \mathrm{m}$ cónico simples & 35 & \\
\hline & & L- 4979-F1 & Formol 4\% & & 35 & \\
\hline $15 / 01 / 2015$ & & L- 4979-F2 & Formol $4 \%$ & $300 \mu \mathrm{m}$ bongó & 35 & \\
\hline 15/01/2015 & UBA118 & Z- 297-200 & Formol $4 \%$ & $200 \mu \mathrm{m}$ cónico simples & 35 & Veliger II \\
\hline & & Z- 297-50 & Formol 4\% & $50 \mu \mathrm{m}$ cónico simples & 35 & \\
\hline & & L- 4980-F1 & Formol 4\% & & 35 & \\
\hline $15 / 02 / 2015$ & UBA119 & L- 4980-F2 & Formol $4 \%$ & $300 \mu \mathrm{m}$ bongô & 35 & \\
\hline $15 / 02 / 2015$ & UВА119 & Z- 298.-200 & Formol $4 \%$ & $200 \mu$ m cónico simples & 35 & \\
\hline & & Z- 298-50 & Formol 4\% & $50 \mu \mathrm{m}$ cónico simples & 35 & \\
\hline
\end{tabular}




\subsubsection{Amostragem do plâncton \\ 6.1.2.1 Clorofila $a$ - Fitoplâncton}

Para a obtenção de amostras de água para estimativa da concentração de clorofila $a$ foram coletadas amostras de água com garrafas Niskin com capacidade de $11 \mathrm{~L}$, em cinco níveis de profundidade: 0,5 (superfície), 5, 10, 25 e $38 \mathrm{~m}$. Essas amostras foram armazenadas em garrafas térmicas de $10 \mathrm{~L}$ e protegidas do sol, para posterior filtração em terra (Fig. 3).

\subsubsection{Microzooplâncton}

Arrastro vertical, no sentido fundo - superfície até $5 \mathrm{~m}$ acima do fundo, com rede cônica simples de $50 \mu \mathrm{m}$ de malha, boca de $50 \mathrm{~cm}$ e comprimento de $1,20 \mathrm{~m}$. Para estimar o volume de água filtrado foi acoplado um fluxômetro à boca da rede. As amostras foram fixadas em solução 4\% de formaldeído tamponado com água de mar (Fig. 3).

\subsubsection{Mesozooplâncton}

Arrastro vertical, no sentido fundo - superfície a partir de $5 \mathrm{~m}$ acima do fundo. Foi utilizada uma rede cônica simples com $200 \mu \mathrm{m}$ de malha, boca de $50 \mathrm{~cm}$ e comprimento de 1,20 m. Para estimar o volume de água filtrado foi acoplado um fluxômetro à boca da rede. As amostras foram fixadas em solução $4 \%$ de formaldeído tamponado com água de mar (Fig. 3)

\subsubsection{Ictioplâncton}

Arrastro oblíquo com rede bongô, no sentido superfície-fundo-superfície, atingindo uma profundidade máxima de $5 \mathrm{~m}$ acima do fundo, com aproximadamente cinco minutos de arrasto e velocidade máxima de 4 nós $(\sim 2 \mathrm{~m} / \mathrm{s})$. Essa rede é constituída de um suporte binocular onde são fixadas duas redes cônico-cilíndricas, sendo o tamanho das malhas de $300 \mu \mathrm{m}$ com $3 \mathrm{~m}$ de comprimento, boca de $60 \mathrm{~cm}$ e fluxômetros acoplados (Smith \& Richardson, 1977). Uma das amostras (F1) foi imediatamente fixada com solução de Bouin (5\%) e conservadas em álcool 70\% (Figueiredo et al., 2005) e a outra (F2) em solução 4\% de formaldeído tamponado com água de mar (Fig. 3).

Foram analisadas tanto as amostras fixadas com formol $4 \%$ como aquelas fixadas com bouin 5\% e conservadas em álcool 70\%. Vale ressaltar que algumas das larvas fixadas em álcool $70 \%$ perderam a pigmentação e o tecido foi danificado em consequência a analise foi prejudicada. Recomenda-se não usar bouin (5\%) para a fixação de amostras de zooplâncton - ictioplâncton. 


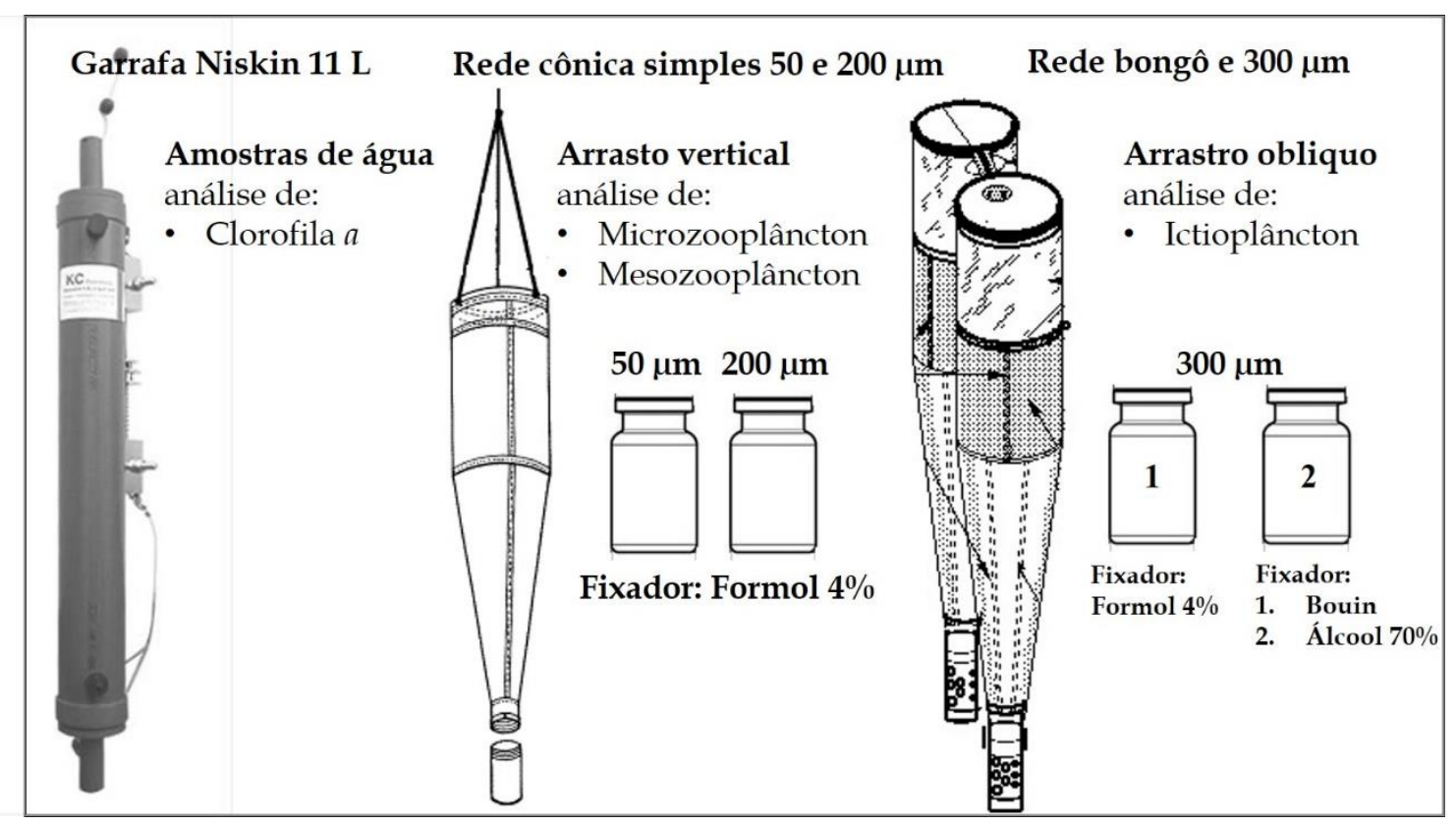

Figura 4. Instrumentos de amostragem de água e de plâncton e método de fixação das amostras do zooplâncton e do ictioplâncton.

\section{Análise de amostras}

\subsection{Clorofila $a$}

No laboratório, aproximadamente duas horas após a coleta, 2 L de água foram filtrados através de filtros de fibra de vidro Whatman ${ }^{\circledR} \mathrm{GF} / \mathrm{F}$ (47 $\mathrm{mm}$ de diâmetro) para retenção do material particulado. A concentração de clorofila $a$ foi obtida a partir da extração dos pigmentos em acetona a 90\%, por $24 \mathrm{~h}$, seguida da leitura por fluorimetria (Welschmeyer, 1994) e expressa em $\mathrm{mg} \mathrm{m}^{-3}$. Os dados de clorofila $a$ foram cedidos pelo Laboratório de Produção Primária do IOUSP.

\subsection{Biomassa do plâncton}

Para caracterizar o ambiente pelagial da área de estudo, foi estimada a biomassa

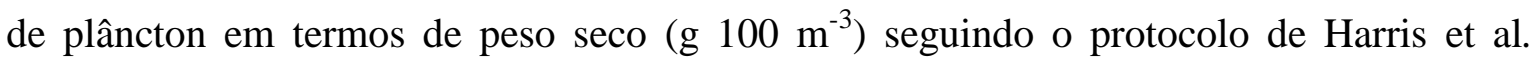
(2000). Este procedimento foi realizado para uma fração das amostras coletadas com a rede de $50 \mu \mathrm{m}$ - microplâncton e de $200 \mu \mathrm{m}$ - mesozooplâncton; nas amostras das duas redes da bongô, esse procedimento foi realizado após a triagem do ictioplâncton.

Inicialmente, as amostras das quatro redes foram fracionadas, com auxílio de um subamostrador Motoda (Omori \& Ikeda, 1984), da seguinte maneira: rede bongo $300 \mu \mathrm{m}$ $1 / 8$, rede de $200 \mu \mathrm{m} 1 / 4$ e rede de $50 \mu \mathrm{m}$ até $1 / 2$. O restante das amostras foi armazenado 
novamente. Para diminuir a quantidade de organismos menores ao tamanho da rede a ser analisada, cada fração foi peneirada por malhas mais finas da seguinte maneira: as amostras da rede de $300 \mu \mathrm{m}$ passaram pela malha de $200 \mu \mathrm{m}$; as de $200 \mu \mathrm{m}$ passaram pela malha de $60 \mu \mathrm{m}$ e finalmente as amostras da rede de $50 \mu \mathrm{m}$ passaram pela rede de $10 \mu \mathrm{m}$.

A seguir, cada fração foi retirada do fixador, e transferida para um fragmento de papel alumínio de peso conhecido, pesada em uma balança analítica de quatro casas decimais (TOLEDO AR2140 ${ }^{\circledR}$ ) para obtenção do peso úmido e colocada em estufa (Estufa com renovação de ar 420-TD ethik technology ${ }^{\circledR}$ ) a $60^{\circ} \mathrm{C}$ por $24 \mathrm{~h}$. Depois da secagem, as amostras foram transferidas para um dessecador e novamente pesadas.

A biomassa de plâncton de cada amostra foi obtida através da razão entre a estimativa do peso seco de toda a amostra e o volume de água filtrada pelas redes.

Biomassa $\left(\right.$ grlo0 $\left.\mathrm{m}^{-3}\right)=\left[(\right.$ subamostra seca $(\mathrm{g}) /$ fração* $) /$ volume de água filtrado $\left.\left(\mathrm{m}^{3}\right)\right] \times 100$ * fração especifica para cada tamanho de amostra: $50 \mu \mathrm{m}=1 / 2 ; 200 \mu \mathrm{m}=1 / 4 ; 300 \mu \mathrm{m}=1 / 8$

\subsection{Ictioplâncton}

As amostras obtidas com a rede bongô foram triadas, sendo retirados os ovos e as larvas de peixes. As larvas de peixe foram identificadas até o nível de família. Larvas das famílias mais abundantes e/ou mais frequentes foram identificadas, quando possível, até nível específico.

A identificação das larvas de peixe baseia-se em características tais como número de miômeros e raios das nadadeiras, padrão de pigmentação, desenvolvimento sequencial das nadadeiras e raios, formato dos órgãos internos, presença de dentes, tamanho e formato da boca, formato dos olhos, presença e localização de espinhos, entre outras. A identificação das larvas foi baseada em bibliografia especializada: Leis \& Rennis (1983), Leis \& Trnsk (1989), Katsuragawa (1990), Moser (1996), Chao (2002), Ditty et al. (2006), Richards (2006 a e b), Fahay (2007 a e b), Itagaki et al. (2007), Bonecker et al., (2014). A classificação taxonômica está de acordo com Nelson et al. (2016).

As larvas das famílias que ocorreram em pelo menos $50 \%$ das campanhas e contribuíram com pelo menos $2 \%$ da densidade total foram classificadas de acordo com a flexão da notocorda nos estágios de desenvolvimento de pré-flexão, flexão e pós-flexão, segundo Kendall et al. (1984). 


\section{Análise dos dados}

\subsection{Massas de água}

Para identificar e analisar a distribuição vertical das massas de água presentes na área de estudo, AC, AT e ACAS, foi utilizada a técnica conhecida como Análise Percentual de Massas de Água (Shtokman, 1946). Esta técnica exige o conhecimento dos índices termohalinos das massas de água envolvidas no processo de mistura.

Neste trabalho foram utilizados os índices termohalinos calculados na análise climatológica realizada por Amor (2004) (Tab. 4).

Tabela 4. Índices termohalinos utilizados para o cálculo dos percentuais de massa de água (Amor, 2004).

\begin{tabular}{clccc}
\hline Estação & \multicolumn{1}{c}{ Variavel } & AC & AT & ACAS \\
\hline \multirow{2}{*}{ Verão } & Temperatura ${ }^{\circ} \mathrm{C}$ & 27,50 & 24,00 & 13,00 \\
& Salinidade & 34,00 & 37,00 & 35,20 \\
\hline \multirow{2}{*}{ Outono } & Temperatura $^{\circ} \mathrm{C}$ & 24,00 & 24,00 & 13,00 \\
& Salinidade & 34,00 & 37,00 & 35,20 \\
\hline \multirow{2}{*}{ Inverno } & Temperatura ${ }^{\circ} \mathrm{C}$ & 22,00 & 24,00 & 13,00 \\
& Salinidade & 34,25 & 37,00 & 35,20 \\
\hline \multirow{2}{*}{ Primavera } & Temperatura ${ }^{\circ} \mathrm{C}$ & 25,00 & 24,00 & 13,00 \\
& Salinidade & 34,75 & 37,00 & 35,20 \\
\hline
\end{tabular}

De acordo com Mamayev (1975), na presença de três massas de água, o porcentual de cada uma delas pode ser determinado através da resolução do seguinte sistema linear:

$$
\begin{gathered}
\mathrm{m} 1 \mathrm{~T} 1+\mathrm{m} 2 \mathrm{~T} 2+\mathrm{m} 3 \mathrm{~T} 3=\mathrm{T} \\
\mathrm{m} 1 \mathrm{~S} 1+\mathrm{m} 2 \mathrm{~S} 2+\mathrm{m} 3 \mathrm{S3}=\mathrm{S} \\
\mathrm{m} 1+\mathrm{m} 2+\mathrm{m} 3=1
\end{gathered}
$$

Segundo este método, conhecendo-se a temperatura $\mathbf{T}$ e a salinidade $\mathbf{S}$ e os índices termohalinos (T1, S1) (T2, S2), (T3, S3) das massas de água, é possível determinar as quantidades porcentuais $\mathbf{m} \mathbf{1}, \mathbf{m} \mathbf{2}$ e $\mathbf{m} \mathbf{3}$ dessas massas. Os sistemas lineares baseiam-se na suposição de que os processos de mistura que ocorrem nas massas de água são processos lineares e que afetam igualmente todos os parâmetros.

Junto a essa análise foram realizados gráficos TS espalhados. Nestes gráficos também foram representadas as linhas paramétricas de anomalia da densidade, com intuito 
de evidenciar a estabilidade da coluna de água, e os índices termohalinos da análise climatológica feita por Amor (2004).

A exploração gráfica das porcentagens de massa de água foi realizada mediante perfis verticais de cada mês de coleta.

Duas características da coluna de água de grande importância para a produção primária são a zona de mistura $(\mathrm{Zm})$ e a zona eufótica (Zeu); estas foram consideradas para a descrição das variáveis oceanográficas (temperatura, salinidade, densidade e clorofila $a$ ).

O critério para a definição da $\mathrm{Zm}$ foi considerado como o valor máximo de densidade na coluna de água no mês de coleta; para isto foram calculadas as variações da densidade a cada metro da coluna de água (Coachman, 1985; Aidar et al., 1993)

\subsection{Zona de mistura e zona eufótica}

A zona eufótica (Zeu) está definida como a profundidade onde a radiação luminosa incidente é de 1\% daquela que incide na superfície (Tyler, 1968). Neste trabalho, para obter a profundidade da Zeu foi aplicada a seguinte equação:

$$
\mathrm{Zeu}=\mathrm{Z}_{\mathrm{ds}} \times \mathrm{fz}
$$

Onde $\mathrm{Z}_{\mathrm{ds}}=$ a profundidade do disco de Secchi; $\mathrm{fz}=2,709$.

\subsection{Densidade de ovos e larvas de peixes}

O estudo da densidade dos ovos e das larvas de peixes foi feito com o material proveniente das coletas com a rede bongô.

A densidade foi padronizada em número de ovos ou larvas por $100 \mathrm{~m}^{3}$ através da fórmula:

$$
N=100 \cdot x / V
$$

Onde $\mathrm{N}=$ densidade de ovos ou larvas por $100 \mathrm{~m}^{-3} ; \mathrm{x}=$ número de ovos ou larvas coletadas em cada amostra; $V=$ volume de água filtrada pela rede $\left(\mathrm{m}^{3}\right)$.

O volume de água filtrada é dado pela expressão:

$$
V=a . n . c
$$

Onde, $\mathrm{V}=$ volume de água filtrada pela rede $\left(\mathrm{m}^{3}\right) ; \mathrm{a}=$ área da boca da rede $\left(\mathrm{m}^{2}\right) ; \mathrm{n}$ $=$ número de rotações do fluxômetro e $\mathrm{c}=$ taxa de calibração do fluxômetro $(\mathrm{m} /$ rotação $)$ 
A densidade mensal do ictioplâncton foi obtida a partir da média das densidades (organismos $/ 100 \mathrm{~m}^{-3}$ ) das duas redes da bongô (fixadas em formol e em solução de Bouin) uma vez que elas tinham a mesma malha $(300 \mu \mathrm{m})$.

\subsection{Frequência de ocorrência das famílias}

A frequência de ocorrência (\%) foi calculada segundo a fórmula de Guille (1970).

$$
F_{O}(\%)=(N i / N t) * 100
$$

Onde $F O=$ frequência de ocorrência $(\%) ; N i=$ número de estações positivas para a categoria taxonômica; $N t=$ número total de estações de coleta.

\subsection{Análise estatística}

A partir da análise de percentuais de massas de água, foi estabelecida uma classificação do período de estudo em meses com alta influência da ACAS ((meses com percentual da ACAS superior ou igual a 80\%) e meses com baixa influência da ACAS (percentual da ACAS inferior a $80 \%$ ).

Foi verificada a normalidade dos dados, tanto físicos como biológicos, pelo teste de Kolmogorov-Smirnov antes das análises estatísticas dos dados. Devido ao resultado obtido nesse teste, o teste não paramétrico de Mann-Whitney $U$-test com significância de 5\% foi aplicado para verificar a existência de diferença significativa, entre os meses com alta e com baixa influência da ACAS, dos dados bióticos e abióticos. Esta análise foi realizada com auxílio do programa PAST (Version 3.20; Hammer et al., 2001)

Foram feitos gráficos da densidade das larvas de peixes das famílias mais abundantes e frequentes versus a biomassa do microzooplâncton (g $\left.100 \mathrm{~m}^{-3}\right)$ e clorofila $a$ com objetivo de visualizar uma possível relação entre elas e observar a variação temporal da densidade de cada espécie.

Para investigar a relação entre a distribuição das espécies e os fatores temperatura, salinidade, biomassa de zooplâncton e clorofila $a$, foi aplicada a análise multivariada de componentes principais (ACP). Para a ACP os dados foram condensados em duas matrizes, uma para os dados ambientais e outra para as espécies das famílias predominantes, versus cada mês de coleta. Para reduzir a diferença existente devido às unidades e amplitude de variação das variáveis, os dados foram transformados aplicandose $\log (n+1)$, com exceção da densidade das larvas cujos dados foram transformados pela 
sua raiz quadrada. Esta análise foi realizada com auxílio do programa PAST (Version 3.20; Hammer et al., 2001) e do CANOCO 4.54 (Braak \& Smilauer, 2006)

A ACP transforma linearmente um conjunto original de variáveis, inicialmente correlacionadas entre si, num conjunto substancialmente menor de variáveis não correlacionadas que contém a maior parte da informação do conjunto original. Estas novas variáveis, denominadas componentes principais, irão explicar a estrutura da variância e covariância de um vetor aleatório, composto de p-variáveis aleatórias, por meio de combinações lineares das variáveis originais (Draper \& Smith, 1966; Legendre \& Legendre, 1984a; 1984b; Hongyu et al., 2015). 


\section{Resultados}

\subsection{Variáveis ambientais}

\subsubsection{Massas de água}

Durante o período de amostragem (fevereiro/2014 a fevereiro/2015) estiveram presentes três massas de água na área de estudo: AC - Água Costeira, AT - Água Tropical e ACAS - Água Central do Atlântico Sul. O regime hidrográfico dominante na região foi previamente descrito por Castro Filho et al. (1987).

A alta influência da $\mathrm{AC}(\geq 50 \%)$ nos primeiros $10 \mathrm{~m}$ de profundidade foi evidente em todos os meses de coleta, diminuindo com o aumento da profundidade. Nos meses de dezembro/2014 e janeiro e fevereiro/2015 entre os $5 \mathrm{~m}, 20 \mathrm{~m}$ e $15 \mathrm{~m}$ respectivamente esta massa de água teve percentuais relativamente altos ( $\geq 80 \%)$ (Fig. 5 e 6$)$.

A AT é uma massa de água presente na região de estudo no entanto devido à profundidade da estação de coleta $(40 \mathrm{~m})$ essa massa de água não foi identificada com altos percentuais $(\geq 50 \%)$. Ainda assim, nos meses de junho e julho, a mais de $20 \mathrm{~m}$ de profundidade, foi possível detectar a AT com percentual 50\% (Fig. 5 e 6).

A ACAS comparece com altos percentuais $(\geq 50 \%)$ a partir dos $5 \mathrm{~m}$ de profundidade em fevereiro, outubro, novembro e dezembro/2014. Em janeiro e fevereiro/2015, a ACAS atingiu $50 \%$ a partir dos $20 \mathrm{~m}$ de profundidade (Fig. 7 e 9).

Os meses com alta influência de ACAS foram fevereiro, outubro, novembro e dezembro de 2014, e os com baixa influência, março, junho, julho, agosto, setembro de 2014 e janeiro e fevereiro de 2015. (Fig. 5e 6 ).

Meses com alta influência de ACAS: nesses meses a temperatura variou entre $27,27^{\circ} \mathrm{C}$ e $14,66^{\circ} \mathrm{C}$. Em alguns meses houve a presença de termoclina sazonal (Fig. 7 e 9). A salinidade variou entre 35,69 a 34,79. Nos meses de outubro e novembro houve ruídos nos dados entre a superficie e os $10 \mathrm{~m}$ de profundidade, atribuídos a falha no sensor do CDT, mas que não afetaram as análises posteriores (Fig. 8). Com referência à densidade, observou-se que nos meses de outubro e novembro, entre 5 e $10 \mathrm{~m}$ de profundiade, ocorreu a picnoclina bem definida principalmente pela variação de temperatura (Fig. 9). A Zm foi pouco profunda $(7-4 \mathrm{~m})$ (Tab. 3).

Meses com baixa influência de ACAS: a temperatura variou entre $28,78^{\circ} \mathrm{C}$ e 16,22 ${ }^{\circ} \mathrm{C}$. Em janeiro e fevereiro/2015 a termoclina foi acentuada, presente a partir dos 18 e $10 \mathrm{~m}$, respetivamente. Nos outros meses houve uma relativa homogeneidade térmica da coluna 
de água. Em junho e julho/2014 entre 30 e $40 \mathrm{~m}$ a salinidade variou entre 35,90 a 35,7 (Fig. 7 e 9). A densidade nos meses de maio/2014, janeiro e fevereiro/2015 mostrou uma picnoclina relativamente acentuada a partir dos $15 \mathrm{~m}$, provavelmente devido às mudanças de temperatura nessa profundiade (Fig. 6). A Zm teve um valor máximo em setembro/2014 de 24 m e mínimo de 14 m em março/2014 e fevereriro/2015 (Fig. 9; Tab. 3).

O valor médio da temperatura nas campanhas com alta influência da ACAS $\left(16,71 \pm 2,83^{\circ} \mathrm{C}\right)$ foi significativamente inferior às campanhas com baixa influência da ACAS $\left(21,48 \pm 3,14{ }^{\circ} \mathrm{C}\right)$ (Teste de Mann-Whitney; $\left.\mathrm{p}<0,05\right)$. A salinidade nos meses com alta influência de ACAS $(35,42 \pm 0,01)$ não diferiu significativamente dos meses com baixa influência da ACAS $(35,45 \pm 0,2)$ (Teste de Mann Whitney; $p>0,05)$.

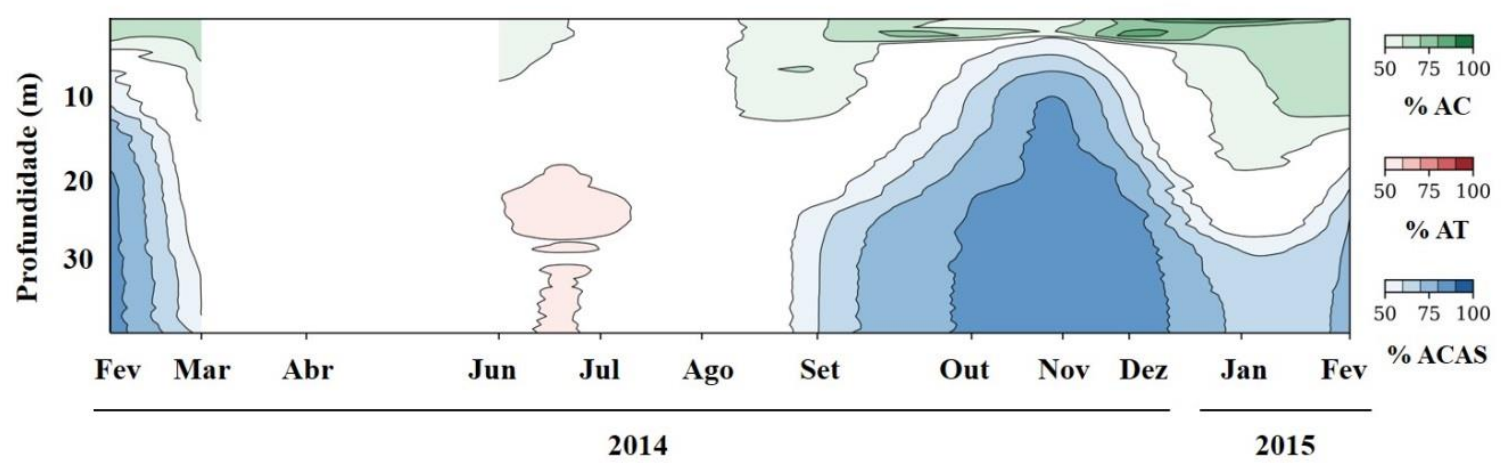

Figura 5. Variação temporal dos percentuais de massas de água presentes no período de coleta de fevereiro/2014 a fevereiro/2015 na estação fixa da rede - Antares localizada em Ubatuba-SP Brasil. AC - Água Costeira; AT - Água Tropical; ACAS Água Central do Atlântico Sul. 
Percentuais de massa de água
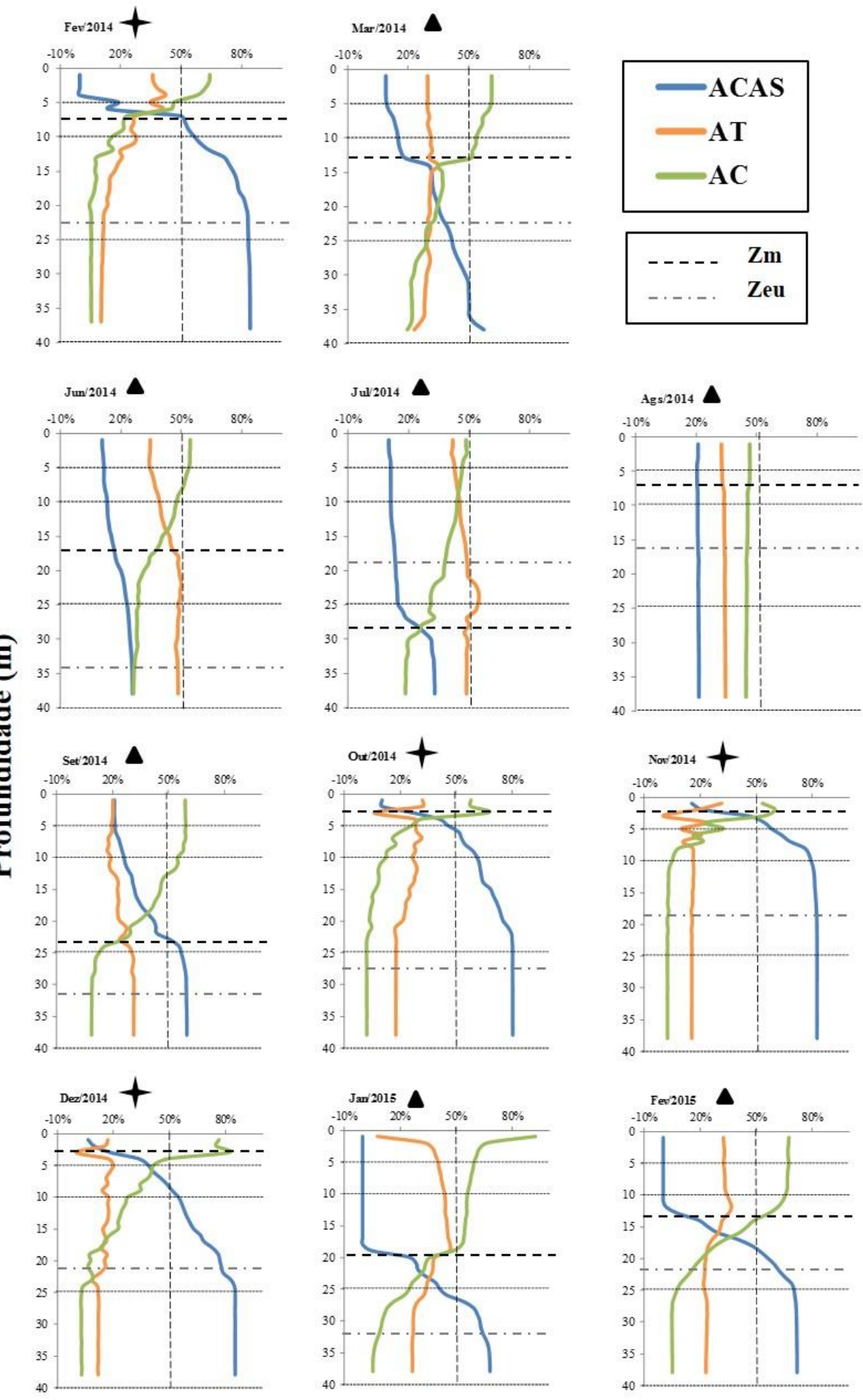

Figura 6.Variação vertical dos percentuais de massas de água presentes na estação fixa rede Antares localizada em Ubatuba-SP Brasil: As linhas pontilhadas horizontais destacam as profundidades em que houve coleta de clorofila $a$. Linha pontilhada vertical ressalta o percentual de $50 \%$. $\boldsymbol{+}$ - meses com alta influência da ACAS; $\mathbf{\Delta}$ - meses com baixa influência da ACAS. AC- Água Costeira; AT - Água Tropical; ACAS - Água Central do Atlântico Sul; Zm = Zona de mistura e Zeu = Zona eufótica. 


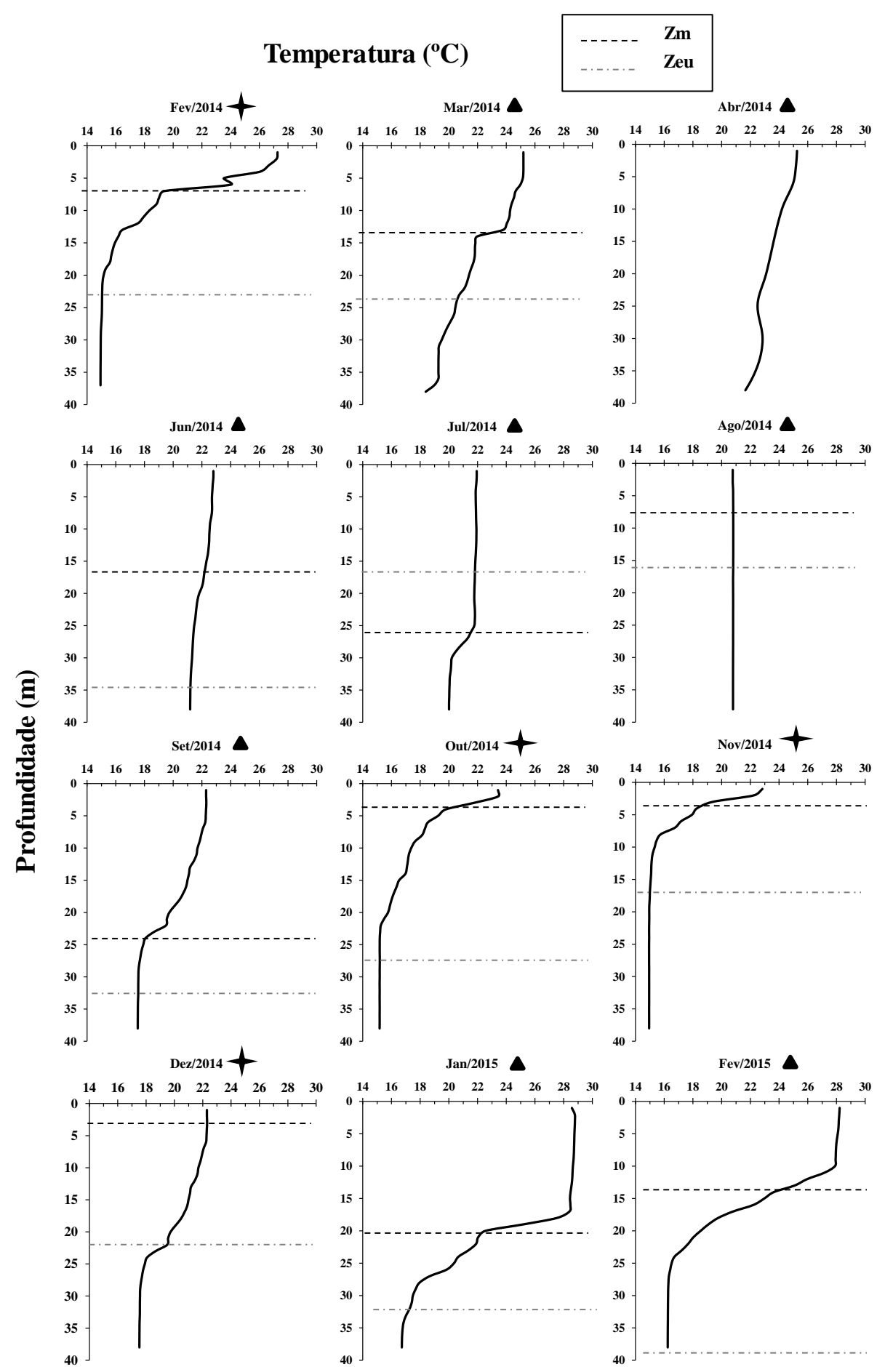

Figura 7. Variação vertical da temperatura $\left({ }^{\circ} \mathrm{C}\right)$ na estação fixa da rede Antares, localizada em Ubatuba-SP Brasil. + - meses com alta influência da ACAS; $\Delta$ - meses com baixa influência da ACAS. Zm = Zona de mistura e Zeu = Zona eufótica. 
Salinidade

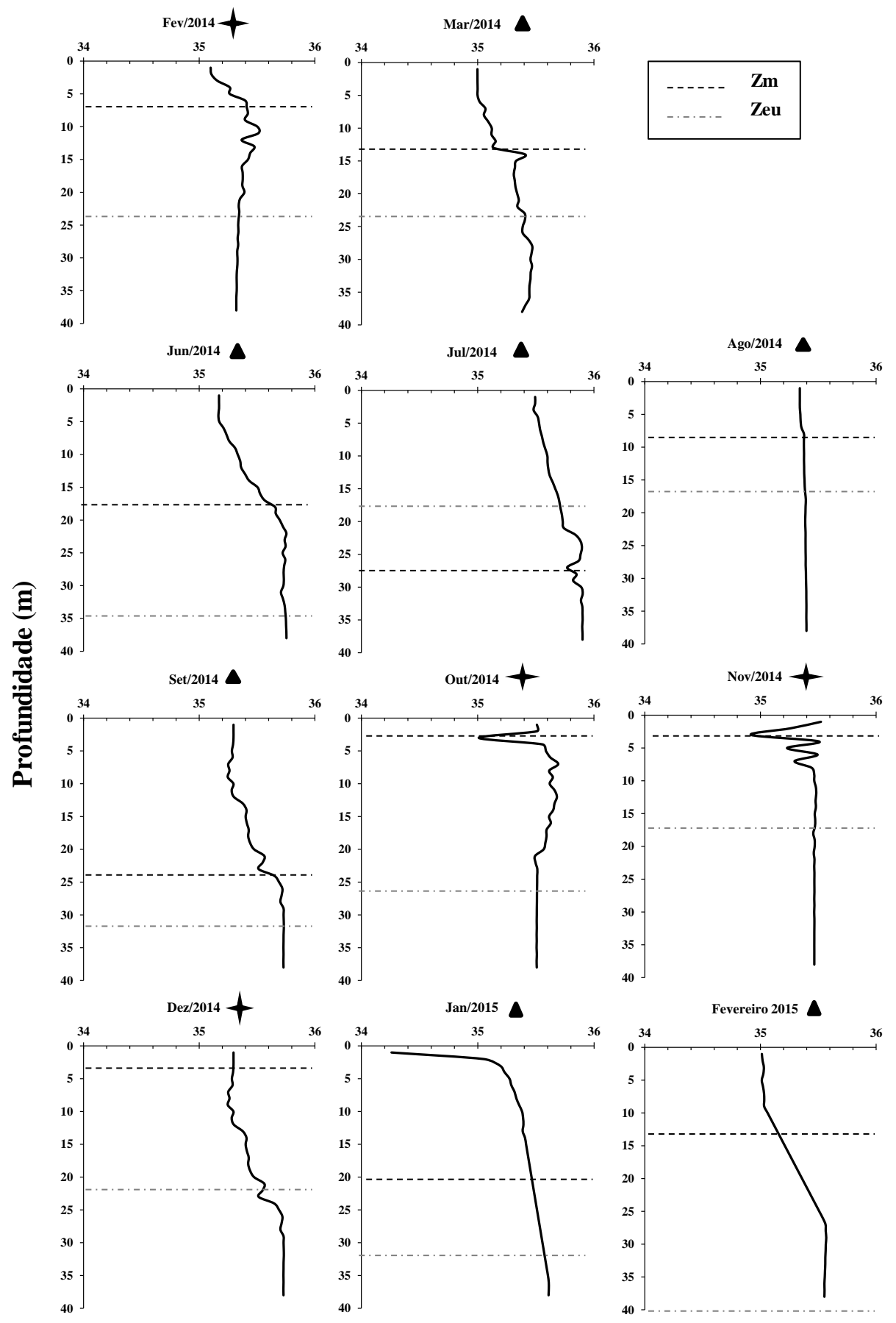

Figura 8. Variação vertical da salinidade na estação fixa da rede Antares, localizada em Ubatuba-SP Brasil. + - meses com alta influência da ACAS; $\Delta$ - meses com baixa influência da ACAS. Zm = Zona de mistura e Zeu = Zona eufótica. 


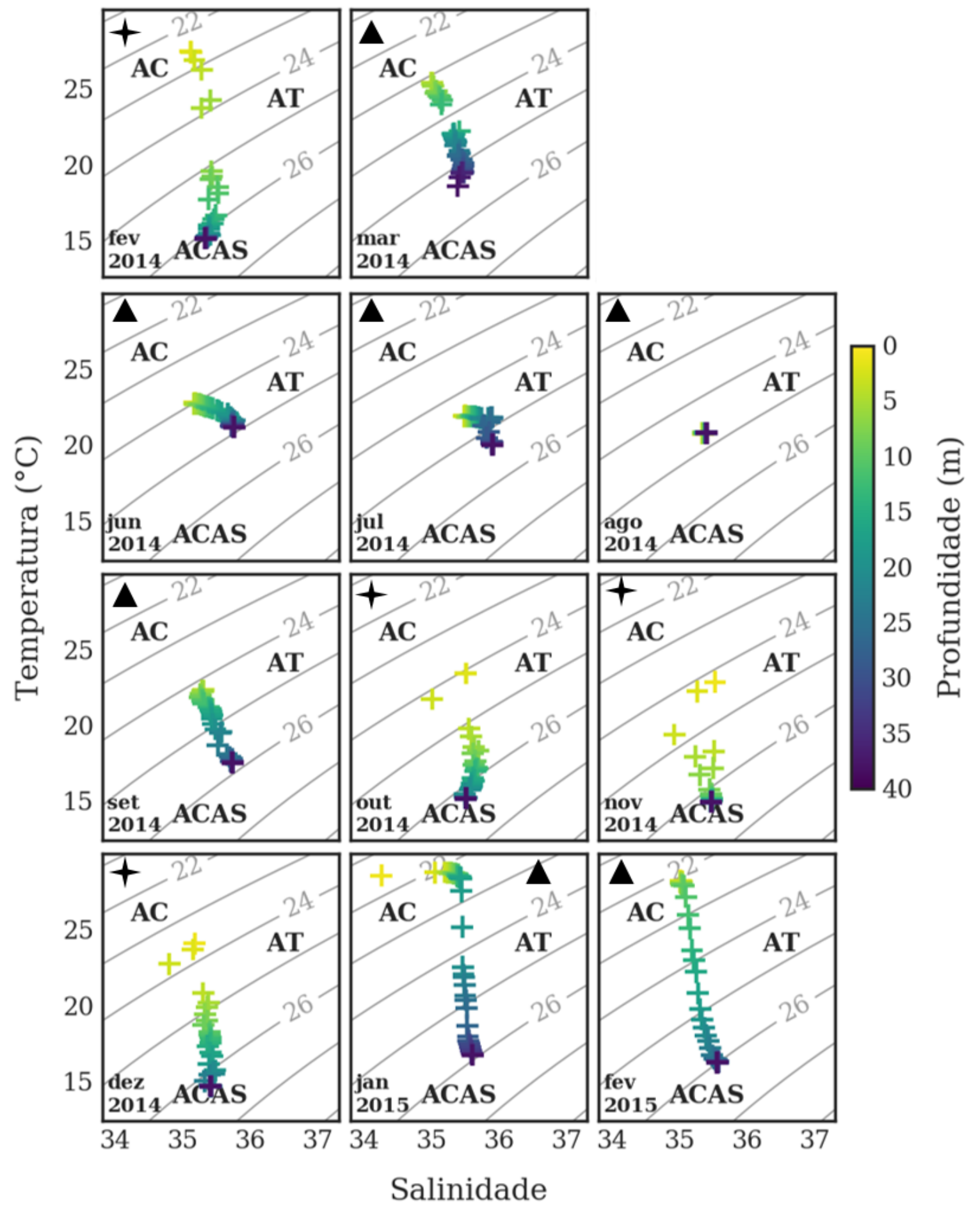

Figura 9. Diagrama TS espalhado mensal no período de fevereiro/2014 a fevereiro/2015 na estação fixa da rede Antares. Estão representados os índices termohalinos das massas de água (Amor, 2004). + - meses com alta influência de ACAS; $\Delta$ - meses com baixa influência de ACAS. AC- Água Costeira; AT - Água Tropical; ACAS - Água Central do Atlântico Sul. 


\subsection{Dados biológicos}

\subsubsection{Clorofila a}

As coletas discretas de clorofila $a$ em superfície $(0,5 \mathrm{~m}), 5 \mathrm{~m}, 10 \mathrm{~m}, 25 \mathrm{~m}$ e fundo ( $38 \mathrm{~m})$ indicaram que a concentração dessa variável teve núcleos de valor máximo que coincidiram com os meses de alta influência da ACAS.

Em fevereiro/2014, mês com alta influência da ACAS, ocorreu um máximo superficial de clorofila $a$ de $11,38 \mathrm{mg} \mathrm{m}^{-3}$. Nos meses de outubro, novembro e dezembro houve máximos sub superficiais aos $25 \mathrm{~m}, 10 \mathrm{~m}$ e $5 \mathrm{~m}$, respectivamente, sem superar 5,48 $\mathrm{mg} \mathrm{m}^{-3}$. O mínimo de $0,42 \mathrm{mg} \mathrm{m}^{-3}$ ocorreu na superfície em outubro/2014 (Fig. 10).

Nos meses com baixa influência de ACAS, a clorofila $a$ variou entre 0,26 e 3,36 $\mathrm{mg} \mathrm{m}^{-3}$. De junho a agosto/2014 os valores de clorofila $a$ não foram superiores a 1,88 $\mathrm{mg}$ $\mathrm{m}^{-3}$ (Fig. 10).

O valor médio da clorofila $a$ nas campanhas com alta influência da ACAS foi de $1,98 \pm 1,25 \mathrm{mg} \mathrm{m}^{-3}$ significativamente superior ao das campanhas com baixa influência da ACAS com valor médio de 1,04 $\pm 0,71 \mathrm{mg} \mathrm{m}^{-3}$ (Teste de Mann-Whitney; $\mathrm{p}<0,05$ ).

A biomassa de fitoplâncton em termos de concentração de clorofila $a$ foi pequena na camada de mistura. Em referência à zona eufótica, não houve diferenças significativas entre os meses com alta influência de ACAS e os meses com baixa influência de ACAS (Mann Whitney $\mathrm{p}>0,05)$ (Tab. 5). Contudo, sob condições de luz limitante, as concentrações de clorofila $a$ desde camadas profundas até as de sub superfície foi altamente variável. Durante os meses com baixa influência de ACAS, o limite inferior da $\mathrm{Zm}$ foi mais profundo e a diferença de profundidade com o limite inferior da Zeu foi menor do que nos meses com alta influência de ACAS (Fig. 10).

No período de estudo, a quantidade de clorofila $a$ integrada variou entre 20 e 80

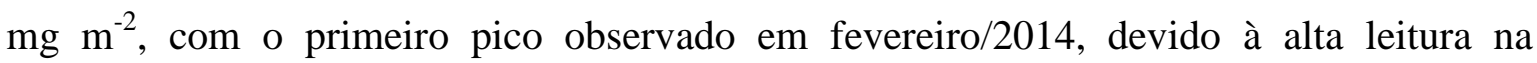
superfície, e redução gradativa de março até junho. Em julho ouve um pico moderado e, em sequência, a clorofila $a$ integrada aumentou até dezembro onde observou-se o outro máximo por causa da clorofila $a$ aos $5 \mathrm{~m}$. Finalmente os registros dos dois últimos meses tem variaram entre 58 a $60 \mathrm{mg} \mathrm{m}^{-2}$. As elevadas medidas de clorofila $a$ integrada nos meses de outubro/2014 e janeiro/2015 ocorreram devido aos altos valores de clorofila $a$ sub superficiais (Fig. 11). 


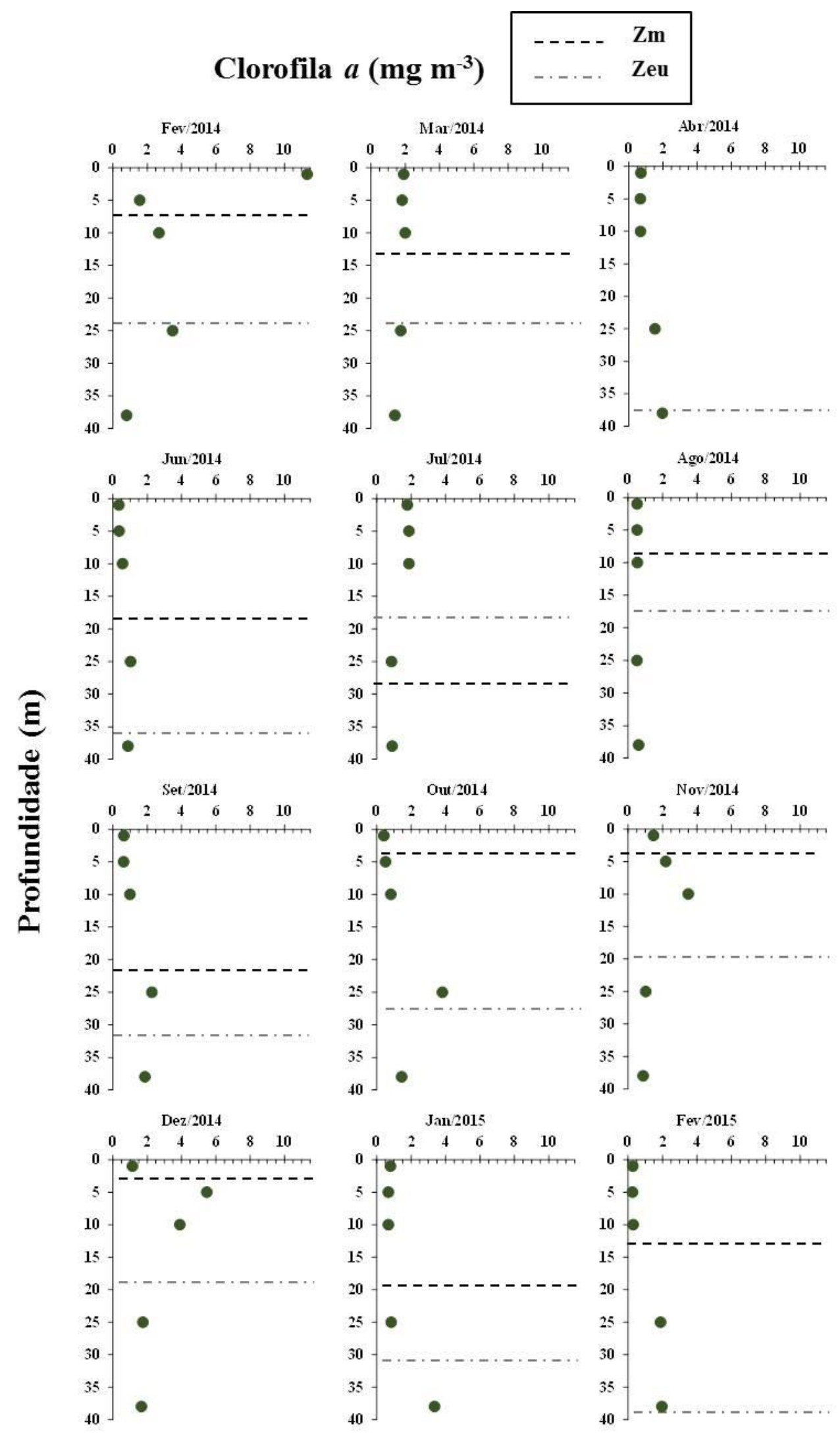

Figura 10. Variação vertical da clorofila $a\left(\mathrm{mg} \mathrm{m}^{3}{ }^{3}\right)$ no período de fevereiro/2014 a fevereiro/2015 na estação fixa da rede Antares, localizada em Ubatuba-SP. As linhas pontilhadas representam: preta $=$ limite inferior da zona de mistura e cinza $=$ limite da zona eufótica. 
Tabela 5. Valores da profundidade $(\mathrm{m})$ da Zona de Mistura $(\mathrm{Zm})$ e da Zona eufótica (Zeu) em estação fixa da rede Antares localizada em Ubatuba-SP. No mês de abril não há densidade já que não foi registrada a salinidade. Em cinza são ressaltados os meses com alta influência de ACAS.

\begin{tabular}{|c|c|c|c|c|c|c|}
\hline \multirow{2}{*}{ Ano } & \multirow{2}{*}{ Mês } & \multicolumn{2}{|c|}{ Densidade } & \multicolumn{3}{|c|}{ Profundidade (m) } \\
\hline & & Máximo & Média \pm SD & Secchi & $\mathbf{Z m}$ & Zeu \\
\hline \multirow{10}{*}{2014} & fevereiro & 1,31 & $0,10 \pm 0,25$ & 9 & 7 & 24 \\
\hline & março & 0,72 & $0,06 \pm 0,12$ & 9 & 14 & 24 \\
\hline & abril & & & 14 & & 39 \\
\hline & junho & 0,09 & $0,03 \pm 0,02$ & 13 & 18 & 35 \\
\hline & julho & 0,18 & $0,03 \pm 0,04$ & 7 & 28 & 19 \\
\hline & agosto & 0,02 & $0,01 \pm 0,00$ & 6 & 8 & 16 \\
\hline & setembro & 0,26 & $0,05 \pm 0,06$ & 12 & 24 & 32 \\
\hline & outubro & 0,94 & $0,06 \pm 0,16$ & 10 & 4 & 27 \\
\hline & novembro & 0,73 & $0,06 \pm 0,16$ & 7 & 4 & 19 \\
\hline & dezembro & 0,91 & $0,07 \pm 0,15$ & 8 & 4 & 22 \\
\hline \multirow{2}{*}{2015} & \begin{tabular}{|l} 
janeiro \\
\end{tabular} & 0,79 & $0,12 \pm 0,19$ & 12 & 20 & 32 \\
\hline & fevereiro & 0,45 & $0,11 \pm 0,13$ & 16 & 14 & 43 \\
\hline
\end{tabular}
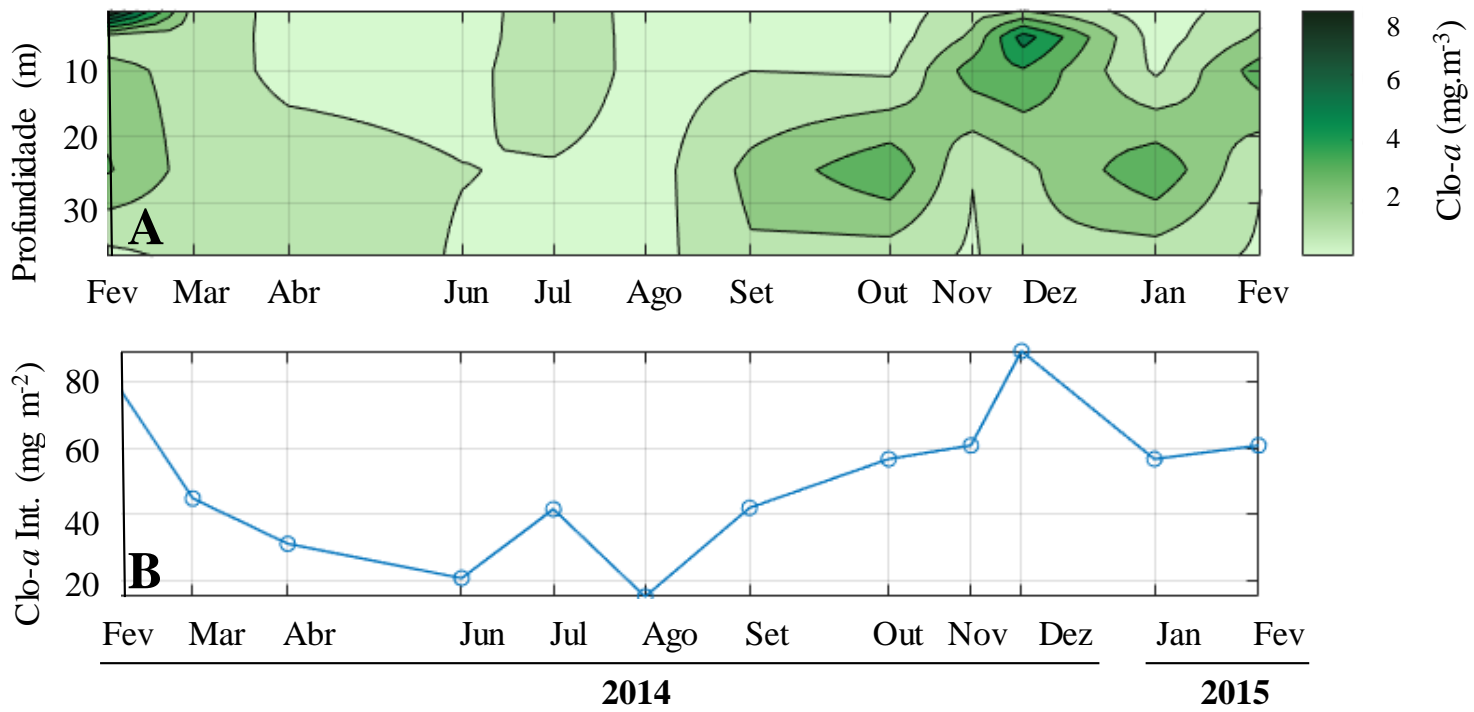

Figura 11. Variação temporal da clorofila $a$ em estação fixa da rede Antares localizada em Ubatuba-SP. A. Interpolação temporal das coletas discretas de clorofila $a$. B. Clorofila $a$ integrada. 


\subsubsection{Biomassa do zooplâncton}

O peso seco da biomassa total do zooplâncton foi maior na rede de $50 \mu \mathrm{m}$ e menor

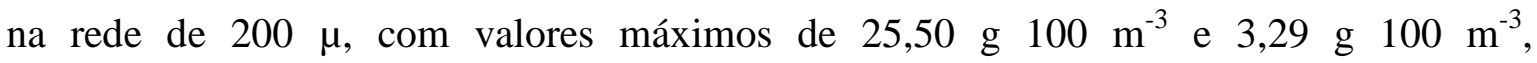
respectivamente, em dezembro/2014 (Tab. 6, Fig. 12).

O peso seco da biomassa total de zooplâncton das redes de $50 \mu \mathrm{m}$ e de $200 \mu \mathrm{m}$ não foram significativamente diferentes quando comparadas as amostras das campanhas com alta e baixa influência de ACAS (Teste de Mann-Whitney: p > 0,05); somente as amostras da rede de $300 \mu \mathrm{m}$ apresentaram essa diferença (Teste de Mann-Whitney: $\mathrm{p}$ < $0,05)$.

Tabela 6. Peso seco da biomassa do plâncton coletado com diferentes malhas no período de fevereiro/2014 a fevereiro/2015 em estação fixa da rede Antares localizada em Ubatuba-SP .

\begin{tabular}{lccc}
\cline { 2 - 4 } & \multicolumn{3}{c}{ Biomassa de plâncton $\mathbf{~} \mathbf{1 0 0} \mathbf{~ m}^{-\mathbf{3}}$} \\
\cline { 2 - 4 } Mínimo & $\mathbf{5 0 ~ u m}$ & $\mathbf{2 0 0}$ um & $\mathbf{3 0 0} \mathbf{~ u m}$ \\
\cline { 2 - 4 } Máximo & 1,09 & 0,15 & 0,46 \\
Média & 25,50 & 3,29 & 4,18 \\
Desvio padrão & 7,83 & 1,21 & 1,41 \\
\hline
\end{tabular}

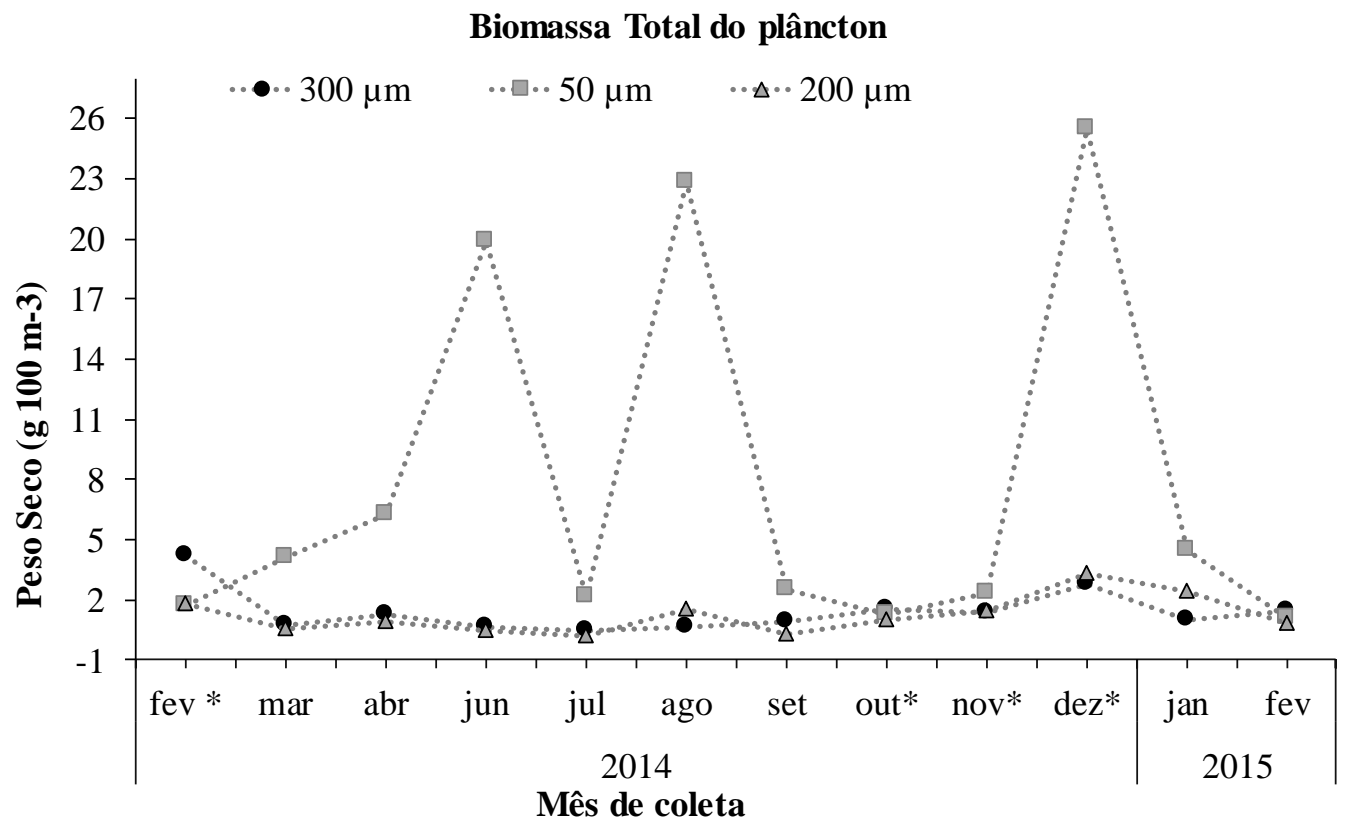

Figura 12. Variação da biomassa total de zooplâncton em termos de peso seco (g $100 \mathrm{~m}^{-3}$ ), em estação fixa da rede Antares localizada em Ubatuba-SP. * - Meses com alta influência de ACAS. 


\subsubsection{Ictioplâncton}

\subsubsection{Composição taxonômica}

Do total de 2.446 larvas analisadas, 1.906 foram identificadas em níveis taxonômicos diversos, restando 481 espécimes não identificados $(19,6 \%)$ devido ao seu estágio inicial de desenvolvimento ou por estarem danificados. Foi possível identificar 17 ordens, 25 famílias, 23 gêneros e 26 espécies (Tab. 7). Somente as larvas das famílias com frequência de ocorrência entre $50-100 \%$ e densidade igual ou superior a 1 larva $100 \mathrm{~m}^{-3}$, além de Clupeidae, família de maior densidade, foram identificadas até o nível de espécie (Fig. 16). 
Tabela 7. Composição taxonômica das larvas de peixes coletadas no período de fevereiro/2014 a fevereiro/2015 em estação fixa da rede Antares localizada em UbatubaSP. Classificação baseada em Nelson et al., 2016.

\begin{tabular}{|c|c|c|}
\hline Ordem & Família & Genero / Espécie \\
\hline \multirow{4}{*}{ Clupeiformes } & Engraulidae & Engraulis anchoita \\
\hline & Clupeidae & Harengula jaguana \\
\hline & & Sardinella brasiliensis \\
\hline & & Opisthonema oglinum \\
\hline Stomiiformes & Phosichthyidae & \\
\hline Aulopiformes & Synodontidae & Trachinocephalus myops \\
\hline Gadiformes & Bregmacerotidae & \\
\hline Holocentriformes & Holocentridae & \\
\hline \multirow[t]{2}{*}{ Ophidiiformes } & Ophidiidae & Ophidion holbrookii \\
\hline & & Lepophidium brevibarbe \\
\hline \multirow[t]{2}{*}{ Gobiiformes } & Gobiidae & \\
\hline & Pomacentridae & \\
\hline Blenniiformes & Blenniidae & \\
\hline \multirow[t]{5}{*}{ Carangiformes } & Carangidae & Caranx sp. \\
\hline & & Chloroscombrus chrysurus \\
\hline & & Selene setapinnis \\
\hline & & Selene vomer \\
\hline & & Trachurus lathami \\
\hline \multirow{2}{*}{ Istiophoriformes } & Sphyraenidae & \\
\hline & Istiophoridae & \\
\hline \multirow[t]{5}{*}{ Pleuronectiformes } & Paralichthyidae & Cyclopsetta fimbriata \\
\hline & & Etropus crossotus \\
\hline & & Syacium papillosum \\
\hline & Cynoglossidae & Symphurus tesselatus \\
\hline & & Symphurus trewavasae \\
\hline Scombriformes & Trichiuridae & \\
\hline Trachiniformes & Percophidae & \\
\hline \multirow[t]{9}{*}{ Perciformes } & Gerreidae & \\
\hline & Serranidae & Diplectrum sp. \\
\hline & & Epinephelus sp. \\
\hline & & Serranus sp. \\
\hline & Pomacanthidae & \\
\hline & Lutjanidae & \\
\hline & Haemulidae & Anisotremus virginicus \\
\hline & & Haemulon sp. \\
\hline & & Orthopristis ruber \\
\hline Scorpaeniformes & Triglidae & \\
\hline \multirow[t]{8}{*}{ Acanthuriformes } & Sciaenidae & Cynoscion sp. \\
\hline & & Isopisthus parvipinnis \\
\hline & & Menticirrhus sp \\
\hline & & Menthicirrus americanus \\
\hline & & Micropogonias furnieri \\
\hline & & Stellifer sp. \\
\hline & & Stellifer stellifer \\
\hline & & Stellifer rastrifer \\
\hline Lophiiformes & Lophiidae & \\
\hline
\end{tabular}




\subsubsection{Densidade total}

Foi coletado no período de estudo 3.421 ovos e 2.446 larvas de peixes. A densidade dos ovos e das larvas foi maior em janeiro/2015, com 246,22 ovos $100 \mathrm{~m}^{-3} \mathrm{e}$ 266,81 larvas $100 \mathrm{~m}^{-3}$ (Tab. 8. Fig. 13).

A diferença da densidade dos ovos de peixes entre os meses com alta e baixa influência de ACAS foi significativa (Teste Mann- Whitney: $p<0,05$ ); o mesmo não foi observado para as larvas de peixes (Teste Mann- Whitney: $\mathrm{p}>0,1$ ).

Tabela 8. Número de indivíduos $(\mathrm{N})$, densidade (ovos ou larvas $\mathrm{m}^{-3}$ ), porcentagem da densidade total (\%), densidade média (Média) e desvio padrão (dp) dos ovos e larvas de peixes coletados em estação fixa da rede Antares localizada em Ubatuba-SP. Realce cinza indica meses com alta influência de ACAS.

\begin{tabular}{|c|c|c|c|c|c|c|c|}
\hline \multirow{2}{*}{ Ano } & \multirow{2}{*}{ Mês } & \multicolumn{3}{|c|}{ Ovos } & \multicolumn{3}{|c|}{ Larvas } \\
\hline & & $\mathbf{N}$ & Org. $100 \mathrm{~m}^{-3}$ & $\%$ & $\mathbf{N}$ & Org. $100 \mathrm{~m}^{-3}$ & $\%$ \\
\hline \multirow{10}{*}{$\overrightarrow{\vec{N}}$} & fevereiro & 41 & 10,93 & 1,30 & 21 & 5,51 & 0,86 \\
\hline & março & 368 & 84,03 & 9,99 & 324 & 74,28 & 11,55 \\
\hline & abril & 583 & 131,07 & 15,58 & 124 & 27,92 & 4,34 \\
\hline & junho & 163 & 32,63 & 3,88 & 155 & 31,11 & 4,84 \\
\hline & julho & 347 & 56,66 & 6,74 & 109 & 18,93 & 2,94 \\
\hline & agosto & 272 & 69,02 & 8,20 & 57 & 15,09 & 2,35 \\
\hline & setembro & 69 & 21,84 & 2,60 & 88 & 27,23 & 4,23 \\
\hline & outubro & 63 & 18,28 & 2,17 & 121 & 32,77 & 5,09 \\
\hline & novembro & 247 & 52,88 & 6,29 & 76 & 16,81 & 2,61 \\
\hline & dezembro & 34 & 9,43 & 1,12 & 31 & 8,58 & 1,33 \\
\hline \multirow{7}{*}{$\stackrel{n}{3}$} & janeiro & 805 & 246,22 & 29,27 & 872 & 266,81 & 41,48 \\
\hline & fevereiro & 429 & 108,28 & 12,87 & 468 & 118,22 & 18,38 \\
\hline & Total & 3421 & 841,26 & 100,00 & 2446 & 643,25 & 100,00 \\
\hline & Máximo & & 246,22 & & & 266,81 & \\
\hline & Minímo & & 9,43 & & & 5,51 & \\
\hline & Média & & 70,10 & & & 53,60 & \\
\hline & dp & & 67,73 & & & 74,31 & \\
\hline
\end{tabular}




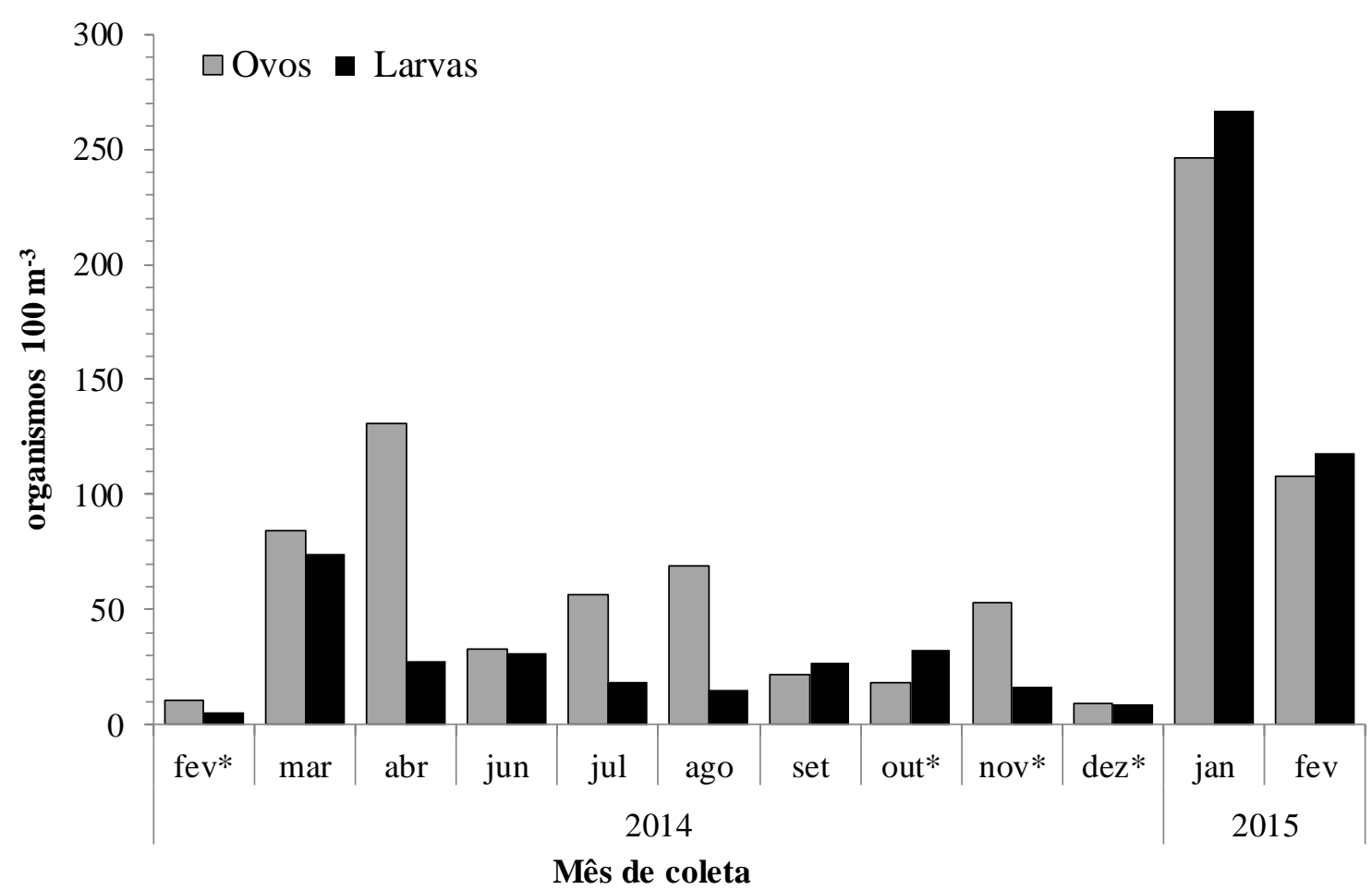

Figura 13. Densidade do ictioplâncton (ovos ou larvas $100 \mathrm{~m}^{-3}$ ) em estação fixa da rede Antares localizada em Ubatuba-SP. * - meses com alta influência da ACAS.

\subsubsection{Frequência de ocorrência de larvas de peixes (\%)}

Das 25 famílias identificadas, Paralichthyidae e Sciaenidae se destacam pela frequência de ocorrência superior a $80 \%$ e densidade superior a 40 larvas $100 \mathrm{~m}^{-3}$. A frequência de ocorrência de Ophidiidae e Carangidae foi de 58 e 67\% respetivamente e densidade inferior a 35 larvas $100 \mathrm{~m}^{-3}$. Synodontidae, Cynoglossidae, Serranidae, Haemulidae ocorreram em 50\% dos meses amostrados com menos de 15 larvas $100 \mathrm{~m}^{-3}$. Apesar da família Clupeidae ter ocorrido em $40 \%$ dos meses amostrados, ela apresentou a maior densidade larval, 146 larvas $100 \mathrm{~m}^{-3}$, este valor não foi representado na figura 13. As famílias Lutjanidae, Phosichthyidae, Gobiidae, Holocentridae, Istiophoridae, Percophidae, Pomacanthidae e Lophiidae tiveram uma frequência de ocorrência de $10 \%$, a densidade dessas famílias menor que cinco larvas $100 \mathrm{~m}^{-3}$ (Fig. 14). Em todos os meses de coleta foram encontradas larvas vitelínicas, danificadas ou muito pequenas, o que impossibilitou sua identificação. 


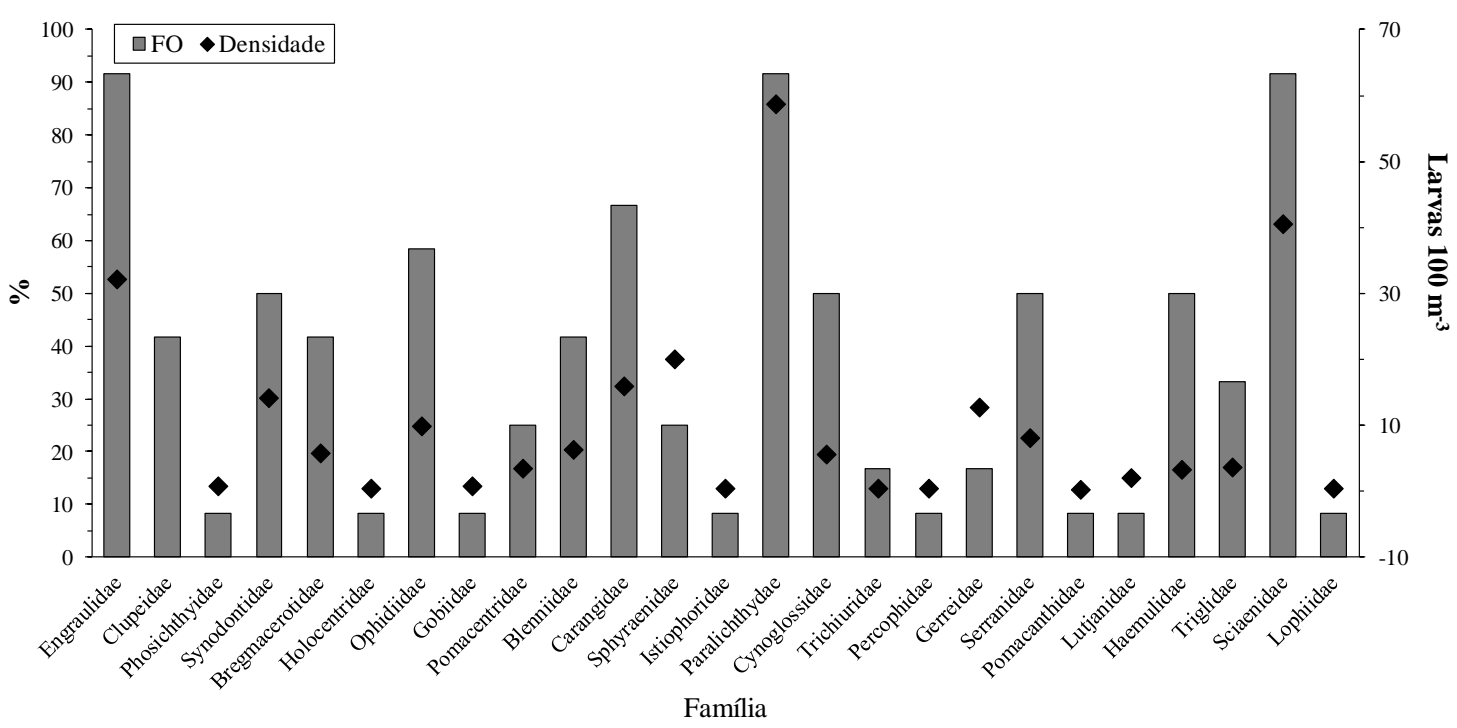

Figura 14. Representação do percentual da frequência de ocorrência (FO \%) e da densidade (larvas $100 \mathrm{~m}^{-3}$ ) das famílias coletadas no período de fevereiro/2014 a fevereiro/2015 em estação fixa da rede Antares localizada em Ubatuba-SP. A linha pontilhada representa $50 \%$ de frequência de ocorrência. 


\subsubsection{Densidade mensal das famílias mais frequentes}

Foram classificadas como famílias mais frequentes aquelas que tiveram frequência de ocorrência de no mínimo $50 \%$.

Engraulidae - Esteve presente em 11 dos 12 meses de coleta, não ocorrendo em abril/2014. A maior densidade ocorreu em setembro/2014 (7 larvas $100 \mathrm{~m}^{-3}$ ). Esta família foi a que mais contribuiu à composição da comunidade do ictioplâncton em dezembro/2014 (72\%) e menos em janeiro/2015 (2\%), nos outros nove meses de coleta essa família participou com menos de 50\% na composição da comunidade (Fig. 15A; Tab. 9).

$\underline{\text { Synodontidae }}$ - Esteve presente em 50\% dos meses de coleta. Em novembro/2014, quando foi mais abundante (11 larvas $100 \mathrm{~m}^{-3}$ ), participou com o $50 \%$ na composição da comunidade. Os menores valores de contribuição por família (2\%) assim como de densidade (0,5 larvas $100 \mathrm{~m}^{-3}$ ) ocorreram em julho/2014 (Fig. 15A; Tab. 9).

Ophidiidae - Esteve presente em sete dos 12 meses. Com relação à contribuição por família o maior percentual ocorreu no mês de novembro/2014 (16\%). A maior quantidade de larvas foi registrada no mês de fevereiro/2015 (12 larvas $\left.100 \mathrm{~m}^{-3}\right)$ e o menor em junho/2014 (0,37 larvas $\left.100 \mathrm{~m}^{-3}\right)$ (Fig. 15A; Tab. 9).

Carangidae - A maior densidade desta família ocorreu em fevereiro/2015 (16 larvas $\left.100 \mathrm{~m}^{-3}\right)$ e a menor em abril/2014 (0,45 larvas $\left.100 \mathrm{~m}^{-3}\right)$. Nos outros sete meses, a densidade variou entre 1 e 4 larvas $100 \mathrm{~m}^{-3}$. Na composição da comunidade, sua maior contribuição ocorreu em agosto/2014 (17\%) e a menor em janeiro/2015 (9\%) (Fig. 15A; Tab. 9).

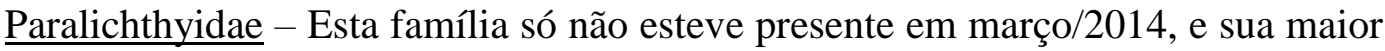
contribuição à comunidade foi em fevereiro/2014 (73\%). Sua maior densidade ocorreu em março/2014 (49 larvas $100 \mathrm{~m}^{-3}$ ) e a menor em janeiro/2015 (1 larva $100^{-3}$ ), quando foi a família menos abundante (Fig. 15A; Tabela 9).

Cynoglossidae - O maior valor de aporte à comunidade ocorreu no mês outubro/2014 (13\%). O máximo valor de densidade ocorreu em fevereiro/2015 (4 larvas $100 \mathrm{~m}^{-3}$ ) e o mínimo em abril/2014 simultaneamente com o menor percentual de aporte à comunidade, 0,45 larvas $100^{-3}$ e 2\%, respetivamente (Fig. 15A; Tab. 9). 
Serranidae - o maior aporte à comunidade foi no mês de fevereiro/2014 (9\%) e o menor em agosto/2014 (2\%). Apesar de estar presente em seis meses de coleta essa família não foi muito abundante o máximo valor ocorreu em março/2014 e o mínimo em fevereiro/2014 (Fig. 15A; Tab. 9).

$\underline{\text { Haemulidae }}$ - $\mathrm{O}$ maior percentual de aporte à comunidade foi registrado no mês de fevereiro/2015 (1\%) e o mínimo em março/2014. A densidade máxima observada foi de 2 larvas $100 \mathrm{~m}^{-3}$ e o mínimo, 0,16 larvas $100 \mathrm{~m}^{-3} \mathrm{em}$ julho/2014. Entre as famílias com frequência de ocorrência $50 \%$ dos meses de coleta foi a que teve o menor número de larvas (Fig. 15A; Tab. 9).

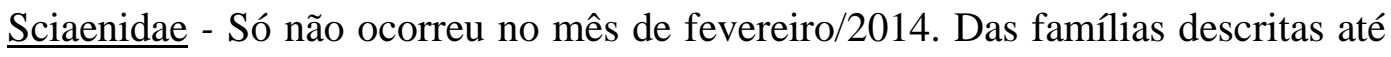
agora é a que apresentou maior variação na densidade, com valor máximo de 15 larvas 100 $\mathrm{m}^{-3}$ no mês de março e mínimo de 0,45 larvas $100 \mathrm{~m}^{-3}$ em novembro/2014. O maior aporte à comunidade ocorreu no mês de abril/2014 (57\%) e o menor em janeiro/2015. (Fig. 15A; Tabela 9).

Clupeidae - Embora sua frequência de ocorrência tenha sido 33\%, essa família foi a mais abundante, representando $40 \%$ da densidade total das larvas. Vale ressaltar a alta densidade de organismos nos meses de janeiro e fevereiro /2015. Em janeiro/2015 essa parcela foi de $80 \%$ com densidade de 146 larvas $100 \mathrm{~m}^{-3}$ (Fig. 15B; Tabela 9).

Sphyraenidae - essa família só foi encontrada nos meses de março/2014 e janeiro/2015 onde teve o maior valor (Fig. 15B; Tabela 9).

As famílias Holocentridae, Istiophoridae, Percophidae, Pomacanthidae, e Lophiidae estiveram representadas por apenas uma larva (Fig. 15B; Tabela 9).

Foi identificado um número mínimo de famílias, três no total, em fevereiro e dezembro/2014 e um número máximo de 14, em fevereiro/2015. Foi calculada média de oito famílias por mês de coleta. Nos meses de julho, agosto, setembro/2014 ocorreram 9 famílias, em outubro/2014 ocorreram 7 famílias e em abril e novembro/2014 ocorreram 6 famílias.

Nos meses com alta influência de ACAS (fevereiro, outubro, novembro e dezembro/2014) não foram identificadas mais de sete famílias por mês, número baixo em comparação com outros meses de coleta. O teste de Mann-Whitney mostrou diferenças significativas entre o número de famílias para os meses com alta e com baixa influência de ACAS (Mann-Whitney p <0,05). 

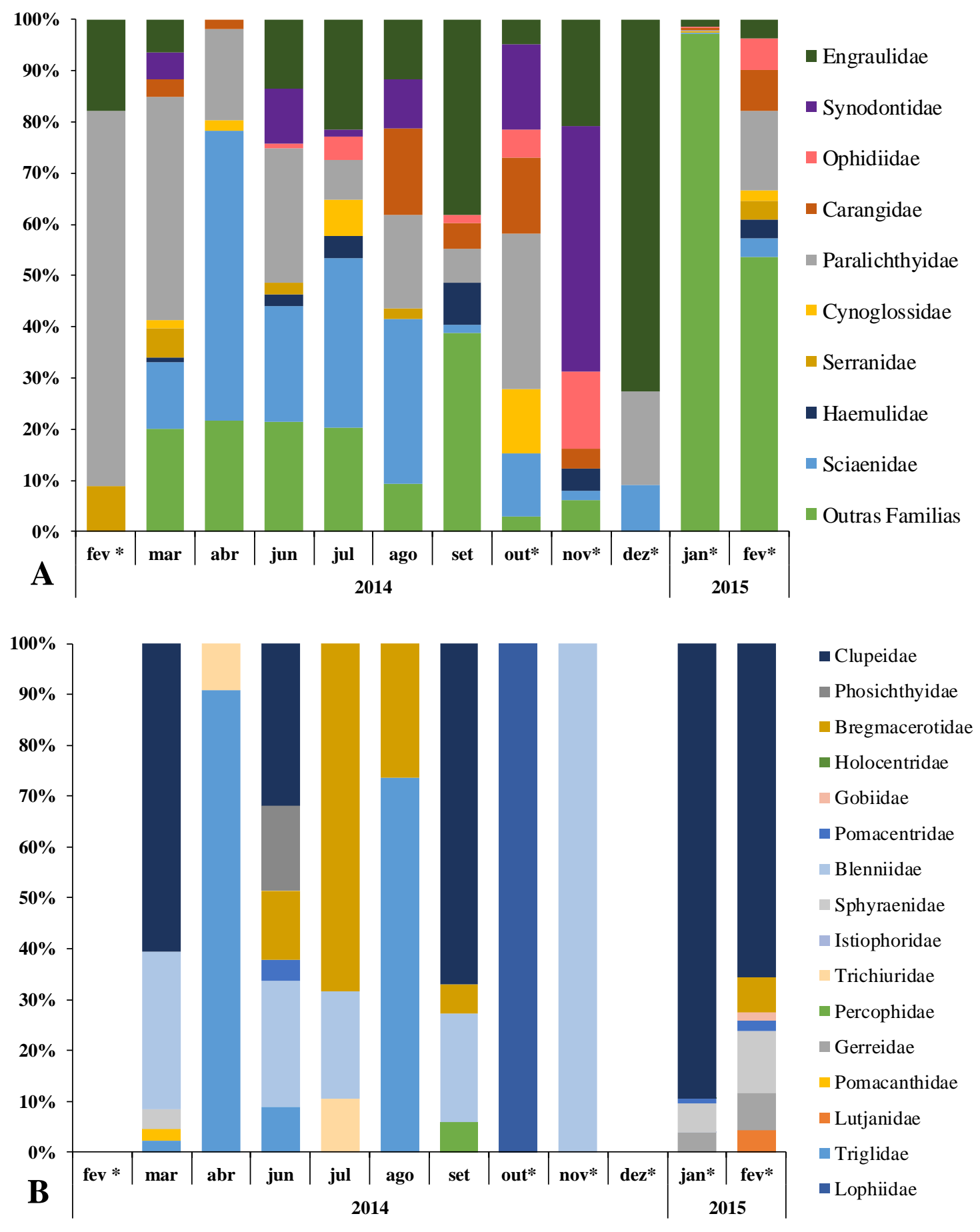

Figura 15. Distribuição percentual mensal da densidade das larvas de peixe Distribuição mensal do número de larvas nos estágios de desenvolvimento pré-flexão, flexão e pós-flexão coletadas em estação fixa da rede Antares localizada em Ubatuba-SP. A. Densidade das famílias com frequência de ocorrência maior ou igual a 50\%, e outras famílias; B. Detalhamento de "outras famílias". Categoria "outras famílias" inclui aquelas com frequência de ocorrência inferior a 50\%. * - meses com alta influência da ACAS. 
Tabela 9. Número de indivíduos $(\mathrm{N})$, densidade total (larvas $100 \mathrm{~m}^{-3}$ ), porcentagem (\%), densidade média (Média), desvio padrão (dp), das famílias coletadas no período de fevereiro/2014 a fevereiro/2015 em estação fixa da rede Antares localizada em Ubatuba-SP.

\begin{tabular}{|c|c|c|c|c|c|c|c|}
\hline \multirow{2}{*}{ Ordem } & \multirow{2}{*}{ Família } & \multirow{2}{*}{$\mathbf{N}$} & \multirow{2}{*}{ FO } & \multicolumn{4}{|c|}{ Densidade (Org. $100 \mathrm{~m}^{-3}$ ) } \\
\hline & & & & Total & Média & dp & $\%$ \\
\hline \multirow[t]{3}{*}{ Clupeiformes } & $\mathrm{NI}$ & 59 & & 15,00 & 5,00 & 6,08 & 2,3 \\
\hline & Engraulidae & 128 & 92 & 32,09 & 2,92 & 1,82 & 5,0 \\
\hline & Clupeidae & 882 & 42 & 145,58 & 29,12 & 42,83 & 40,5 \\
\hline Stomiiformes & Phosichthyidae & 4 & 8 & 0,73 & 0,73 & 0,00 & 0,1 \\
\hline Aulopiformes & Synodontidae & 62 & 50 & 14,10 & 2,35 & 1,88 & 2,2 \\
\hline Gadiformes & Bregmacerotidae & 25 & 42 & 5,71 & 1,14 & 1,25 & 0,9 \\
\hline Holocentriformes & Holocentridae & 1 & 8 & 0,30 & 0,30 & 0,00 & $<0.1$ \\
\hline Ophidiiformes & Ophidiidae & 40 & 58 & 9,75 & 1,39 & 2,01 & 1,5 \\
\hline \multicolumn{8}{|l|}{ Gobïformes } \\
\hline & Gobiidae & 3 & 8 & 0,76 & 0,76 & 0,00 & 0,1 \\
\hline & Pomacentridae & 12 & 25 & 3,33 & 1,11 & 0,98 & 0,5 \\
\hline Blenniiformes & Blenniidae & 28 & 42 & 6,21 & 1,04 & 1,23 & 1,0 \\
\hline Carangiformes & Carangidae & 62 & 67 & 15,93 & 1,99 & 2,44 & 2,5 \\
\hline \multicolumn{8}{|l|}{ Istiophoriformes } \\
\hline & Sphyraenidae & 70 & 25 & 20,01 & 6,67 & 6,71 & 3,1 \\
\hline & Istiophoridae & 1 & 8 & 0,31 & 0,31 & 0,00 & $<0.1$ \\
\hline \multirow[t]{3}{*}{ Pleuronectiformes } & $\mathrm{NI}$ & 13 & & 3,00 & 0,50 & 0,55 & 0,5 \\
\hline & Paralichthyidae & 248 & 92 & 58,65 & 5,33 & 7,59 & 9,1 \\
\hline & Cynoglossidae & 24 & 50 & 5,57 & 0,93 & 0,67 & 0,9 \\
\hline Scombriformes & Trichiuridae & 2 & 17 & 0,41 & 0,21 & 0,02 & 0,1 \\
\hline Trachiniformes & Percophidae & 1 & 8 & 0,32 & 0,32 & 0,00 & $<0.1$ \\
\hline \multicolumn{8}{|l|}{ Perciformes } \\
\hline & Gerreidae & 44 & 17 & 12,74 & 6,37 & 4,00 & 2,0 \\
\hline & Serranidae & 34 & 50 & 8,06 & 1,34 & 1,56 & 1,3 \\
\hline & Pomacanthidae & 1 & 8 & 0,24 & 0,24 & 0,00 & $<0.1$ \\
\hline & Haemulidae & 14 & 50 & 3,47 & 0,58 & 0,64 & 0,5 \\
\hline & Lutjanidae & 8 & 8 & 2,03 & 2,03 & 0,00 & 0,3 \\
\hline Scorpaeniformes & Triglidae & 16 & 33 & 3,66 & 0,92 & 0,92 & 0,6 \\
\hline Acanthuriformes & Sciaenidae & 182 & 92 & 40,51 & 3,68 & 4,29 & 6,3 \\
\hline Caproiformes & Lophiidae & 1 & 8 & 0,29 & 0,29 & 0,00 & $<0.1$ \\
\hline $\mathrm{NI}$ & & 481 & & 119,00 & 9,92 & 5,71 & 18,5 \\
\hline$\overline{\text { TOTAL }}$ & & 2446 & & 1286,49 & 107,21 & 148,61 & 100,00 \\
\hline
\end{tabular}




\subsubsection{Densidade das espécies das famílias predominantes}

A seguir se descreve a variação temporal da densidade das espécies das famílias predominantes (frequência de ocorrência $\geq 50 \%$ ) versus clorofila $a$ integrada $\left(\mathrm{mg} \mathrm{m}^{-2}\right)$ e peso seco do zooplâncton $\left(\mathrm{g} 100 \mathrm{~m}^{-3}\right)$ coletado com a rede de $50 \mu \mathrm{m}$.

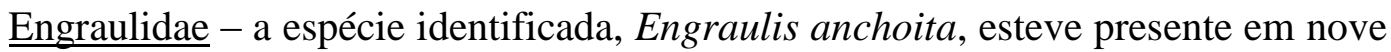
dos 12 meses de coleta. Sua densidade não variou muito ao longo do ano, com os maiores valores em janeiro e fevereiro/2015. Destaca-se o pico de microzooplâncton em dezembro/2014 que ocorreu simultaneamente com o de clorofila $a$, e com a presença de $E$. anchoita (Fig. 16).

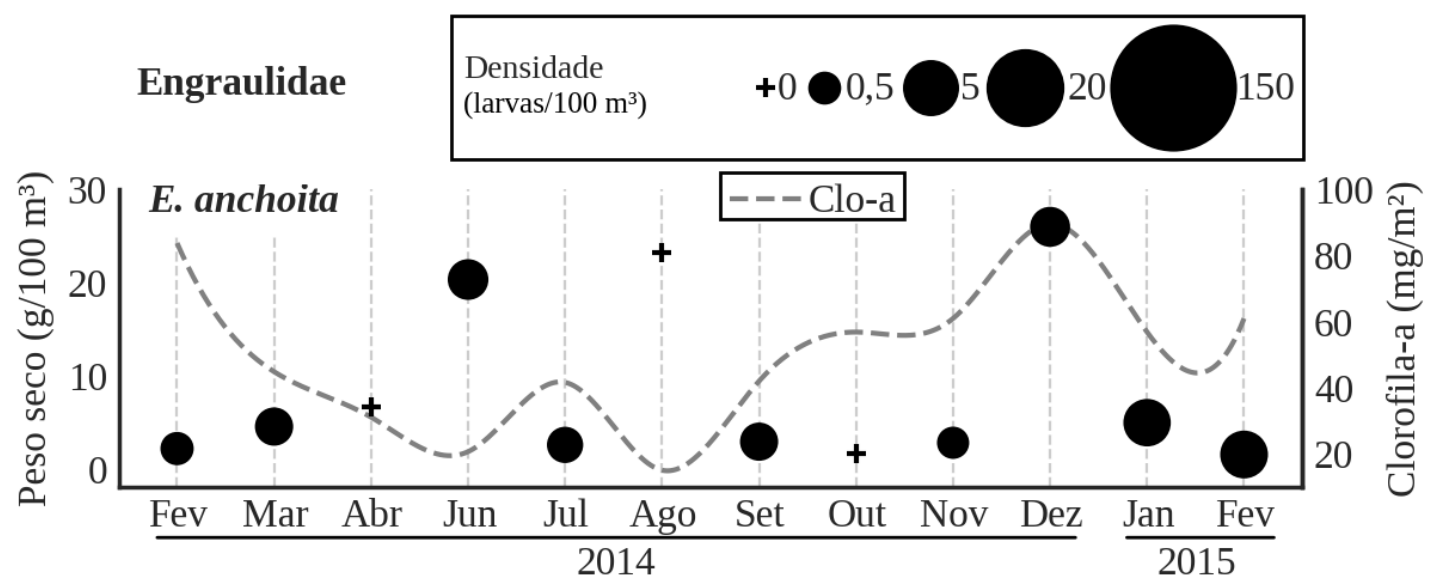

Figura 16. Distribuição mensal da densidade (larvas $100 \mathrm{~m}^{-3}$ ) da espécie de Engraulidae - Engraulis anchoita - versus a clorofila $a$ integrada $\left(\mathrm{mg} \mathrm{m}^{-2}\right)$ e a biomassa do

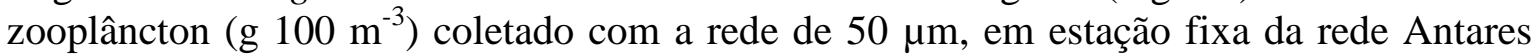
localizada em Ubatuba-SP. • - a sua posição no gráfico indica o peso seco.

Clupeidae - foram identificadas três espécies: Harengula jaguana, Opisthonema oglinum e Sardinella brasiliensis. A densidade dessas três espécies foi maior em janeiro/2015 (Fig. 17). Nesse mês, a densidade de S. brasiliensis (141,97 larvas $100 \mathrm{~m}^{-3}$ ) foi superior à de todas as espécies identificadas (Fig. 16). No mês de junho houve registros de $H$. jaguana e $S$. brasiliensis. No mês de setembro as densidades próximas a 5 larvas $100 \mathrm{~m}^{-3}$ de $H$. jaguana e O. oglinum ocorreram simultaneamente com valores baixos de biomassa zooplanctônica e clorofila $a$ integrada (Fig. 17). 


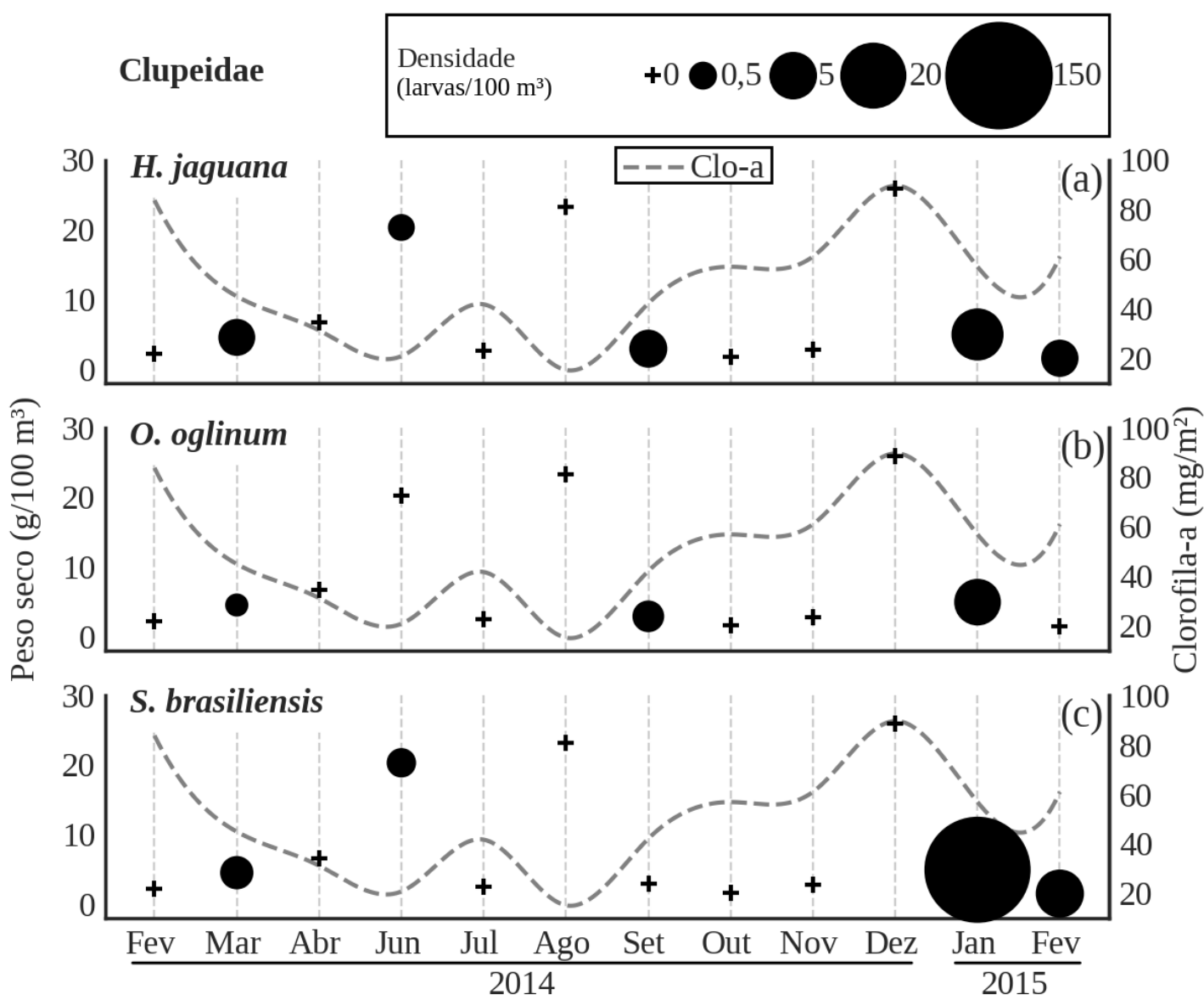

Figura 17. Distribuição mensal da densidade (larvas $100 \mathrm{~m}^{-3}$ ) das espécies de Clupeidae - Harengula jaguana, Opisthonema oglinum e Sardinella brasiliensis - versus a clorofila $a$ integrada $\left(\mathrm{mg} \mathrm{m}^{-2}\right)$ e a biomassa do zooplâncton $\left(\mathrm{g} 100 \mathrm{~m}^{-3}\right)$ coletado com a rede de $50 \mu \mathrm{m}$, em estação fixa da rede Antares localizada em Ubatuba-SP. - - a sua posição no gráfico indica o peso seco. 
Synodontidae - Trachinocephalus myops, a única espécie identificada, ocorreu em quatro meses, em agosto/2014 teve o menor valor de densidade e o maior de biomassa zooplanctônica e, em novembro/2014, o maior valor de densidade $\left(10,55\right.$ larvas $\left.100 \mathrm{~m}^{-3}\right) \mathrm{e}$

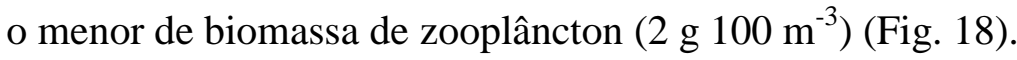

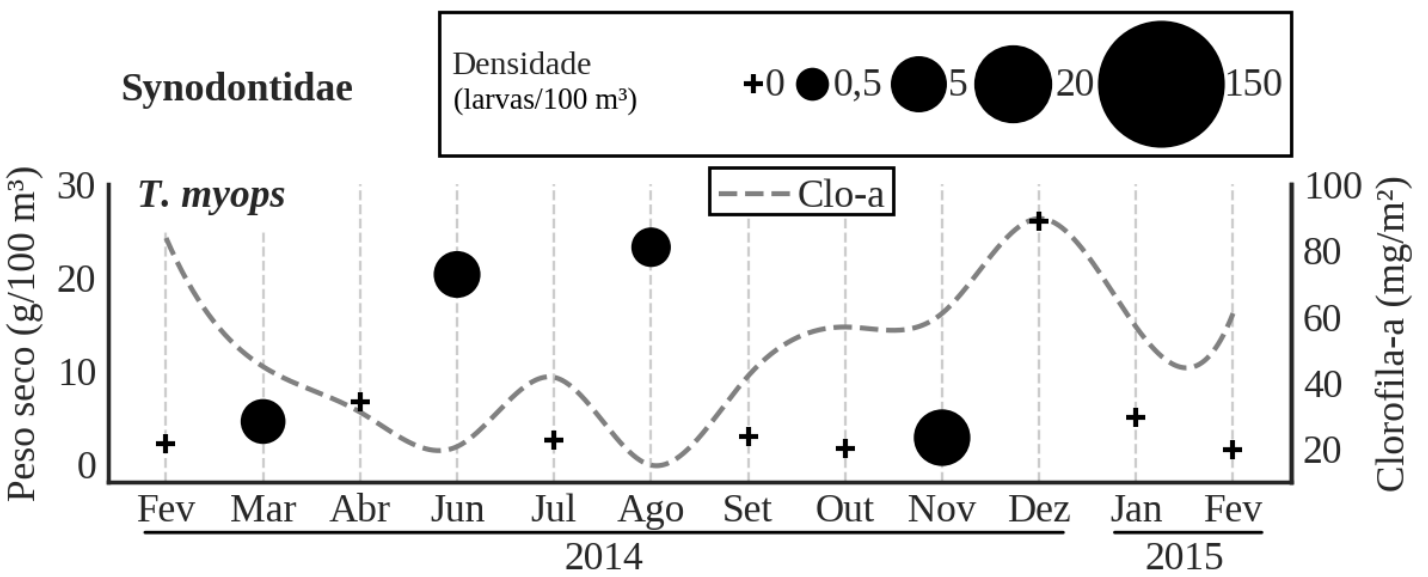

Figura 18. Distribuição anual da densidade (larvas $100 \mathrm{~m}^{-3}$ ) da espécie de Synodontidae - Trachinocephalus myops - versus a clorofila $a$ integrada $\left(\mathrm{mg} \mathrm{m}^{-2}\right)$ e a biomassa do zooplâncton $\left(\mathrm{g} 100 \mathrm{~m}^{-3}\right)$ coletado com a rede de $50 \mu \mathrm{m}$, em estação fixa da rede Antares localizada em Ubatuba-SP. - a sua posição no gráfico indica o peso seco. 
Ophidiidae - foram identificadas duas espécies, Lepophidium brevibarbe e Ophidion holbrookii, esta última com a maior densidade em janeiro/2015. Lepophidium brevibarbe só foi encontrada em julho e agosto com densidades inferiores a 0,5-larvas 100 $\mathrm{m}^{-3}$. A maior densidade de $O$. holbrookii ocorreu em janeiro/2015 (12,84 larvas $\left.100 \mathrm{~m}^{-3}\right) \mathrm{e}$ a menor, em julho/2014 (Fig. 19).

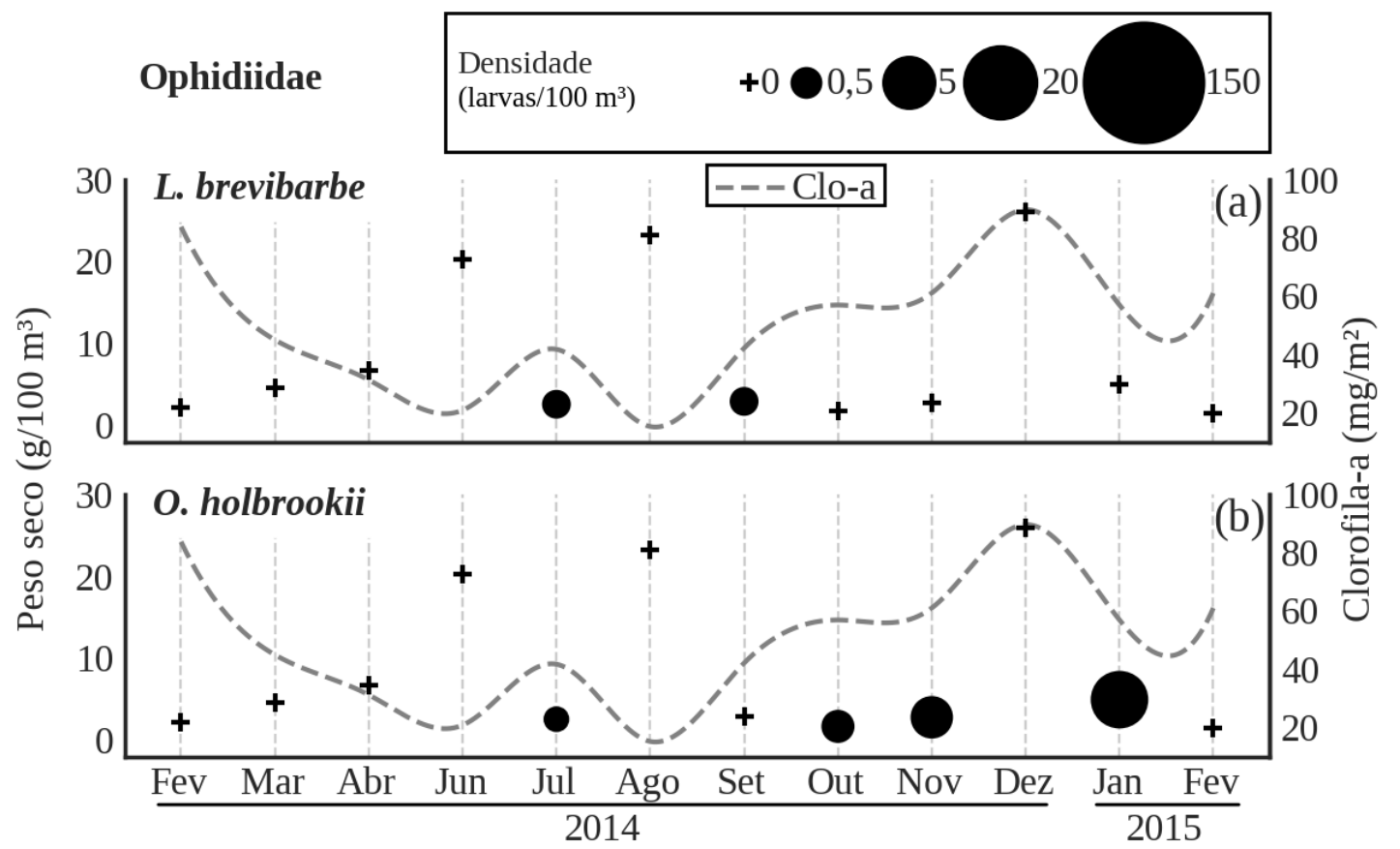

Figura 19. Distribuição mensal da densidade (larvas $100 \mathrm{~m}^{-3}$ ) das espécies de Ophidiidae - Lepophidium brevibarbe e Ophidion holbrookii - versus a clorofila $a$

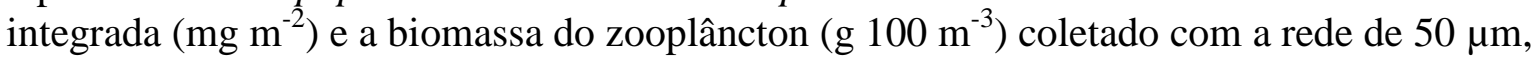
em estação fixa da rede Antares localizada em Ubatuba-SP. - - a sua posição no gráfico indica o peso seco.

Carangidae - esta família teve cinco representantes em nível de espécie: Caranx sp., Chloroscombrus chysurus, Selene setapinnis, S. vomer e Trachurus lathami. Caranx sp. ocorreu somente em janeiro/2014 com baixa densidade (1,23 larvas $\left.100 \mathrm{~m}^{-3}\right)$. A presença de $C$. chysurus foi registrada em quatro meses do período de estudo, sendo que, entre os meses de ocorrência dessa espécie, abril registrou o menor valor de clorofila $a$ $\left(31,20 \mathrm{mg} \mathrm{m}^{-2}\right)$. Em fevereiro/2015 S. setapinnis teve o maior valor de densidade entre os carangideos $\left(13,13\right.$ larvas $\left.100 \mathrm{~m}^{-3}\right)$. A outra espécie do mesmo gênero, S. vomer, foi encontrada em dois meses, mas não superou 2 larvas $100 \mathrm{~m}^{-3}$. O valor de densidade de $T$. lathami $\left(3,87\right.$ larvas $\left.100 \mathrm{~m}^{-3}\right)$ coincidiu com o maior valor de biomassa zooplânctonica

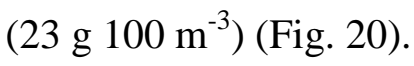



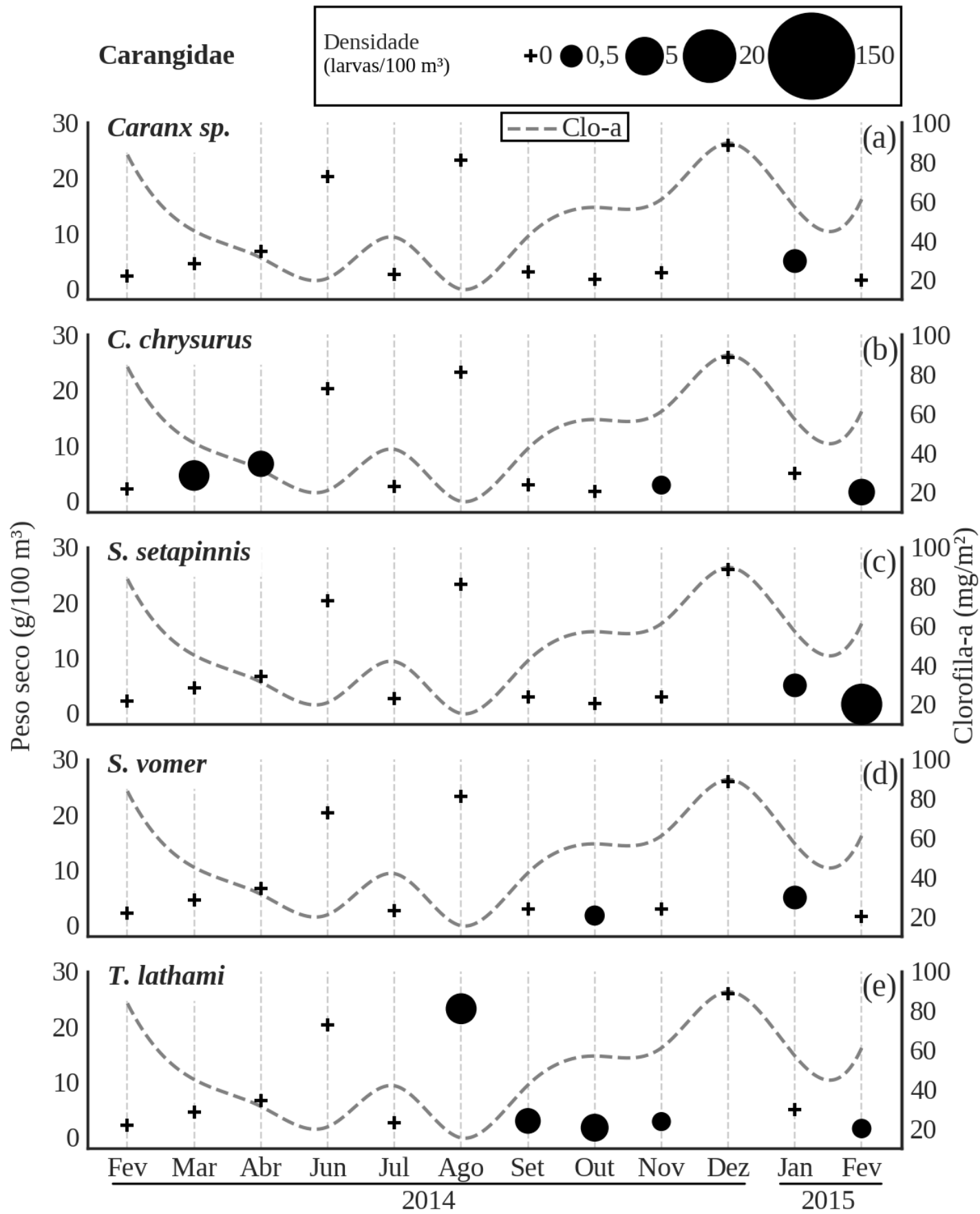

Figura 20. Distribuição mensal da densidade (larvas $100 \mathrm{~m}^{-3}$ ) das espécies de Carangidae - Caranx sp., Chloroscombrus chysurus, Selene setapinnis, S. vomer $e$ Trachurus lathami - versus a clorofila $a$ integrada $\left(\mathrm{mg} \mathrm{m}^{-2}\right)$ e a biomassa do zooplâncton ( $\mathrm{g}$ $100 \mathrm{~m}^{-3}$ ) coletado com a rede de $50 \mu \mathrm{m}$, em estação fixa da rede Antares localizada em Ubatuba-SP. - a sua posição no gráfico indica o peso seco. 
Paralichthyidae - dessa família, presente em 10 dos 12 meses de coleta, foram identificadas três espécies: Cyclopsetta fimbriata, Etropus crossotus e Syacium papillosum. Cyclopsetta fimbriata e S. papillosum foram encontradas pontualmente em fevereiro/2015 e março/2014, respetivamente. Etropus crossotus só não foi encontrada em novembro/2014 e janeiro/2015. Essa espécie teve o maior densidade em março/2014 sem coincidir com os maiores valores de biomassa de zooplâncton e de clorofila $a$ (Fig. 21).

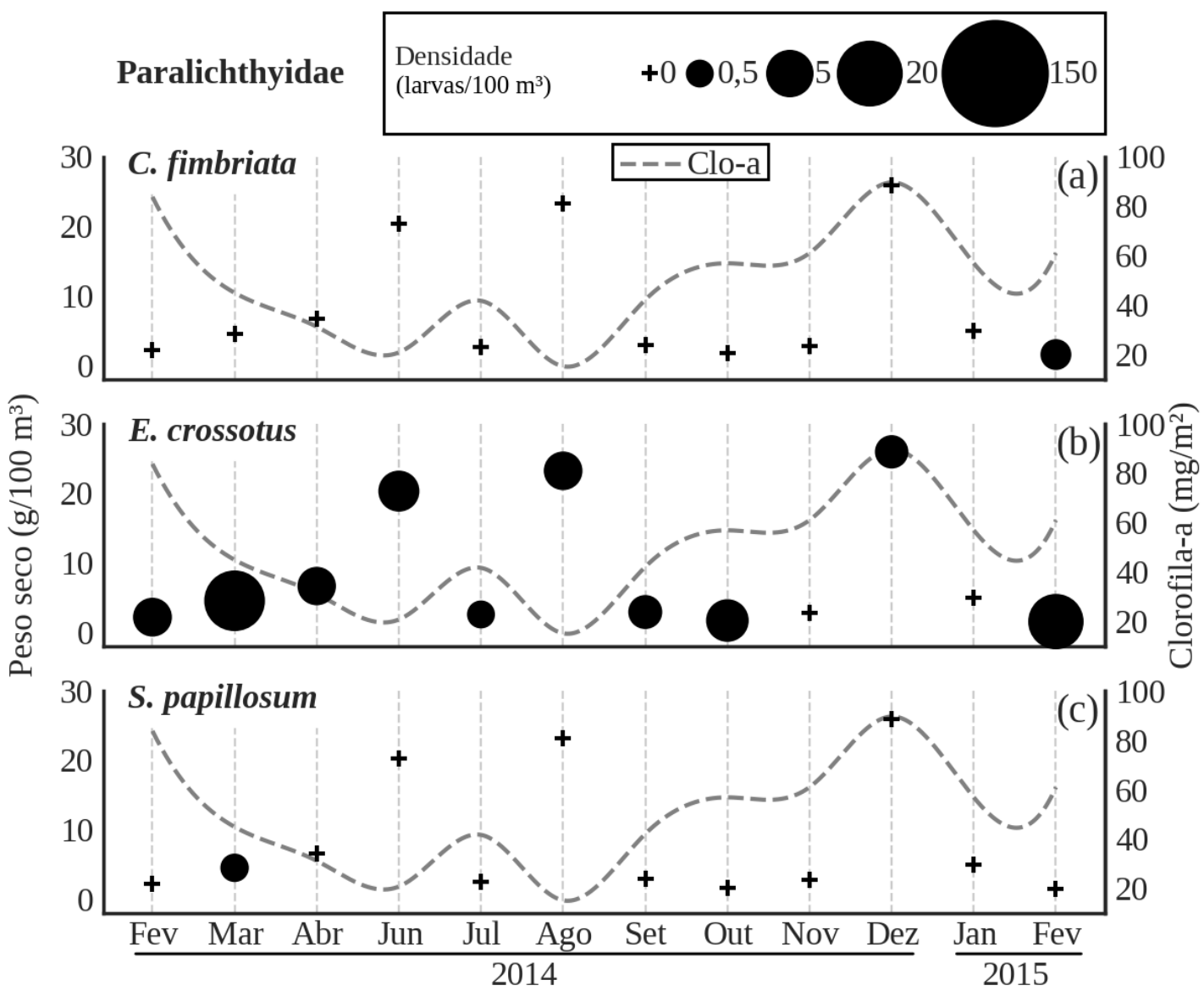

Figura 21. Distribuição mensal da densidade (larvas $100 \mathrm{~m}^{-3}$ ) das espécies de Paralichthyidae - Cyclopsetta fimbriata, Etropus crossotus e Syacium papillosum - versus a clorofila $a$ integrada $\left(\mathrm{mg} \mathrm{m}^{-2}\right)$ e a biomassa do zooplâncton $\left(\mathrm{g} 100 \mathrm{~m}^{-3}\right)$ coletado com a rede de $50 \mu \mathrm{m}$, em estação fixa da rede Antares localizada em Ubatuba-SP. - - a sua posição no gráfico indica o peso seco. 
Cynoglossidae - esta família esteve representada por duas espécies do mesmo gênero, Symphurus tessellatus e S. trewavasae. Symphurus tesellatus esteve presente em cinco dos 12 meses de coleta e o maior valor de densidade ocorreu em fevereiro/2015. Symphurus trewavasae só esteve presente em julho/2014 coincidindo com valores baixos de biomassa do zooplâncton e clorofila $a$ (Fig. 22).

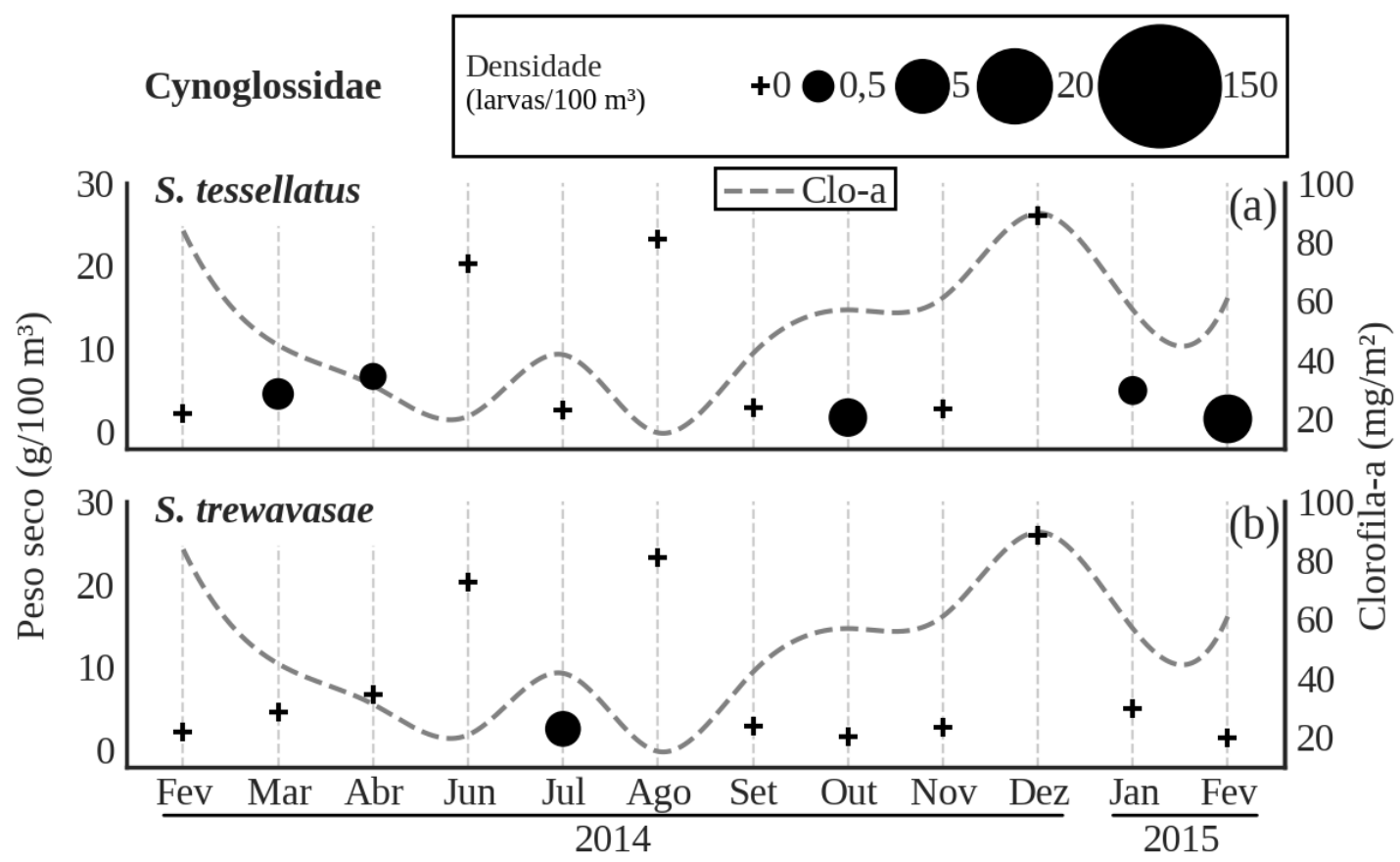

Figura 22. Distribuição mensal da densidade (larvas $100 \mathrm{~m}^{-3}$ ) das espécies de Cynoglossidae - Symphurus tessellatus e $S$. trewavasae - versus a clorofila $a$ integrada (mg $\mathrm{m}^{-2}$ ) e a biomassa do zooplâncton $\left(\mathrm{g} 100 \mathrm{~m}^{-3}\right)$ coletado com a rede de $50 \mu \mathrm{m}$, em estação fixa da rede Antares localizada em Ubatuba-SP. • - a sua posição no gráfico indica o peso seco. 


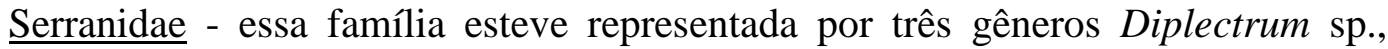
Serranus sp. e Epinephelus sp. Devido à fase inicial de desenvolvimento e tamanho das larvas, não foi possível sua identificação até o nível de espécie. Os três gêneros ocorreram em fevereiro/2015 (Fig. 23).

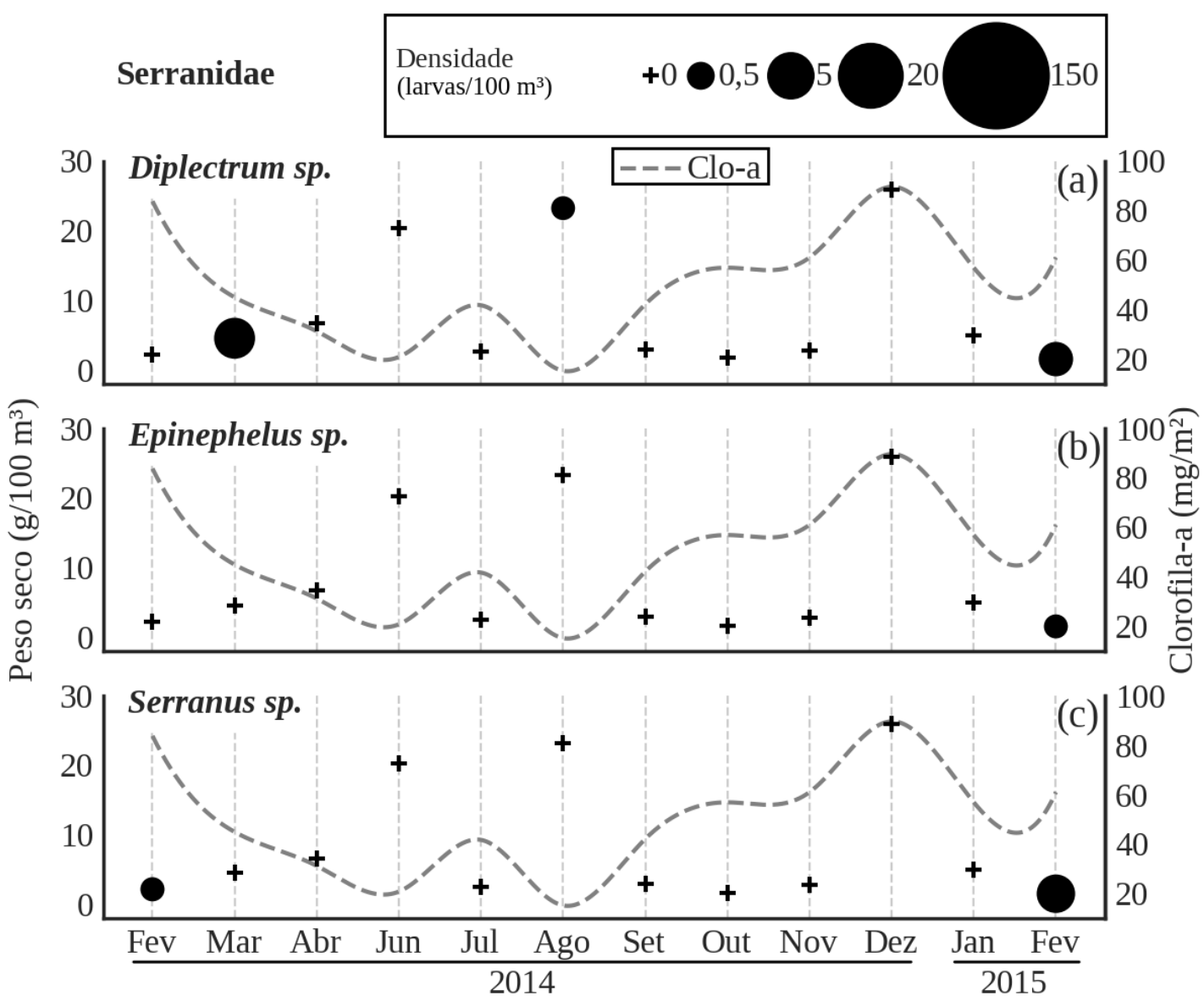

Figura 23. Distribuição mensal da densidade (larvas $100 \mathrm{~m}^{-3}$ ) das espécies de Serranidae - Diplectrum sp., Epinephelus sp. e Serranus sp. - versus a clorofila $a$ integrada $\left(\mathrm{mg} \mathrm{m}^{-2}\right)$ e a biomassa do zooplâncton $\left(\mathrm{g} 100 \mathrm{~m}^{-3}\right)$ coletado com a rede de $50 \mu \mathrm{m}$, em estação fixa da rede Antares localizada em Ubatuba-SP. • - a sua posição no gráfico indica o peso seco.

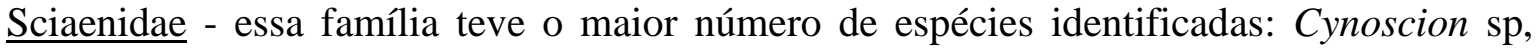
Isopisthus parvipinnis, Menticirrhus americanus, Micropogonias furnieri, Stellifer sp., S. rastrifer e S. stellifer. Cynoscion sp. foi uma das espécies com maior frequência de ocorrência, acima de 50\%, e sua densidade máxima foi 4 larvas $100 \mathrm{~m}^{-3}$ (Fig. 23). Isopisthus parvipinnis ocorreu em abril, junho e agosto/2014 e com densidades baixas $(<2$ larvas $100 \mathrm{~m}^{-3}$ ) (Fig. 23). Menticirrhus americanus esteve presente em quatro meses com 
maior densidade em agosto e dezembro/2014, sendo que nesse último mês ocorreram picos de biomassa zooplanctônica e de clorofila $a$ (Fig. 24).
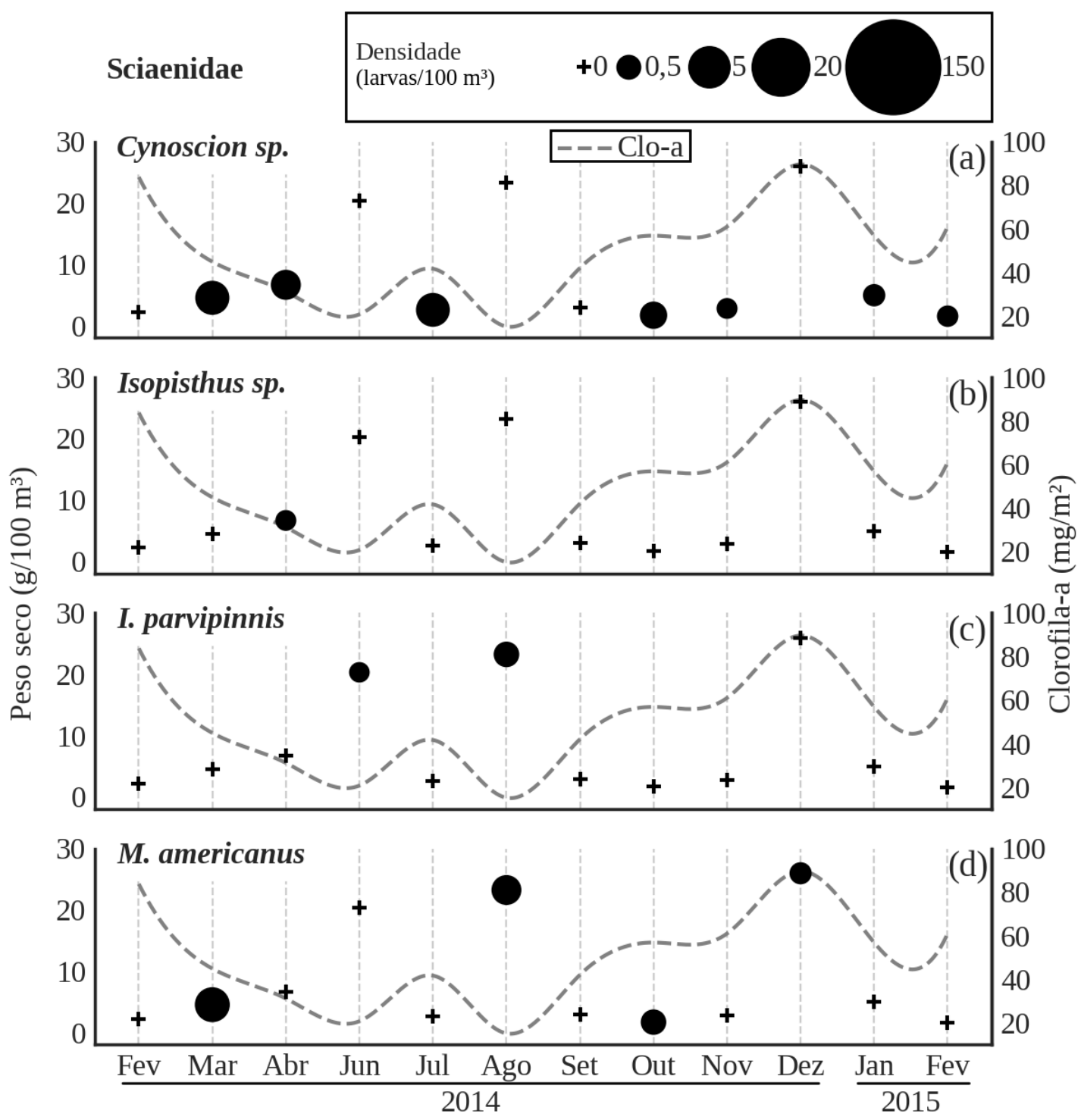

Figura 24. Distribuição mensal da densidade (larvas $100 \mathrm{~m}^{-3}$ ) das espécies de Sciaenidade - Cynoscion sp., Isopisthus parvipinnis e Menticirrhus americanus - versus a

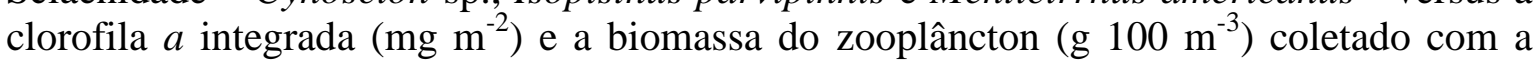
rede de $50 \mu \mathrm{m}$, em estação fixa da rede Antares localizada em Ubatuba-SP. - a sua posição no gráfico indica o peso seco. 
Micropogonias furnieri só foi identificada em agosto/2014, coincidindo com o pico de biomassa zooplanctônica (Fig. 24). Junto a Cynoscion sp., Stellifer sp. foi outro cienídeo com maior frequência de ocorrência, sendo o máximo valor de densidade observado em março/2014 e, em junho e agosto/2014, sua ocorrência coincidiu com altos

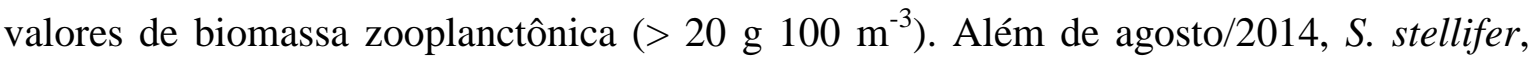
assim como S. rastrifer, ocorreu nos meses de março, junho e julho/2014, fevereiro/2015. Essas duas espécies apresentaram maior densidade em junho/2014, sendo que S. stellifer foi mais abundante (10,04 larvas $\left.100 \mathrm{~m}^{-3}\right)$ (Fig.25).
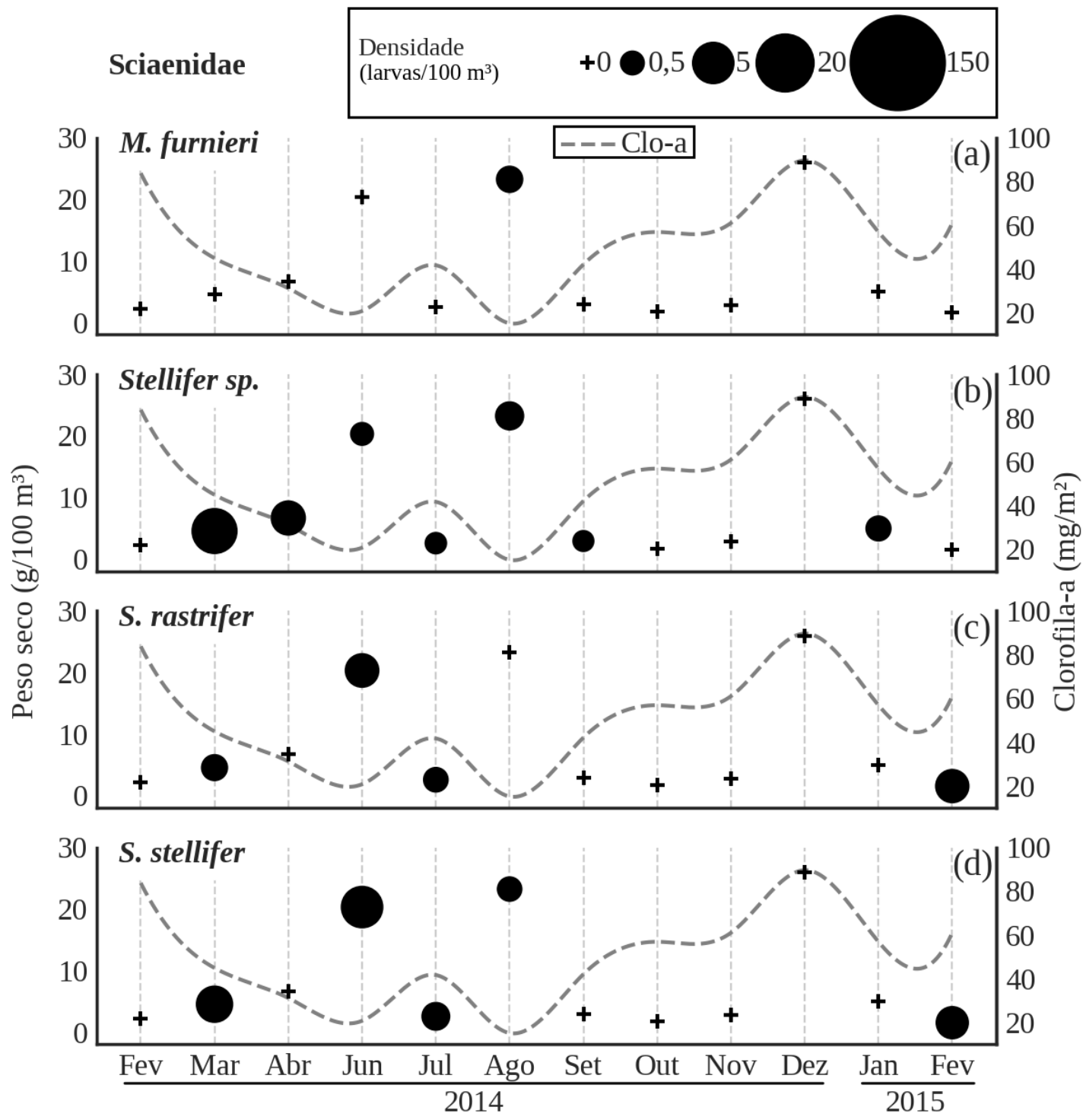

Figura 25. Distribuição mensal da densidade (larvas 100m-3) das espécies de Sciaenidae - Micropogonias furnieri, Stellifer sp., S. rastrifer e S. stellifer - versus a

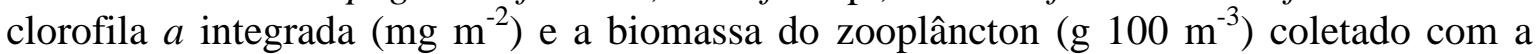
rede de $50 \mu \mathrm{m}$, em estação fixa da rede Antares localizada em Ubatuba-SP. - - a sua posição no gráfico indica o peso seco. 


\subsubsection{Estágio de desenvolvimento larval}

Os estágios de desenvolvimento foram analisados para aqueles organismos identificados até o nível de espécie, ou gênero, das famílias predominantes.

\section{ENGRAULIDAE}

E. anchoita: O maior número de larvas estava no estágio de pré-flexão e ocorreram em cinco meses no período de março a dezembro/2014. Larvas no estágio de flexão ocorreram em quatro meses no período de fevereiro a novembro/2014. O maior número de larvas foi registrado em junho/2014 $(n=6)($ Fig. 26).

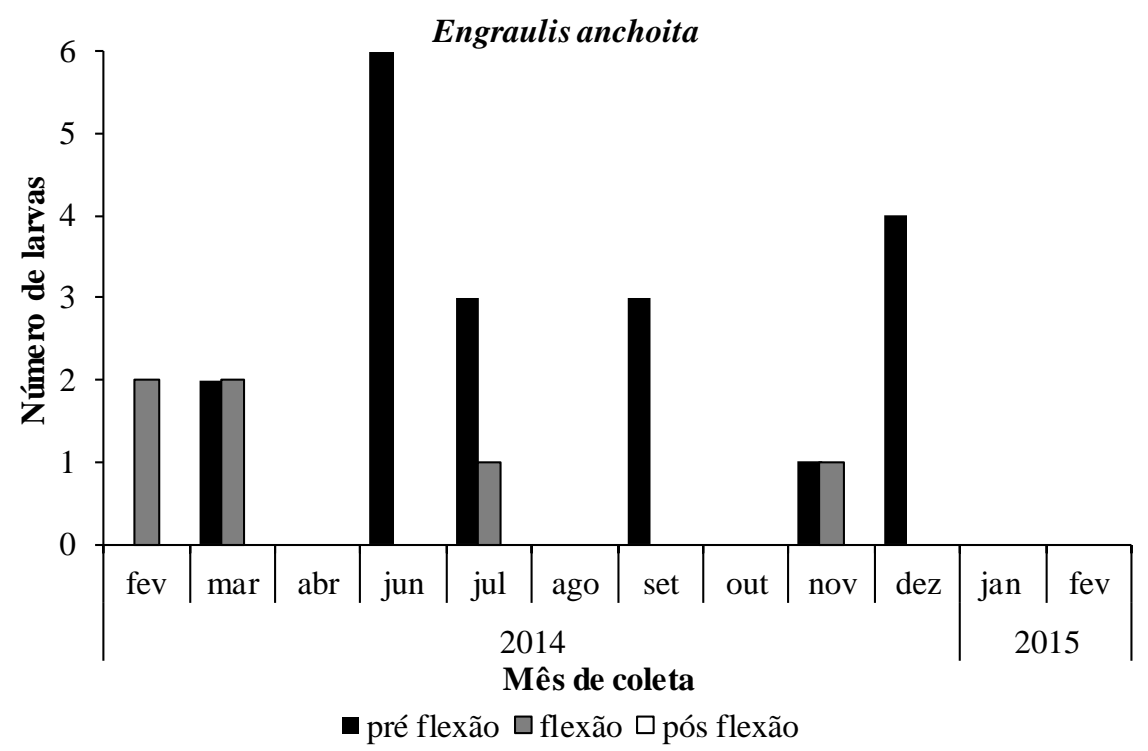

Figura 26. E. anchoita - Distribuição mensal do número de larvas nos estágios de desenvolvimento pré-flexão, flexão e pós-flexão coletadas em estação fixa da rede Antares localizada em Ubatuba-SP. 


\section{CLUPEIDAE}

Harengula jaguana - Foram identificados os três estágios larvais no período de estudo, no entanto só no mês de janeiro/2015 os três ocorreram simultaneamente. O maior número de larvas em pré-flexão esteve em março/204 7 espécimes. No caso do estágio de flexão o maior número de larvas (19) foi observado no mês de janeiro/2015. Por sua vez, as larvas do estágio de pós-flexão só foram encontrados no mês de janeiro/2015 (Fig. 27).

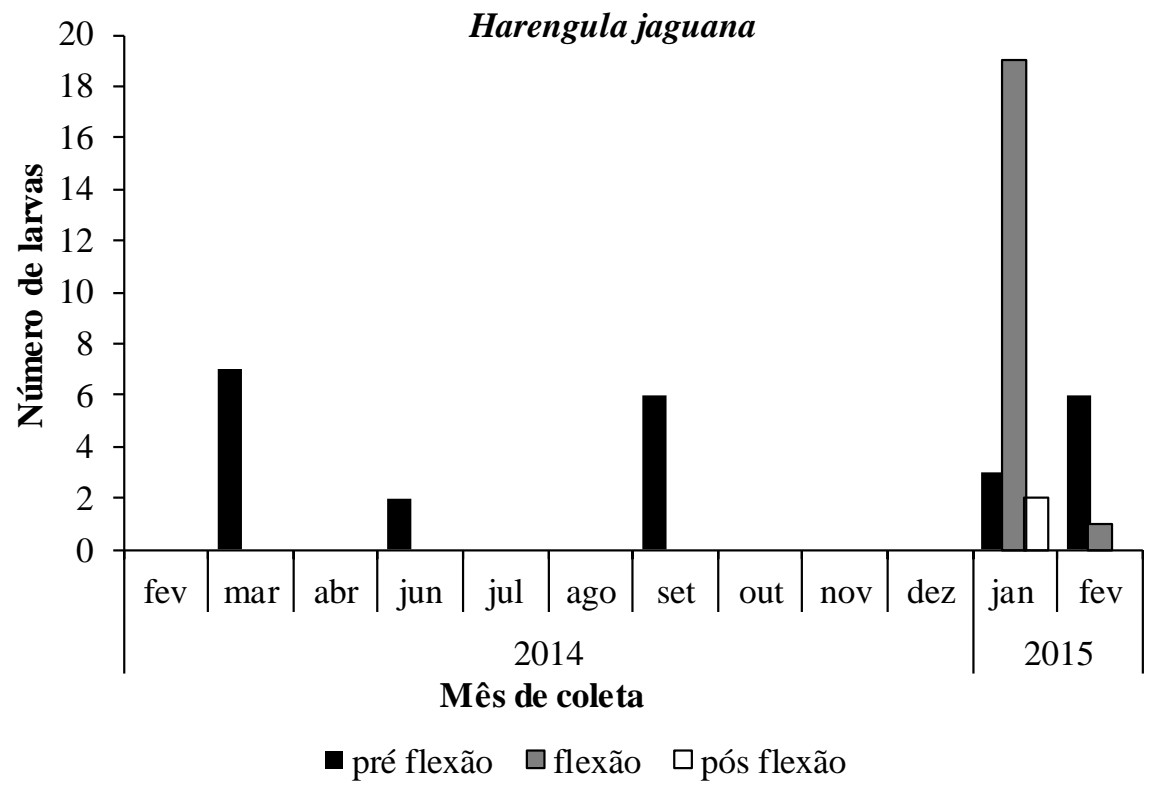

Figura 27. Harengula jaguana - Distribuição mensal do número de larvas nos estágios de desenvolvimento pré-flexão, flexão e pós-flexão coletadas em estação fixa da rede Antares localizada em Ubatuba-SP. 
Sardinella brasiliensis - O estágio de pré-flexão teve o maior percentual (48\%) seguido do estágio de flexão (46\%), ambos ocorrendo quase exclusivamente em janeiro/2015. O estágio de pós-flexão, só foi identificado em janeiro/2015 (Fig. 28).

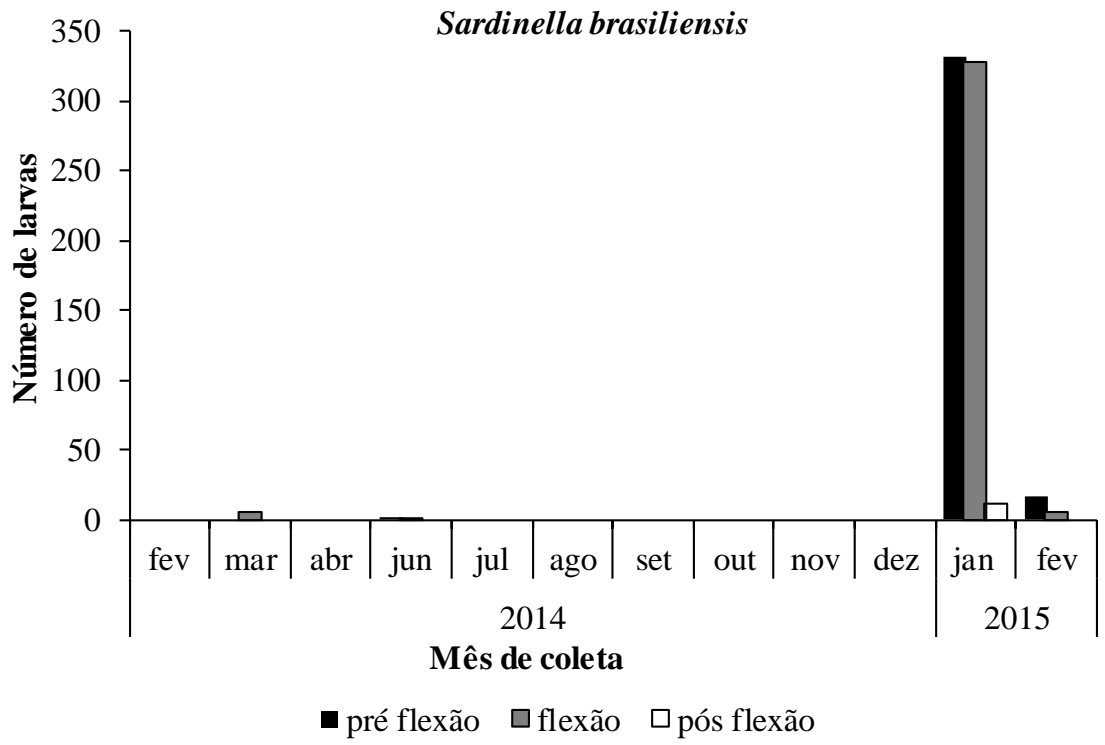

Figura 28. S. brasiliensis - Distribuição mensal do número de larvas nos estágios de desenvolvimento pré-flexão, flexão e pós-flexão coletadas em estação fixa da rede Antares localizada em Ubatuba-SP.

Opisthonema oglinum - Foram registrados os estágios de flexão e pós-flexão. Em janeiro/2015 foi registrado o maior número de larvas em flexão e pós-flexão, únicos estágios de desenvolvimento observados para O. oglinum (Fig. 29).

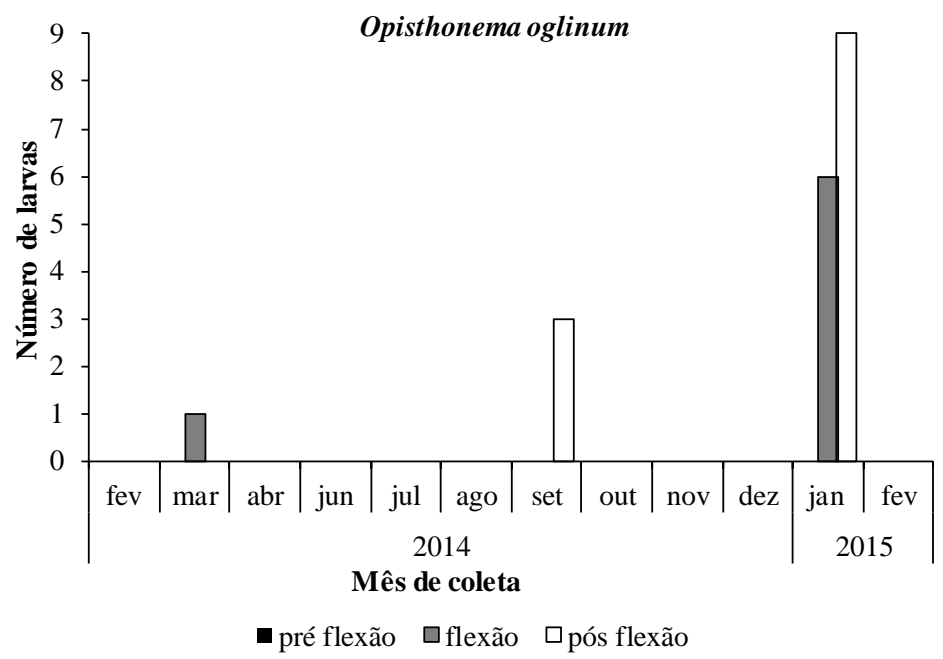

Figura 29. O. oglinum - Distribuição mensal do número de larvas nos estágios de desenvolvimento pré-flexão, flexão e pós-flexão coletadas em estação fixa da rede Antares localizada em Ubatuba-SP. 


\section{SYNODONTIDAE}

T. myops: estas larvas somente ocorreram na fase de pré-flexão, nos meses de março $(n=8)$ e junho $(n=10)$ de 2014.

\section{OPHIDIIDAE}

O. holbrooki: Os três estágios larvais foram identificados no mês de novembro. A fase larval de pré-flexão foi encontrada em maior número em fevereiro/2015 e foi a de maior percentual de presença no período de estudo (85\%). Só foi identificado um organismo na fase de pós-flexão em novembro/2014 (Fig. 30)

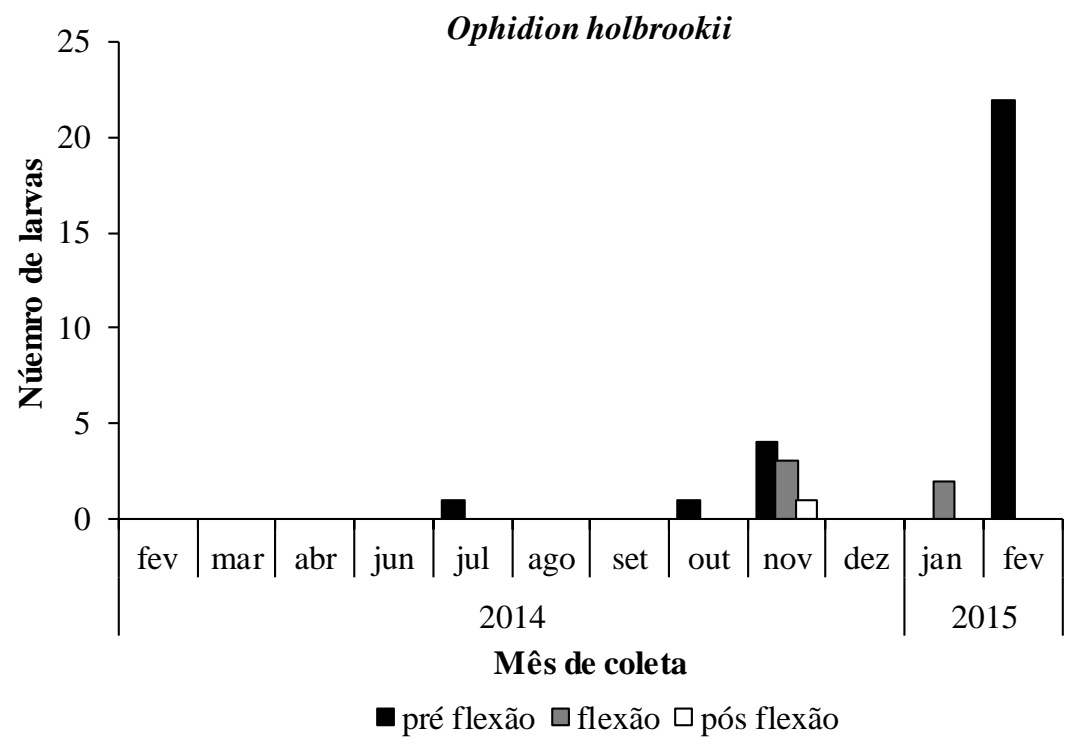

Figura 30. O. holbrookii - Distribuição mensal do número de larvas nos estágios de desenvolvimento pré-flexão, flexão e pós-flexão coletadas em estação fixa da rede Antares localizada em Ubatuba-SP.

L. brevibarbe: só foram identificadas três larvas desta espécie, dos quais uma esteve na fase de pré-flexão (setembro/14) e duas na fase de flexão (julho/2014). 


\section{CARANGIDAE}

Caranx sp. - Ocorreram duas larvas na fase de flexão em janeiro/2015.

C. chrysurus - foram registradas 13 larvas na fase de flexão, com maior ocorrência em março/2014 (Fig. 31).

Chloroscombrus chrysurus.

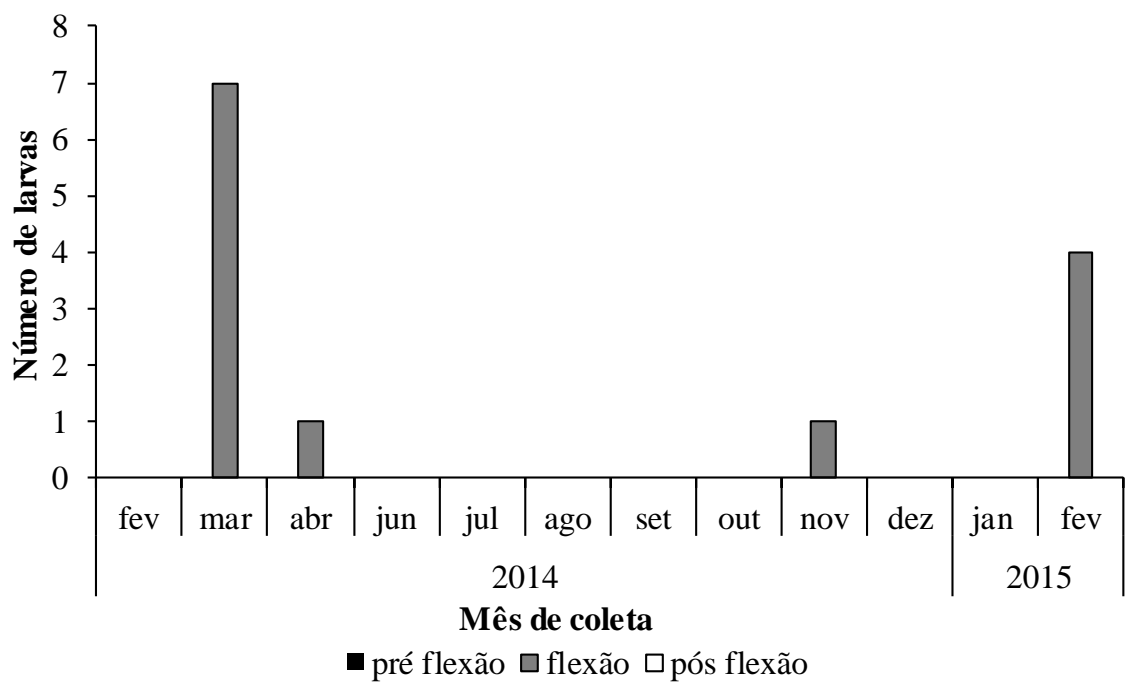

Figura 31 C. chrysurus - Distribuição mensal do número de larvas nos estágios de desenvolvimento pré-flexão, flexão e pós-flexão coletadas em estação fixa da rede Antares localizada em Ubatuba-SP. 
S. setapinnis - O maior percentual de larvas de $S$. setapinnins foi identificado em estágio de pré-flexão (85\%), Fevereiro/2015 foi um mês particular para essa espécie, pois foram encontradas as três fases larvais, com a maior frequência de larvas em pré-flexão. (Fig. 32).

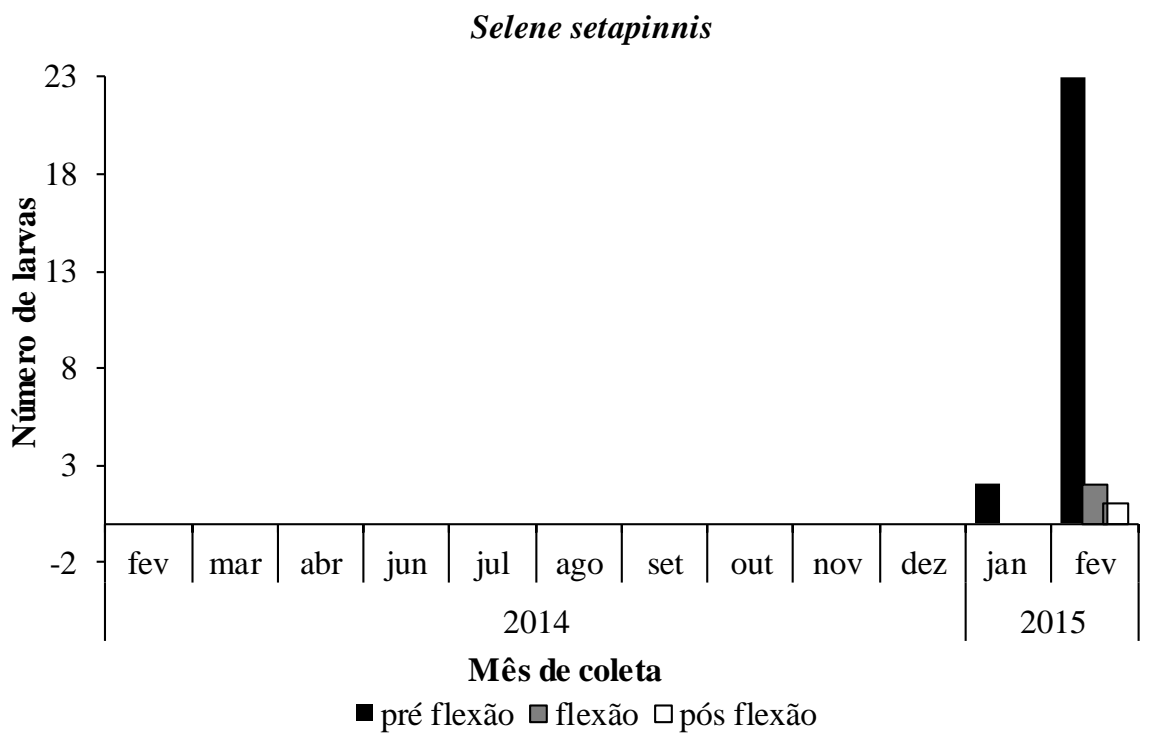

Figura 32. S. setapinnis - Distribuição mensal do número de larvas nos estágios de desenvolvimento pré-flexão, flexão e pós-flexão coletadas em estação fixa da rede Antares localizada em Ubatuba-SP.

S. vomer - Para esta espécie foram identificados três indivíduos nas três fases larvais. O estágio de pré-flexão esteve presente no mês de outubro/2014 e flexão e pósflexão no mês de janeiro/2015. 
T. lathami - Foram encontradas larvas nas três fases de desenvolvimento. A fase de pré-flexão ocorreu nos meses de outubro/2014 e fevereiro/2015. O maior número de larvas foi observada no mês de agosto/2014, na fase de flexão,. Este estágio foi o que teve o maior percentual de representantes (59\%). Nos meses de setembro/2014 e novembro/2014 foi identificada a fase de pós-flexão (Fig. 33).

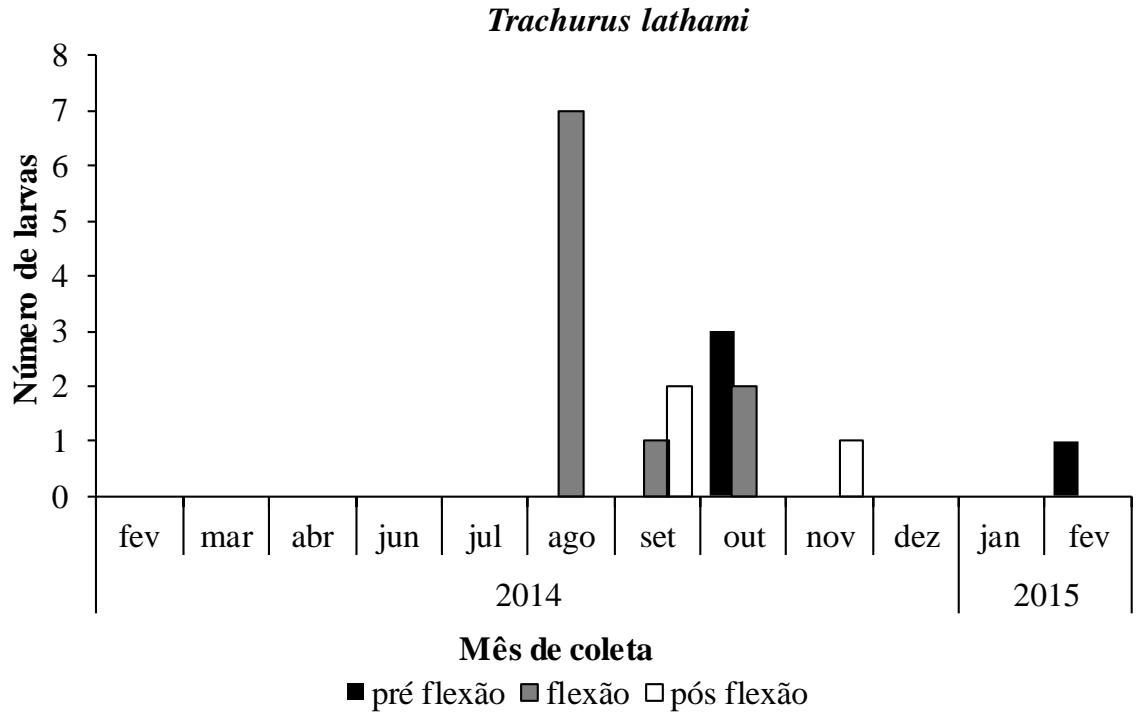

Figura 33. T. lathami - Distribuição mensal do número de larvas nos estágios de desenvolvimento pré-flexão, flexão e pós-flexão coletadas em estação fixa da rede Antares localizada em Ubatuba-SP. 


\section{PARALICHTHYIDAE}

C. fimbriata - Em fevereiro/2015 foram identificadas duas larvas dessa espécie, ambas em estado de pós-flexão.

E. crossotus - Essa espécie foi uma das mais frequentes e só não esteve presente em dezembro/2014 e janeiro/2015. A maioria das larvas (70\%) estavam em pré-flexão, estágio com maior quantidade de larvas identificadas em março/2014. Os estágios de flexão e pós-flexão tiveram abundância total semelhante, ocorrendo em maior número em fevereiro/2015 e fevereiro/2014, respectivamente. (Fig. 34).

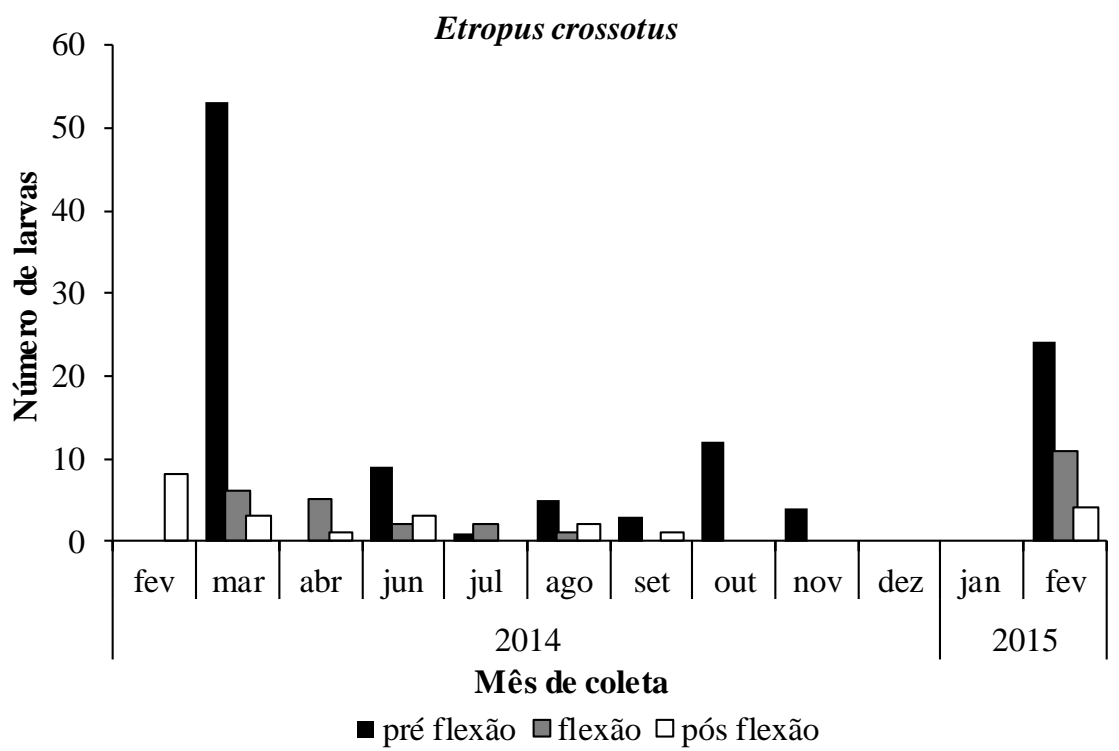

Figura 34. E. crossotus - Distribuição mensal do número de larvas nos estágios de desenvolvimento pré-flexão, flexão e pós-flexão coletadas em estação fixa da rede Antares localizada em Ubatuba-SP. 


\section{CYNOGLOSSIDAE}

S. papillosum - Foram observados apenas dois exemplares dessa espécie nas fases de pré-flexão e pós-flexão em março/2014 e janeiro/2015, respectivamente.

S. tessellatus - Foram identificadas as três fases de desenvolvimento larval com ocorrência simultânea em março/2014. A maioria das larvas desta espécie (64\%) estava na fase de pré-flexão com maior número de larvas em fevereiro/2014. Os estágios de flexão foram registrados em março e outubro/2014 e as larvas em pós-flexão, em três meses consecutivos, fevereiro, março e abril/2014 (Fig. 35).

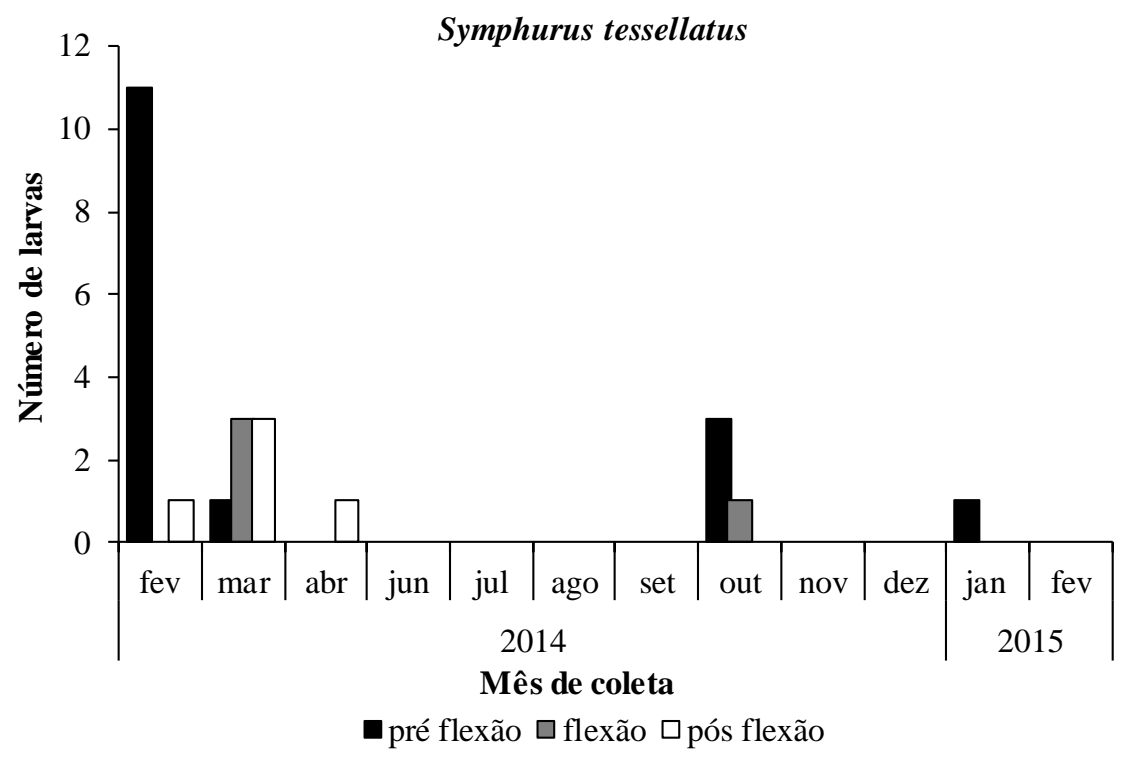

Figura 35. S. tesselatus - Distribuição mensal do número de larvas nos estágios de desenvolvimento pré-flexão, flexão e pós-flexão coletadas em estação fixa da rede Antares localizada em Ubatuba-SP.

S. trewavasae - As cinco larvas dessa espécie estavam em fase de flexão e foram coletadas no mês de julho/2014. 


\section{SERRANIDAE}

Diplectrum sp. - Os três estágios larvais em março/2014 tiveram o maior número de larvas identificadas. O estágio de flexão foi o que teve maior percentual de ocorrência (55\%) e o estágio de pré-flexão, o menor (Fig. 36).

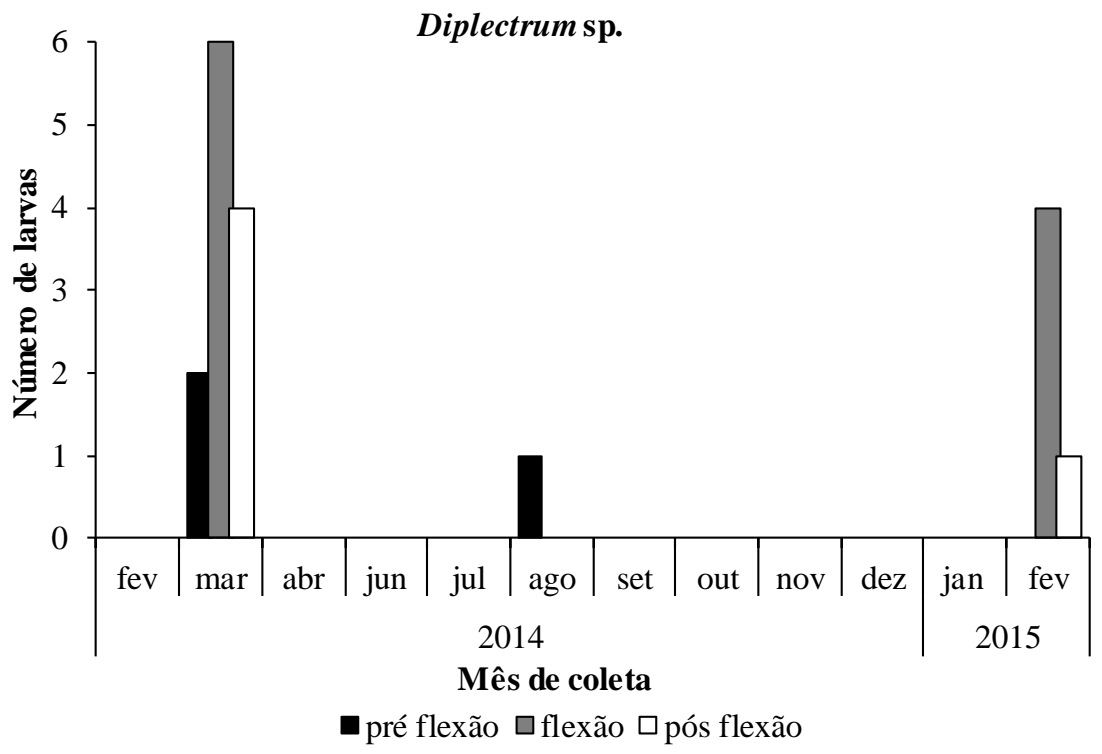

Figura 36. Diplectrum sp. - Distribuição mensal do número de larvas nos estágios de desenvolvimento pré-flexão, flexão e pós-flexão coletadas em estação fixa da rede Antares localizada em Ubatuba-SP.

Epinephelus sp. - Só foi encontrada uma larva no estágio de flexão em fevereiro/2015.

Serranus sp. - para esta espécie o maior percentual foi de larvas em flexão $(n=8)$ com ocorrência em fevereiro/2015. Houve um só indivíduo identificado na fase pós-flexão em fevereiro/2014. 


\section{SCIAENIDAE}

Cynoscion sp. - esta espécie esteve presente em sete dos 12 meses de coleta, com maior quantidade de larvas em março a julho/2014. Todas as larvas foram classificadas no estágio de pré-flexão, com maior número em julho/2014 (Fig. 37).

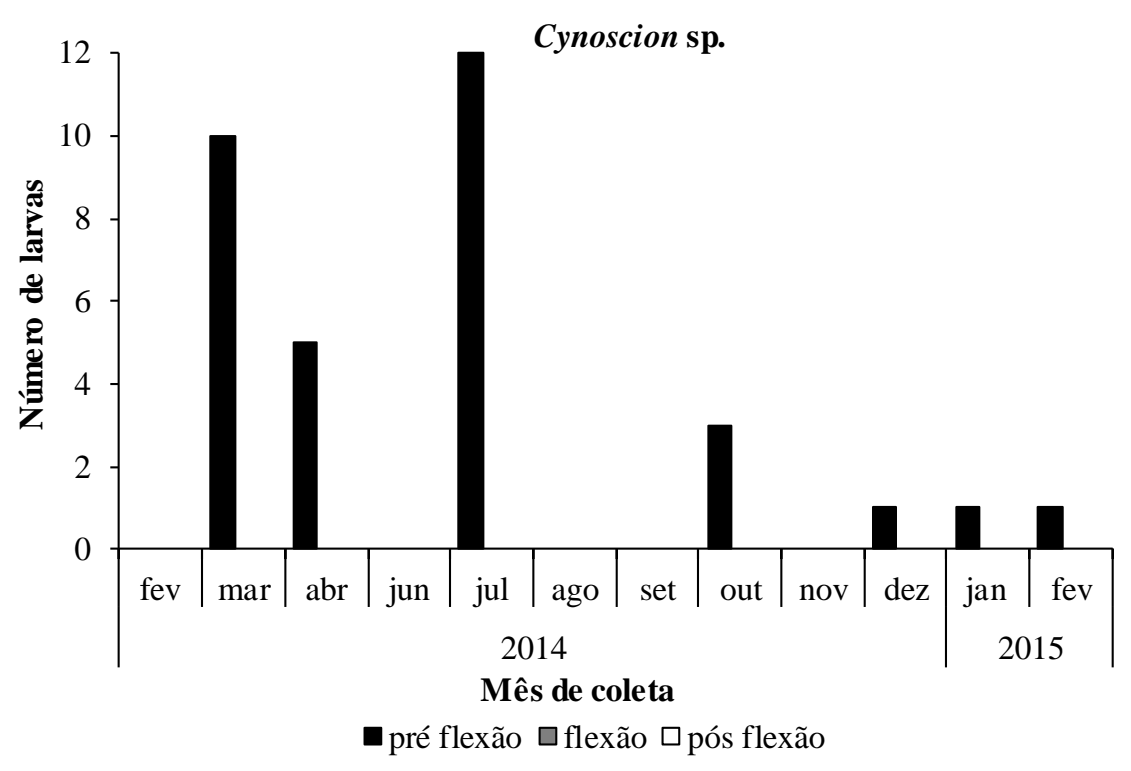

Figura 37. Cynoscion sp. - Distribuição mensal do número de larvas nos estágios de desenvolvimento pré-flexão, flexão e pós-flexão coletadas em estação fixa da rede Antares localizada em Ubatuba-SP.

I. parvipinnis - Das quatro larvas dessa espécie, uma na fase de flexão ocorreu em abril/2014 e três na fase de pós-flexão, em junho e agosto/2014.

M. americanus - os três estágios de desenvolvimento larval ocorreram em março/2014, mês de maior número de larvas dessa espécie. A fase de pré-flexão foi a mais frequente (60\%), ocorrendo também em agosto, outubro e dezembro/2014. As larvas no estágio de flexão, foram registradas também em outubro/2014. Foi identificada apenas uma larva em pós-flexão (Fig. 38). 


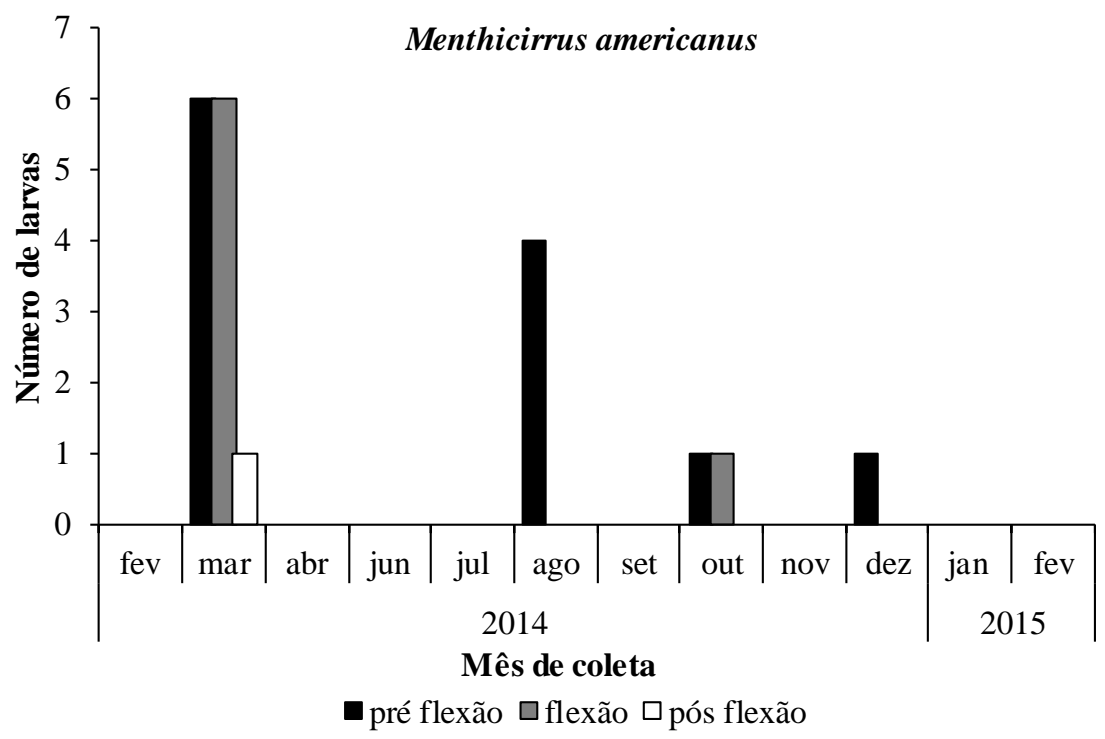

Figura 38 M. americanus - Distribuição mensal do número de larvas nos estágios de desenvolvimento pré-flexão, flexão e pós-flexão coletadas em estação fixa da rede Antares localizada em Ubatuba-SP.

Stellifer sp.: Os três estágios de desenvolvimento larval ocorreram em abril/2014. O estágio de pré-flexão, o mais frequente (55\%), teve maior ocorrência em março/2014. O estágio de flexão ocorreu em três meses e larvas na fase de pós-flexão estiveram presentes apenas em abril/2014 (Fig. 39).

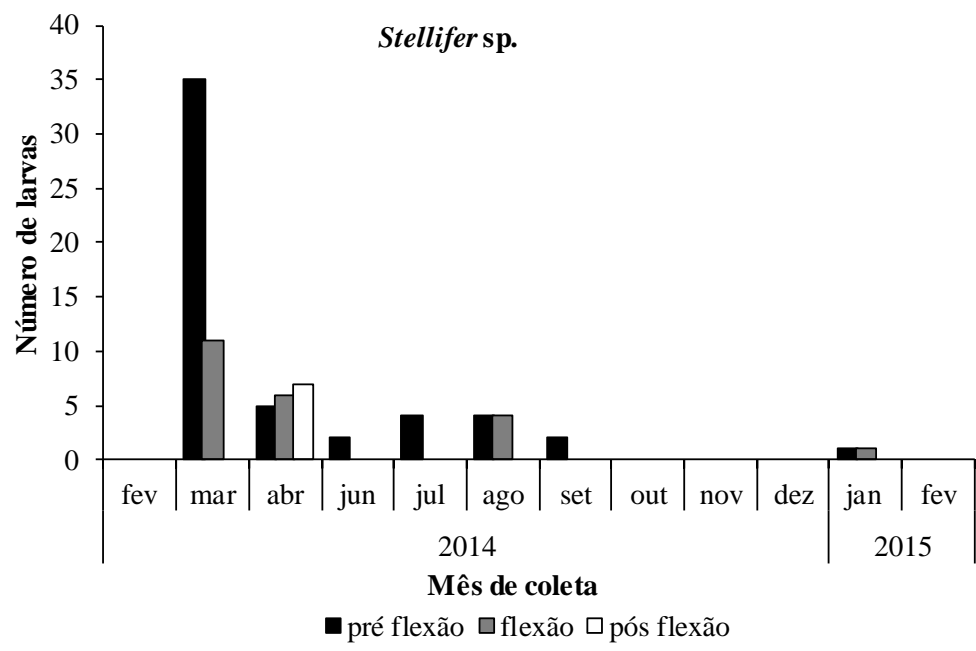

Figura 39. . Stellifer sp. - Distribuição mensal do número de larvas nos estágios de desenvolvimento pré-flexão, flexão e pós-flexão coletadas em estação fixa da rede Antares localizada em Ubatuba-SP. 
S. rastrifier - As 15 larvas dessa espécie estavam no estágio de pré-flexão com ocorrência em março (n=3) e julho $(n=4)$ de 2014 e fevereiro $(n=8)$ de 2015.

S. stellifer - Em março/2014 foram encontradas as três fases larvais para esta espécie. A maioria das larvas (52\%) estavam em pré-flexão. Os estágios de pré-flexão e flexão tiveram o maior número de larvas identificadas particularmente em junho/2014 (Fig. 40).

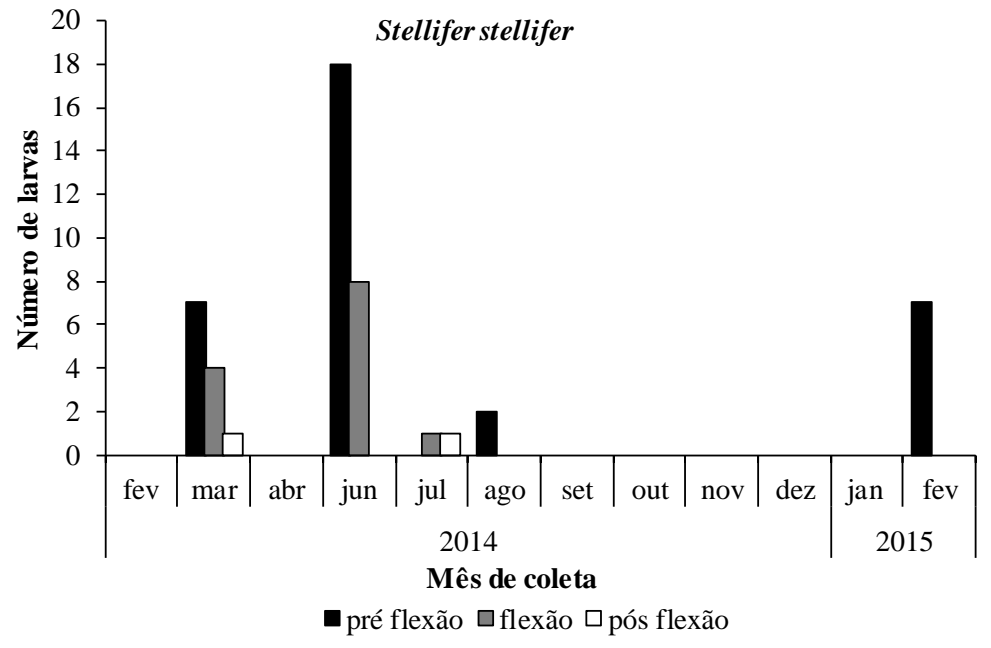

Figura 40. S. stellifer - Distribuição mensal do número de larvas nos estágios de desenvolvimento pré-flexão, flexão e pós-flexão coletadas em estação fixa da rede Antares localizada em Ubatuba-SP. 


\subsection{Análise estatística}

$\mathrm{Na}$ ACP, a maioria dos meses classificados como de baixa influência da ACAS estão próximos ao centro do diagrama caracterizados pela relativa uniformidade das variáveis temperatura e salinidade, e baixos valores de clorofila $a$, e biomassa planctónica de 200 e $300 \mu \mathrm{m}$. Nos meses de junho e setembro/2014, também com baixa influência da ACAS, ocorreram altos valores de biomassa da rede de 200 e $50 \mu \mathrm{m}$, respectivamente. $\mathrm{O}$ mês de fevereiro/14, de alta influência da ACAS, se caracterizou pelos altos valores de clorofila $a$, média e integrada, e biomassa da rede de $300 \mu \mathrm{m}$ (Fig. 41).

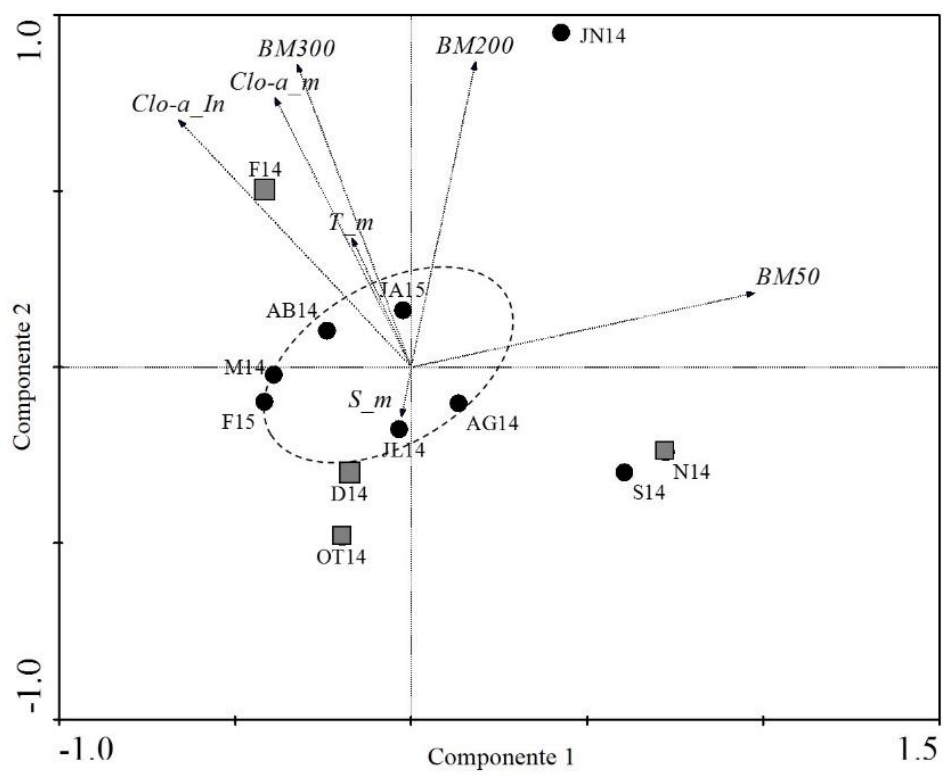

Figura 41. Analise de Componentes Principais para as variáveis ambientais coletadas em estação fixa da rede Antares localizada em Ubatuba-SP. Os dois primeiros componentes explicam $92 \%$ da variância total. T_m: Temperatura média; S_m: salinidade média; Clo-a_In: Clorofila $a$ integrada; Clo-a_m: Clorofila $a$ média; BM50: Biomassa

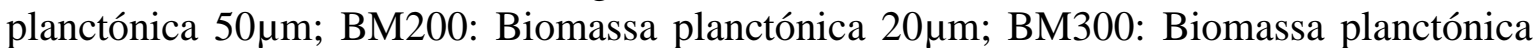
300 $\mu \mathrm{m}$; F14: fevereiro/2014; M14: março/2014; AB14: abril/2014; JN14: junho/2014; JL14: julho/2014; AG14: agosto/2014; S14: setembro/2014; OT14: outubro/2014; N14: novembro/2014; D14: dezembro/2014; JA15: janeiro/2015; F15: fevereiro/2015 Me. Meses com baixa influência de ACAS. $\square$ Meses com alta influência de ACAS. 
No que diz respeito à análise de ACP das espécies das famílias predominantes, foi possível observar separação de três grupos, com base na densidade mensal. No primeiro grupo, estão mais próximos três dos quatro meses com alta influência de ACAS fevereiro, outubro e dezembro/2014, a este grupo também se associaram os meses de julho e setembro/2014 e um pouco mais afastado o mês de janeiro/2015, o mês com alta influência de ACAS que ficou afastado foi novembro/2014. As espécies que favorecem o agrupamento destes meses foram $O$. holbrooki, L. brevibarbe, Caranx sp., S. vômer, T. lathami, S. trewavasae. O segundo grupo esteve formado por março, abril, junho e agosto/2014, aqui se agruparam todas as espécies de Sciaenidae, assim como T. myops, $C$. chrysurus, E. crossotus e Diplectrum sp. No terceiro grupo, só esteve presente fevereiro/2015, este mês se caracterizou por ter a maior quantidade de espécies 13 de 24 , as espécies que se agruparam com este mês foram: E. anchoita, S. setapinnis, C. fimbriata, S. tessellatus, Epinephelus sp., Serranus sp. (Fig. 42)

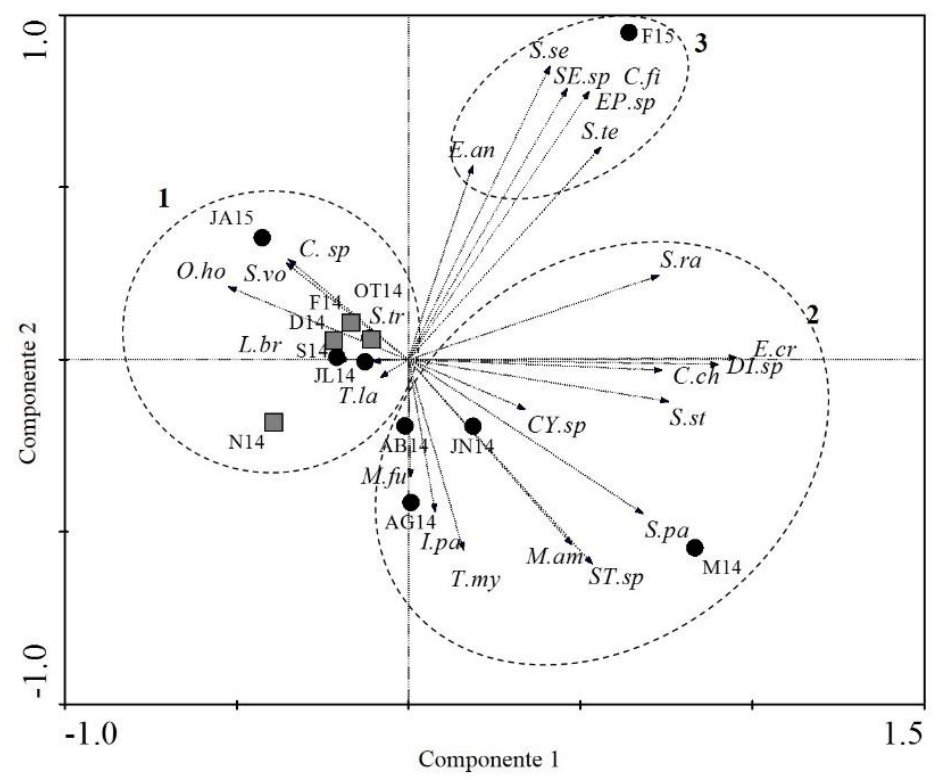

Figura 42. Analise de Componentes Principais para as espécies das famílias predominantes coletadas em estação fixa da rede Antares localizada em Ubatuba-SP. Os dois primeiros componentes explicam 57\% da variância total. E.an: E. anchoita; T.my: T. myops; L.br: L. brevibarbe; O.ho: O. holbrooki; C.ch: C. chrysurus; T.la: T. lathami; C.sp: Caranx sp.; S.se: S. setapinnis; S.vo: S. vômer; E.cr: E. crossotus; C.fi: C. fimbriata; S.pa: S. papillosum; S.te: S. tessellatus; S.tr: S. trewavasae; DI.sp: Diplectrum sp.; SE.sp: Serranus sp.; EP.Sp: Epinephelus sp.; CY.sp: Cynoscion sp.; I.pa: I. parvipinnis; M.am: M. americanus; M.fu: M. furnieri; ST.sp: Stellifer sp.; S.ra: S. rastrifier; S.st: S. stellifer. F14: fevereiro/2014; M14: março/2014; AB14: abril/2014; JN14: junho/2014; JL14: julho/2014; AG14: agosto/2014; S14: setembro/2014; OT14: outubro/2014; N14: novembro/2014; D14: dezembro/2014; JA15: janeiro/2015; F15: fevereiro/2015. - Meses com baixa influência de ACAS. $\square$ Meses com alta influência de ACAS. 


\section{Discussão}

\subsection{Variáveis ambientais}

\subsubsection{Massas de água}

Os dados de temperatura e salinidade registrados no período de estudo (fevereiro/2014 a fevereiro/2015) na estação fixa da rede Antares localizada em Ubatuba$\mathrm{SP}$, indicam que a coluna de água esteve altamente estratificada nos meses de fevereiro, outubro, novembro e dezembro/2014 e janeiro e fevereiro/2015 e com alto grau de mistura em março, junho, julho, agosto e setembro/2014. Estas duas principais características hidrográficas coincidem com as descrições feitas por Castro et al., (1987); Castro et al., (2006a, b); Cerda \& Castro (2014).

Este comportamento é explicado da seguinte maneira: a plataforma continental de Ubatuba apresenta uma variabilidade sazonal da estratificação da coluna de água (Castro, 2014). No fim da primavera e no verão (meses de dezembro, janeiro e fevereiro) uma termoclina sazonal a meia água é a característica hidrográfica recorrente formada a partir do aquecimento da superfície oceânica pela radiação solar e da intrusão pelo fundo da massa de Água Central do Atlântico Sul (ACAS). Durante os meses de outono e inverno, a ACAS se afasta da costa e as condições de mistura caracterizam a coluna de água, como o desaparecimento da termoclina sazonal (Miranda, 1982; Miranda \& Katsuragawa, 1991).

Com relação a temperatura na área de estudo, Santos (2015), evidenciou a presença de um ciclo anual bastante pronunciado. A alternância entre períodos de estratificação e homogeneidade é regular indicando a presença da ACAS em todos os anos de coleta, embora sua intrusão fosse menos pronunciada e restrita.

$\mathrm{Na}$ região estudada, ocorre mistura entre três tipos de massa de água. $\mathrm{O}$ vértice inferior, com baixas temperaturas e salinidades correspondem a ACAS; o máximo de salinidade corresponde a AT; e o mínimo de salinidade, associado a altas temperaturas corresponde a AC (Castro et al., 1987). O formato de espalhamento dos pontos nos meses, de fevereiro, março, setembro, outubro, novembro, dezembro/2014 e janeiro e fevereiro/2015; assim como a localização perto da costa, da estação de coleta, sugere mistura primordialmente bimodal: AC com ACAS tanto na camada superficial, como na camada do fundo este padrão de mistura coincide com o encontrado por Castro et al., (1987) para às estações localizadas mais perto da costa.

As condições mencionadas anteriormente acontecem devido as forçantes hidrográficas tais como: ventos locais e remotos, marés, gradientes de pressão baroclínico 
e a Corrente do Brasil (Castro et al., 2006). Ventos de NE provenientes de Alta Subtropical do Atlântico Sul (ASAS) são característicos do verão. Estes ventos, quando atuam paralelamente à linha de costa empurram as águas superficiais ao largo, através do transporte de Ekman, promovendo a estratificação da coluna de água devido ao preenchimento das regiões mais profundas pela ACAS, massa de água rica em nutrientes. Este fenômeno pode ser denominado intrusão local, uma vez que a ACAS penetra perpendicularmente as isóbatas. A intrusão local tem como via primária a região ao largo de Cabo Frio, recorrente no verão, inverno e primavera, sendo a região ao largo de Ubatuba a via secundária, recorrente na primavera (Cerda \& Castro, 2014; Santos, 2015).

Nos meses de junho, julho, agosto/2014, o diagrama TS reflete homogeneidade termohalina e alta mistura típicas do inverno na plataforma continental do sudeste brasileiro, este comportamento foi evidente nos diagramas de TS espalhados já que os pares TS se agrupam no meio do gráfico, praticamente reduzindo-se a um ponto. Particularmente, Castro et al., (1987) descrevem que a penetração da AT da corrente do Brasil sobre a plataforma continental é menor no verão e maior no inverno; adicionalmente a diminuição dos ventos de nordeste pode enfraquecer o transporte de Ekman, e por tanto não é possível sustentar a intrusão da ACAS sobre a plataforma. A análise de percentuais de massa de água mostrou alto percentual de AT (50 - 60\%) no mês de junho/2014.

Imagens de satélite indicam que houve uma intrusão intensa de AT em direção à plataforma continental (língua mais quente em direção ao norte da Ilha de São Sebastião) devido a um meandro ciclônico de alta intensidade na região de Cabo Frio; a intrusão de AT em direção norte, também pode ser corroborada no contraste de temperatura ao largo da Ilha de São Sebastião Houve a formação de um vórtice anticiclônico ao norte da Ilha de São Sebastião o qual trouxe água do sul-Sudeste. Por tanto, no mês de junho vale ressaltar que a AT registrada no ponto de coleta, era de origem oceânica porquanto bastante misturada, porém, com características próprias de AT ainda (Fig. 43).

No mês de julho/2014 também foi registrado alto percentual de AT no ponto de coleta. A explicação a este evento é semelhante ao mencionado para o mês de junho/2014, ressaltando a importância do vórtice anticiclônico ao norte da ilha de São Sebastião, o qual permite a entrada da plataforma média em direção à costa (Fig. 44).

A intrusão de AT na plataforma continental (isóbata de $50 \mathrm{~m}$ ) também foi registrada por Namiki et al., (2017) estes autores mencionam a entrada de uma língua de AT na plataforma interna, o que é característico de um cenário de inverno a este evento se acoplam a restrição da ACAS às camadas mais profundas e $\mathrm{AC}$ restrita à costa. Este padrão 
é atribuído aos ventos de SE, que se tornam mais frequentes no inverno, assim como a os meandros e redemoinhos da Corrente do Brasil (Campos et al., 2000; Castelao \& Barth, 2006, Palóczy et al., 2014) (Fig. 44).

Finalmente vale mencionar que a profundidade da Zona de mistura ( $\mathrm{Zm})$ : Nos meses de alta influência da ACAS a Zm foi pouco profunda em virtude do aquecimento das águas de superfície e de subsuperfície e ainda, em razão da intrusão mais intensa da ACAS sobre a plataforma continental. No inverno, a pesar da estrutura térmica ser aproximadamente constante na camada correspondente à $\mathrm{Zm}$ foi possível observar altos valores de densidade, este resultado é devido à alta mistura de águas com baixa (AC) e alta (AT) salinidade (Aidar et al., 1993).

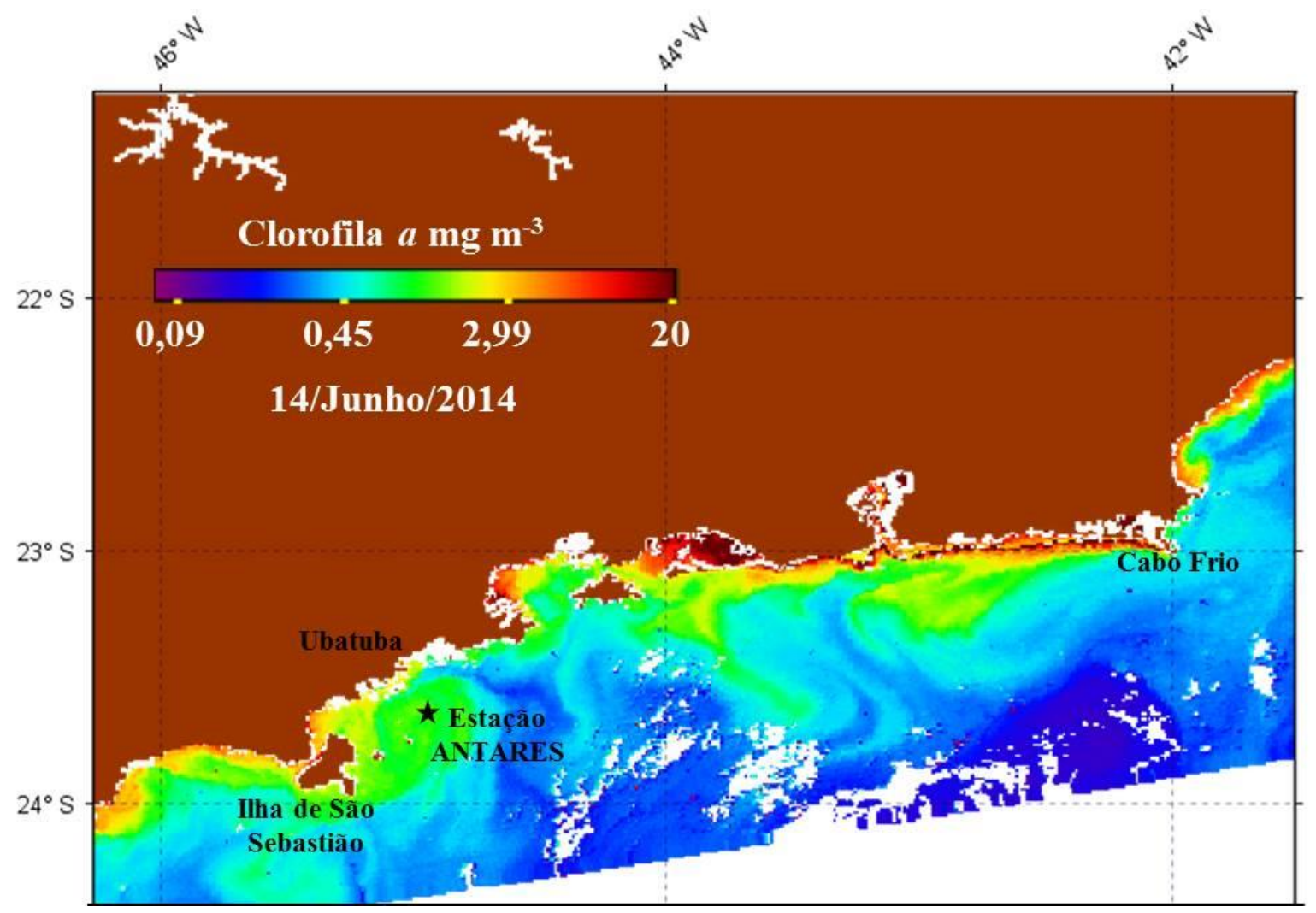

Figura 43. Imagem de satélite do 14/junho/2014 da concentração superficial de clorofila $a \mathrm{mg} \mathrm{m}^{-}{ }^{3}$ é possível identificar os vórtices anticiclônicos perto da Ilha de São Sebastião (fonte: MODIS-Aqua L2A base de dados: https://oceancolor.gsfc.nasa.gov/). 


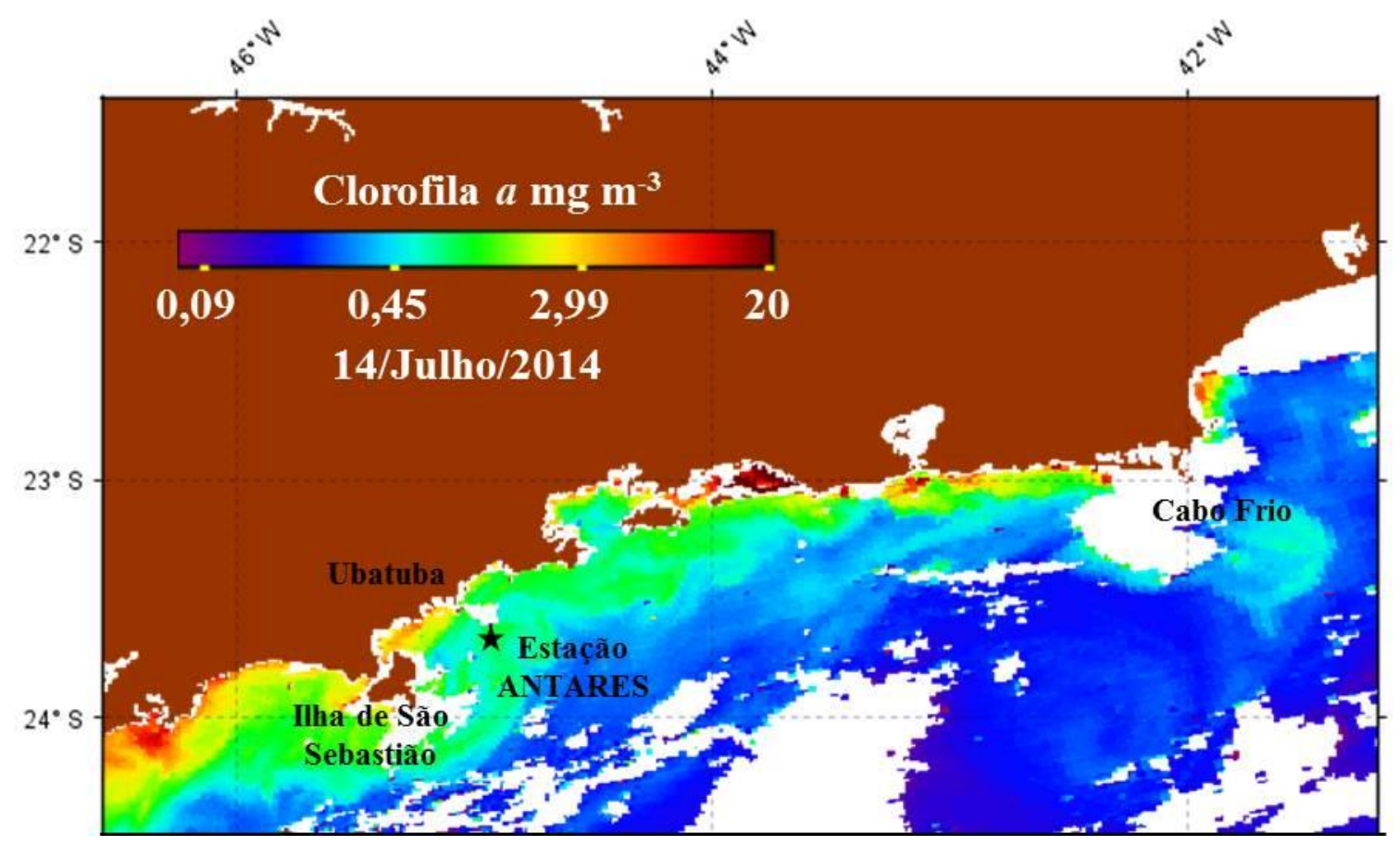

Figura 44. Imagem de satélite do 14/julho/2014 da concentração superficial de clorofila $a \mathrm{mg} \mathrm{m}^{-}{ }^{3}$ é possível identificar os vórtices anticiclônicos perto da Ilha de São Sebastião (fonte: MODIS-Aqua L2A base de dados: https://oceancolor.gsfc.nasa.gov/).

A precipitação pluvial no período de estudo foi altamente particular pois houve déficit critico de precipitação durante 2014 e início de 2015 que foi classificado como excepcionalmente seco com término exageradamente adiantado da estação chuvosa em função da ausência de episódios de ZCAS (Zona de Convergência do Atlântico Sul), particularmente nos primeiros meses de 2014 (Coelho et al., 2016). Vale ressaltar que em 2001 a região do estado de São Paulo teve outro registro de déficit de precipitação gerando uma inesperada crise de energia elétrica devido às perdas no estoque hídrico para geração de energia hidráulica (Drumond \& Ambrizzi, 2005).

$\mathrm{Na}$ análise realizada por Coelho et al. (2016); ressaltam que o ano de 2014 foi o ano mais seco entre 1981 - 2014, já que em termos de quantidade de precipitação este ano não recebeu $75,4 \%$ do total de chuvas acumuladas que era previsto. Entre tanto, este evento não foi particular, pois o estado de São Paulo já passou por situações semelhantes, contudo não tão intensas. Historicamente a menor precipitação ocorreu entre 2013/2014 439,0 mm. A pesquisa destes autores também revelou que esta região vem experimentando temporadas de seca desde 1999/2000 o que indica um padrão de déficit hídrico nos últimos dez e seis anos. 


\subsection{Dados biológicos}

A região de Ubatuba tem características hidrográficas particulares ao longo do ano que leva a variações na estrutura da comunidade planctônica em termos qualitativos e quantitativos. Assim, para entender os padrões de variação anual do ictioplâncton vale mencionar que região de Ubatuba é considerada como uma área oligotrófica (Aidar et al., 1993; Gaeta et al., 1995 e 1999; Brandini et al., 1997).

Os resultados de biomassa fitoplanctônica em termos de clorofila $a$, obtidos para este estudo houve registros de máximo subsuperficial nos meses com alta influencia de ACAS fevereiro, outubro, novembro e dezembro/2014. Os valores de clorofila $a$ deste estudo diferem dos encontrados por Aidar et al., (1993), estes autores reportam valores entre 0,25 a $1,7 \mathrm{mg} \mathrm{m}^{-3}$. Entre tanto coincidem com a análise temporal realizada entre 2005 a 2014 por Santos (2015) onde o valor médio de clorofila $a$ foi de $7 \mathrm{mg} \mathrm{m}^{-3}$ indicando a existência de florações. No presente estudo os valores de clorofila $a$ foram significativamente maiores comparados com o de Aidar et al., (1993) e a média total (1,67 $\mathrm{mg} \mathrm{m}^{-3}$ ) do período de estudo menor do que encontrado por Santos (2015).

Contudo, destaca-se o valor de clorofila $a$ superficial em fevereiro/2014 11,32 mg $\mathrm{m}^{-3}$ devido ao florescimento de Myrionecta rubra, organismo autótrofo protista ciliado de alta capacidade natatória não toxico para humanos ou para organismos marinhos, este evento foi registrado por satélites da NASA em 19/01/2014 a mancha do florescimento cobria aproximadamente $800 \mathrm{~km}$ desde o nordeste e atravessando a plataforma continental no sentido ao sul do pais (Allen et al., 2014). Este evento foi registrado na região de estudo no dia 02/03/1900 e documentado no trabalho de Owen et al., (1992), estes autores atribuem este florescimento às condições de alta luminosidade em subsuperficie o que maximiza a captação de nutrientes por endossimbiose. Por tanto, altas concentrações de nutrientes se fazem necessárias para que aconteçam processos de agregação destes organismos. Por tanto para o evento registrado neste estudo Santos (2015) registrou que as maiores concentrações de nutrientes estiveram associadas à presença de ACAS., o que possivelmente favoreceu a floração de $M$. rubra em fevereiro/2014.

A área de estudo no verão a possui estrutura pelágica definida pela alta radiação luminosa e intenso transporte vertical (Pires-Vanin et al., 1993; Smetacek, 2012). Tais condições de verão levam ao florescimento do fitoplâncton e à chamada produção nova caracteristicamente dominada por diatomáceas. Quando ocorrem florescimentos de fitoplâcnton são transitórios e permanecem por curto tempo na coluna de água. 
Sabe-se que o fitoplâcnton precisa de luz para sua existência, esta condição é expressada em termos de energia luminosa incidente na superfície também conhecida como Zona eufótica $(\mathrm{m})$, esta pode variar ao longo do dia, estando na dependência do regime de circulação da massa de água, da natureza geoquímica da bacia e do regime das chuvas. Em alguns ecossistemas pode atingir poucos centímetros de profundidade, em outros pode atingir profundidades de até $40 \mathrm{~m}$. No presente estudo, a profundidade da zona eufótica variou significativamente em todos os meses de coleta, e não foi possível encontrar um padrão ao longo do ano. Entre tanto, a profundidade de zona eufótica depende, em especial da quantidade de material particulado (orgânico e inorgânico em) presente na coluna de água, apesar das dos altos valore de clorofila $a$ subsuperficial nos meses de outubro, novembro e dezembro/2014 e janeiro/2015 a profundidade da zona eufótica foi maior do que $15 \mathrm{~m}$.

\subsubsection{Biomassa do zooplâncton}

Ambientes costeiros constituem um habitat favorável para as comunidades planctónicas já que existe uma alta disponibilidade de recursos alimentares, cabe ressaltar que na extensão destes ambientes há um elevado índice de capacidade energética, ação de ventos e ondas, além de possuir padrões de circulação que permitem a ancoragem dos estágios ictioplanctônicos (Katsuragawa et al., 1993; Katsuragawa et al., 2011). Diversos estudos revelam que, estes ambientes fornecem alimento e proteção durante as fases inicias do ciclo de vida dos peixes (Barletta-Bergan, et al., 2002, Gonzalez-Bencomo et al., 2003 Bonecker et al., 2007)

Considerando que a região de Ubatuba é uma área oligotrófica, evento que foi comprovado com o registro de baixos valores de clorofila $a\left(\mathrm{mg} \mathrm{m}^{-3}\right)$ o sistema se comporta como de baixa produção (Pires-Vanin et al., 1993). Entretanto neste estudo foram obtidos altos valores de biomassa planctónica com tamanho de $50 \mu \mathrm{m}$

A dominância da biomassa planctónica coletada com a rede de $50 \mu \mathrm{m}$, pode ser atribuída à presencia de copepodito imaturos e de adultos de pequeno porte $(<1000 \mu \mathrm{m})$ que segundo Melo Junior et al., (2016), pertencem aos seguintes gêneros: Oncaea, Temora, Paracallanus, Clausocalanus Oithona e Corycaeus. Esta afirmação é corroborada por Marcolin et al., 2015. A presença destes copepodes de pequeno porte, é explicada, principalmente, pela eficiência de captura sobre o pico e nanoplâncton (Hopcroft et al., 2001; Turner, 2004) quando comparadas com as espécies de maior porte. Agora bem, os 
organismos do nano e picoplâncton são também caracteristicamente abundantes na área de estudo, representando a maior parte da biomassa em termos de clorofila $a$. Em virtude da alta razão entre sua superfície e volume (S/V) esses organismos são capazes de explorar as baixas concentrações de nutrientes dissolvidos, que caracterizam esta região (Aidar et al., 1993; Mesquita, 1993; Pires-Vanin et al., 1993).

Mudanças interanuais na composição da comunidade zooplanctônica são altamente influenciadas pela intensidade de penetração da ACAS pois comunmente esta massa de água está caracterizada por pequenos copépodes e cladoceros mas também organismos de grande porte como C. carinatus são indicadores de ressurgência. Contudo, estes eventos também não duram o suficiente para estimular o crescimento de organismos de grande porte. 


\subsubsection{Ictioplâncton}

A estrutura de assembleias de larvas é resultado de padrões no comportamento de desovas dos adultos, os quais se reproduzem apenas quando as condições são adequadas, como uma tentativa de maximizar sua capacidade reprodutiva, e consequentemente, garantir um número suficiente de sobreviventes (Bialetzki et al., 2005).

A grande variedade de larvas de peixes coletada na região de Ubatuba. Foi possível identificar 17 ordens, 25 famílias, 23 gêneros e 26 espécies, indica a importância da área como local de desova para muitas espécies e reflete a grande diversidade ambiental que caracteriza o ecossistema marinho desta região (Katsuragawa et al., 1993). Uma maior variedade de taxa foi observada anteriormente, mas numa área mais ampla, abrangendo a região até a isóbata de $100 \mathrm{~m} 44$ famílias (Katsuragawa et al., 1993)

Em termos de número de larvas coletadas a família Clupeidae teve uma nítida predominância frente às outras famílias, a espécie que mais contribuiu foi $S$. brasiliensis. A maioria destas larvas foi identificada na fase de pré-flexão e flexão o que indica que houve desovas recentes que segundo Matsuura \& Nakatami (1979), provavelmente fazem parte da desova de alto-mar especificamente da região entre Ilha Grande e Ilha de São Sebastião. O encontrado neste estudo, em termos sazonais, é compatível com a descrição realizada por Matsuura et al. (1992), pois foi identificada durante o fim da primavera e o verão.

Por sua parte Engraulidade e no caso deste estudo a única espécie identificada foi Engraulis anchoita, com alto maior número de larvas, esta família é encontrada durante todo o ano (Matsuura et al., 1992). A presença desta espécie simultaneamente com um alto valor de biomassa de $50 \mu \mathrm{m}$. Em junho/2014 poderia indicar um evento de alimentação bem sucedida por parte da larva pois no inverno quando combinando os efeitos de enriquecimento e relativa estabilidade da coluna de água junto com mecanismos de retenção cream condições ótimas para a alimentação larval (Vascocellos et al., 1998).

Dos Pleuronectiformes a família Paralichthyidade foi a que registrou a maior quantidade de larvas,. Na área de estudo, os adultos desta família são altamente capturados com rede de arrastro de fundo (aproximadamente 30,3\%) (Katsuragawa et al., 1993). Das três espécies identificadas ressalta-se o comportamento de E. crossotus, esta espécie esteve presente ao longo do ano, entre tano nos meses de verão a densidade aumentou, este padrão que não coincide com o encontrado por Garbini et al., (2012) onde as maiores densidades aconteceram no inverno. Vale mencionar que esta espécie pode ser considerada como permanente para a região de Ubatuba pois segue o mesmo comportamento descrito por Bernardes (1995) para o Saco de Mamanguá (RJ). Outra característica relevante é que 
esta espécie é encontrada em locais rasos (Paiva-Filho et al., 1987). As altas densidades destes organismos ocorreram nos meses onde teve alta influencia de ACAS (Rocha 1990). Neste grupo também pertencem as famílias Cynoglossidade, S. tessellatus e S. trewavasae; a primeira espécie segundo Katsuragawa (2014), está entre as quatro espécies de linguado mais abundantes na região sudeste. Souza \& Chaves (2007) afirmam que, tanto Syacium papillosum quanto Symphurus tessellatus possuem seu ciclo reprodutivo incluindo a desova no verão.

A família Sciaenidae esteve presente na maioria dos meses do período de estudo, adicionalmente foi uma com mais número de organismos identificados. De acordo com Soares et al., (2008), em trabalhos de peixes adultos, esta a família mais representativa da região tanto em termos de número como em peso, enquanto que neste estudo assim como nos trabalhos de Katsuragawa et al. $(1993,2008)$ foi a terceira mais abundante. A composição taxonômica desta família associada à frequência de ocorrência e densidade influenciaram a separação dos grupos na análise de APC.

As famílias Synodontidae e Ophidiidae, também fizeram parte das mais frequentes e densas, situação semelhante com a encontrada no trabalho de Katsuragawa et al., (1993). Entretanto a estação de coleta tem como profundidade $40 \mathrm{~m}$, em contraste em outros estudos estas larvas foram coletadas a profundidades maiores entre 60 a $100 \mathrm{~m}$ (Katsuragawa et al., 2008).

Dentro das famílias predominantes estão Carangidade e Serranidae, as maiores densidades destes grupos foram registradas nos meses pertencentes ao verão e ausência quase total delas nos meses do inverno. Vale mencionar que durante a primavera a comunidade do ictioplâncton é dominada por larvas de menor tamanho pertencentes a espécies pelágicas tais como S. brasiliensis, E.anchoita e T.lathami. Estas espécies de pequenos pelágicos têm um padrão de desova alto durante o verão (Katsuragawa \& Matsuura, 1992; Matsuura,1998; Katsuragawa \& Ekau, 2003, Moraes et al., 2012; Katsuragawa et al., 2014).

Vale ressaltar que a família Phosichthyidae só foi identificada em junho/2014. Esta família é mesopelágica e os adultos são conhecidos pelo alto desempenho em migração vertical desde a zona mesopelágica até a zona epipelágica (Priede, 2017). As larvas destes peixes ocorrem em áreas oceânicas ao longo do ano e as altas densidades estão entre 60-80 m, entretanto no inverno se posicionam entre o 40-60 m (Matsuura et al., 1980; Goçalo et al., 2010). Esta família aconteceu simultaneamente com a intrusão de AT na área de estudo verificando a origem oceânica da AT. 
Ao longo do período de estudo foram identificados ovos de peixe, indicando que a região de estudo ocorre desova intensa. É importante mencionar que devido a dificuldade de identificação de ovos, não foi possível aprimorar os resultados neste item.

Tendo em consideração os diferentes comportamentos das larvas identificadas neste estudo cabe mencionar alguns fatores que poderiam ter contribuído para essas diferenças, um deles é a metodologia de amostragem, pois devido ao comportamento agregado do plâncton o arrastro foi feito num lugar onde não estavam localizadas as larvas e não coletar nada, ou pelo contrario a rede passar pelo ponto certo e coletar uma alta quantidade de organismos. Também a estratégia de desova das espécies implica em diferenças na área de ocorrência e forma de reprodução (Katsuragawa et al., 1993).

Uma das estratégias de desova é otimizar o encontro da presa com a larva que precisa de alimento, através de uma sincronia entre a época e local de desova e aumento de zooplâncton. A já mencionada variabilidade intra-anual da comunidade planctônica é uma fonte de presas para os predadores tais como larvas de peixes e medusas; entretanto esta variação é diferente de ano para ano e isso tem consequências importantes para a manter a estabilidade das comunidades ícticas (Marcolin, et al., 2015). Por exemplo, se o alimento de uma espécie é de uma classe de tamanho especifica; a falta desta está diretamente associado ao declínios drásticos da biomassa daquele tipo de peixe na plataforma continental brasileira nos anos seguintes (Matsuura, 1998). 


\section{Considerações Finais}

Foi possível identificar a presença das três massas de água AC, AT e.ACAS. A ACAS esteve presente nos primeiros dois meses do estudo e nos cinco finais, entretanto o percentual de presença na coluna de água variou entre os meses devido a forçantes externas que permitem a entrada desta massa mais perto da costa.

Embora Ubatuba seja considerada como oligotrófica, os altos valores de Clorofila $a$ encontrados neste trabalho, tanto em superfície como em camadas subsuperficias, indicam que esta classificação merece ser reavaliada.

Apesar de na coluna de água da região de Ubatuba o suplemento de nutrientes externos para manter um estoque de produção nova não ser contínuo, os organismos planctônicos de menor tamanho $(50 \mu \mathrm{m})$ conseguem ser bem sucedidos e alcançar altas densidades, superando, em termos de peso seco, os organismos maiores (200 a $300 \mu \mathrm{m}$ ).

A composição taxonômica do ictioplâncton encontrada neste trabalho coincide com àquela conhecida na costa sudeste do Brasil, entre Cabo Frio (RJ) e Cabo de Santa Marta Grande (SC), embora o número de grupos taxonômicos tenha sido inferior.

As larvas de Clupeidae foram as mais abundantes seguidas pelas de Paralichthyidae e Sciaenidae.

O verão foi a época com maior densidade de larvas, indicando maior intensidade de desova nesta região nessa época do ano, simultâneo à entrada de ACAS e o aumento de nutrientes na coluna de água.

O comportamento da densidade de diferentes espécies de larvas de peixes assim como as condições de biomassa fitoplanctônica e zooplactônica evidenciam que a região de Ubatuba segue um caminho diferente da via clássica fitoplâcnton $\rightarrow$ zooplâncton $\rightarrow$ peixe. Portanto é provável que o sistema trófico seja sustentado por outra via alternativa que é o desenvolvimento de uma rede microbiana robusta que se sustenta da degradação de material orgânico que chega ao sistema proveniente do continente ou por entrada de águas de origem oceânica. $\mathrm{O}$ estudo da composição quantitativa e qualitativamente dessa rede microbiana deve ser objeto de futuros estudos. 


\section{Referências bibliográficas}

AIDAR, E.; GAETA, A. S.; GIANESELLA-GALVÃO, S. M. F.; KUTNER, B. M. B.; TEIXEIRA, C. Ecossistema costeiro subtropical: nutrientes dissolvidos, fitoplâncton e clorofila e suas relações com as condições oceanográficas na região de Ubatuba, SP. Publicações Especias Instituto Oceanográfico. Universidade de São Paulo, v. 10, n. 10, p. 9-43, 1993.

ALLEN, J. A.; CARLOWICZ, M.; AND CIOTTI, A. M. In: Earth Observatory. Dark Bloom in the South Atlantic. Disponível em: $<$ https://earthobservatory.nasa.gov/IOTD/view.php?id=82968\&src=ve>. Acesso em: 05 abr 2018.

AMOR, C. C. Intrusões da Água Central do Atlântico Sul sobre a Plataforma Continental situada entre a Ilha de São Sebastião (SP) e o Cabo de São Tomé (RJ). Tese de Doutorado - Instituto Oceanográfico, Universidade de São Paulo, São Paulo, 2004.

BARLETTA-BERGAN, A.; BARLETTA, M.; SAINT-PAUL, U. Structure and seasonal dynamics of larval fish in the Caeté river estuary in North Brazil. Estuar. Coast. Shelf Sci., v. 54, p. 193-206, 2002.

BARROS, F. B. A. G.; CASTRO, M. S.; BONECKER, A. C. T. Descrição e distribuição das larvas de duas espécies da família Fistulariidae (Teleostei, Syngnathiformes) no sudeste do Brasil. Biota Neotrop. v. 7, n. 1, p. 101-104, 2007.

BERNARDES, R. A. Estrutura e dinâmica da ictiofauna do saco de mamanguá (Paraty, RJ). 1995. 145 f. Tese de Doutorado - Instituto Oceanográfico, Universidade de São Paulo, São Paulo, 1995.

BIALETZKI, A.; NAKATANI, K.; SANCHES, P. V.; BAUMGARTNER. G.; GOMES, L. C. Larval fish assemblage in the Baía River (Mato Grosso do Sul State, Brazil): Temporal and spatial patterns. Environ. Biol. Fish., v. 73, p. 37-47, 2005.

BOERSETH, C. Spatial dynamics and characterization of the ichthyoplankton community of natural and artificial reef environments on the coast of Paraná, state, South Brazil. Dissertação de Mestrado - Instituto Oceanográfico, Universidade de São Paulo, São Paulo, 2016.

BONECKER, A. C. T.; NAMIKI, C. A. P.; CASTRO, M. S.; CAMPOS, P. N. Catálogo dos estágios iniciais de desenvolvimento dos peixes da bacia de Campos [online]. 1. ed. Curitiba: Sociedade Brasileira de Zoologia, 2014. 295 p. 
BONECKER, S. L. C.; DIAS, C. O.; FERNANDES, L. D. A.; AVILA L. R. Zooplâncton, In: J.L. VALENTIN (Ed.). Características Hidrobiológicas da Região Central da Zona Econômica Exclusiva Brasileira (Salvador, BA, ao Cabo de São Tomé, RJ). Brasília, Ideal Gráfica e Editora, 2007. p. 125-140.

BONECKER, A. C. T. et al. Estrutura espacial e temporal da comunidade ictioplanctônica. In: FALCÃO, A.P. (Org.). Ambiente Pelágico. 1ed. Rio de Janeiro: Elsevier, 2017. p. 207-245.

BRAAK, C. J. F.; SMILAUER, P. CANOCO for Windows. Version 4.54. Biometrics - Plant Research International. Wageningen, Netherlands, 2006.

BRANDINI, F. P. et al. Planctonologia na plataforma continental do Brasil, diagnose e revisão bibliográfica. Avaliação do potencial sustentável de recursos vivos na zona econômica exclusiva REVIZEE, 1997. p. 196.

BRANDINI, F. P.; TURA, P. M.; SANTOS, P. P. G. M. Ecosystem responses to biogeochemical fronts in the South Brazil Bight. Prog. Oceanogr., n. 164, p. 52-62, 2018.

BAKUN, A. Fronts and eddies as key structures in the habitat of marine fish larvae: opportunity, adaptive response and competitive advantage. Sci. Mar., v. 70S2, p. 105-122, 2006.

CAMPOS, E. J. D.; VELHOTE, D.; SILVEIRA, I. C. A. Shelf break upwelling driven by Brazil current cyclonic meanders. Geophys. Res. Lett., v. 27, p. 751-754, 2000.

CASTElAO, R. M.; BARTH, J. A. Upwelling around Cabo Frio, Brazil: the importance of wind stress curl. Geophys. Res. Lett., v. 33, n. 3, L03602, 2006.

CASTRO FILHO, B. M.; MIRANDA, L. B.; MIYAO, S. Y. Condições Hidrográficas na Plataforma Continental ao Largo de Ubatuba: Variações Sazonais e em Média Escala. Bol. Inst. Oceanogr., n. 35, v. 2, p. 135-151, 1987.

CASTRO B. M. Correntes e massas de água da Plataforma Continental Norte de São Paulo. Tese de Livre-Docência - Instituto Oceanográfico, Universidade de São Paulo, São Paulo, 1996.

CASTRO, B. M.; MIRANDA, L. B. Physical oceanography of the western Atlantic continental shelf located between $4^{\circ} \mathrm{N}$ and $34^{\circ} \mathrm{S}$ coastal segment $(4, \mathrm{~W})$. In: Robinson, A. R.; Brink, K. H. (Eds.). The Sea, volume 11. New York: Jhon Wiley \& Sons, 1998. p. $209-251$. 
CASTRO, B. M. et al. Multidisciplinary oceanographic processes on the Western Atlantic Continental Shelf locate between 4N and 34S. In: In: Robinson, A.R., Brink, K.H. (Eds.), The Sea, volume 14. Cambridge: Harvard University Press, 2006a. p. 259-293.

CASTRO, B. M. et al. Estrutura termohalina e circulação na região entre o Cabo de São Tomé (RJ) e o Chuí (RS). In: Rossi-Wongtschowski, C. L. D. .; Madureira, L. S. P. (Eds.). O Ambiente Oceanográfico da Plataforma Continental e do Talude na Região Sudeste-Sul do Brasil. São Paulo: Edusp. 2006b. p. 11 - 120.

CASTRO, B. M. Summer/winter stratification variability in the central part of the South Brzil Bight. Cont. Shelf. Res., n. 89, p. 15-23, 2014.

CERDA, C., CASTRO, B. M. Hydrographic climatology of South Brazil Bight shelf waters between São Sebastião $\left(24^{\circ} S\right)$ and Cabo São Tomé $\left(22^{\circ} S\right)$. Cont. Shelf Res., v. 89 , p. 5-14, 2014.

CHAO, L. N. Sciaenidae. Croakers (drums). In: CARPENTER, K. E. (Ed.). The living marine resources of the Western Central Atlantic. FAO Species Identification Guide for Fishery Purposes. Special Publications - American Society of Ichthyologists and Herpetologists, n. 5. Rome: Food and Agriculture Organization of the United Nations, 2002. p. 1583-1653.

COACHMAN, L. K. Circulation water masses, and fluxes on the southeastern Bering Sea shelf. Cont. Shelf Res., n. 5, v. 1/2, p. 23 - 108, 1985.

COElHO, C. A. S.; CARDOSO, D. H. F.; FIRPO, M. A. F. Precipitation diagnostics of an exceptionally dry event in São Paulo, Brazil. Theor. Appl. Climatol., v. 125, p. 769-784, 2016.

DIAS, J. F. Avaliação da condição nutricional das larvas de sardinha-verdadeira (Sardinella brasiliensis Steindachner, 1879) Clupeidae e da anchoita (Engraulis anchoita Hubbs; Marini, 1935) Engraulididae, da costa sudeste do Brasil. Tese de Doutorado Instituto Oceanográfico, Universidade de São Paulo, São Paulo, 1995.

DITTY, J. G.; SHAW, R. F.; FAROOQI, T. Sciaenidae. In: RICHARDS, W. J. (Ed.). Early stages of atlantic fishes: an identification guide for the Western Central North Atlantic. CRC marine biology series. Boca Raton: CRC Press, Taylor \& Francis, 2006. p. $1669-1723$.

DRAPER, N. R.; SMITH, H. Applied regression analysis. New York: John Wiley \& Sons, 1966. 
DRUMOND A. R. M.; AMBRIZZI, T. The role of SST on the South American atmospheric circulation during January, February and March 2001. Clim. Dyn., v. 24, n. 7 8, p. 781-791, 2005.

DUGDALE, R., GOERING, J., Uptake of new and regenerated forms of nitrogen in primary productivity. Limnol. Oceanogr., n. 12, p. 196-206, 1967.

EMILSSON, I. The shelf and coastal waters off Southern Brazil. Bol. Inst. Oceanogr., S. Paulo, v. 11, p. 101-112, 1961.

EPPLEY, R. W.; HOLM-HANSEN, O. Primary production in the southern California Bight. In: Eppley, R. W. (ed.) Plankton dynamics of the southern California Bight. New York, Springer-Verlag, 1986. p.176-215.

FAHAY, M. P. Early stages of fishes in the Western North Atlantic Ocean (Davis Strait, Southern Greenland and Flemish Cap to Cape Hatteras), volume 1, p. 1-931, 2007a.

FAHAY, M. P. Early stages of fishes in the Western North Atlantic Ocean (Davis Strait, Southern Greenland and Flemish Cap to Cape Hatteras), v. 2, p. 932-1696. 2007 b.

FAVERO, J. M. et al. Using new tools to identify eggs of Engraulis anchoita (Clupeiformes, Engraulidae). J. Fish. Biol., v. 86, p. 822-826, 2014.

FAVERO, J. M. et al. Spawning areas of Engraulis anchoita in the Southeastern Brazilian Bight during late-spring and early summer. Prog. Oceanogr., v. 153, p. 37-49, $2017 \mathrm{a}$.

FAVERO, J. M. et al. Seasonal and regional variation in egg size of the Argentine anchoita (Engraulis anchoita) in the southeastern Brazilian Bight. Fish B-NOAA, v. 115, p. $517-531,2017 b$.

FIADI, C. B. Influência do ambiente na higidez de larvas de engraulidídeos coletada na região de Santos (SP). Dissertação de Mestrado - Instituto Oceanográfico, Universidade de São Paulo, São Paulo. 2008.

FIGUEIREDO, G. M.; NASH, R. D. M.; MONTANGNES, D. J. S. The role of the generally unrecognized microprey source as food for larval fish in the Irish Sea. Mar. Biol., v. 148, p. 395-404, 2005.

FREIRE, K. M. F. Alimentação de larvas de Engraulis anchoita (Teleostei: Engraulididae) na plataforma continental do Rio Grande do Sul, Brasil. Dissertação de Mestrado - Fundação Universidade do Rio Grande, Rio Grande, 1995. 
FREITAS, D. M.; MUELBERT, J. H. Ichthyoplankton Distribution and Abundance off Southeastern and Southern Brazil. Braz. Arch. Biol. Technol., v. 47, n. 4, p. 601-612, 2004.

GAETA, S. A. et al. Environmental forcing on phytoplankton biomass and primary productivity of the coastal ecosystem in Ubatuba region, Southern Brazil. Rev. Bras. Oceanogr., v. 47, p. 11-27, 1999.

GAETA, S. A. et al. Size-fractionation of primary production and phytoplankton biomass on inshore waters of the Ubatuba region, Brazil. Publ. Esp. Inst. Oceanogr., v. 11, p. 153-162, 1995.

GARBINI, C. N. Distribuição e densidade de larvas de Pleuronectiformes na região entre o cabo de São Tomé (RJ) e a ilha de São Sebastião (SP). Dissertação Mestrado - Instituto Oceanográfico, Universidade de São Paulo, São Paulo, 2012.

GOÇAlO, C. G.; KATSURAGAWA, M. ; SILVEIRA, I. C. A. Patterns of distribution and abundance of larval Phosichthyidae in the Southeastern Brazilian waters. Braz. J. Oceanogr., v. 59, p. 213-229, 2011.

GONZALEZ-BENCOMO, E. J.; BORJAS, J. A. Inventory of the fish of the La Palmita Bay, in the straits of the Lake Maracaibo, Venezuela. Bol. Centro Invest. Biol., v. 37, n. 2, p. 83-102, 2003.

GUILLE, A. Benthic bionomy of continental shelf of the French Catalane coast. II: Benthic communities of the macrofauna. Vie Milieu, v. 21, n. 8, p. 149-280, 1970.

GUY, M. S. P. P. Influência do campo de ventos e do meandramento da Corrente do Brasil na concentração de clorofila a e nutrientes ao largo de Ubatuba - SP. Dissertação de Mestrado - Instituto Oceanográfico, Universidade de São Paulo, São Paulo, 2015.

HAMMER, Ø.; HARPER, D. A. T.; and RYAN, P. D. Past: Paleontological Statistics Software Packeage for Education and Data Analysis. Palaeontol. Electron., n. 1, v. 4, p. 1-9, 2001.

HARRISON, P. J.; PARSONS,T. R. Fisheries Oceanography: an integrative approach to fisheries ecology and management. Oxford: Blackwell Science, 2001.

HEMPEL, G. Early life history of marine fish: the egg stage. Seattle: University of Washington Press, 1979.

HINRICHSEN, D. Coastal Water of the World: Trends, Threats, and Strategies. Washinton D. C.: Island Press, 1998. 
HONGYU, K. et al. Principal component analysis: theory, interpretations and applications. Engineering and Science, v.1, p. 83-90, 2015.

HOPCROFT, R. R.; CHAVEZ, F. P.; ROFF, J. C. Size paradigms in copepod communities: a re-examination. Hydrobiologia, v. 453/454, p. 133-141, 2001.

ITAGAKI, M. K. et al. Description of larvae and juveniles of Bairdiella ronchus (Sciaenidae: Teleostei) in Southeastern Brazil. Sci. Mar., v. 71, n. 2, p. 249- 257, 2007.

JAHNKE, R. A. Global Synthesis. In: LIU, K.-K. et al. (Eds.). Carbon and nutrient fluxes in continental margins. Berlim: Springer, 2010.

KATSURAGAWA, M. 1990. Estudo sobre o desenvolvimento, a distribuição e a densidade de larvas de carangídeos da costa sudeste do Brasil. Tese de doutorado Instituto Oceanográfico, Universidade de são Paulo, São Paulo, 1990.

KATSURAGAWA, M. Larval Development of the Atlantic Moonfish Selene Setapinnis (Osteichthyes, Carangidae) from southeastern Brazil. Bull. Mar. Sci., v. 61, n.3, p. 779-789, 1997.

KATSURAGAWA, M.; MATSUURA, Y. Comparison Of The Diel And Spatial Distribution Patterns Of Ichthyoplankton And Ichthyoneuston In The Southeastern Brazilian Bight. Bol. Inst. Oceanogr., S. Paulo, v. 38, n. 2, p. 133-146, 1990.

KATSURAGAWA, M.; MATSUURA, Y. Distribution and abundance of Carangid Larvae in the Southeastern Brazilian Bight during 1975-1981. Bol. Inst. Oceanogr., S. Paulo, v.40, n. 1-2, p. 55-78, 1992.

KATSURAGAWA, M. et al. O ictioplâncton ao largo de Ubatuba, SP: composição, distribuição e ocorrência sazonal (1985-1988). Publção esp. Inst. Oceanogr., S Paulo, v. 10, p. 85-121, 1993.

KATSURAGAWA, M.; EKAU, W. Distribution, growth and mortality of young rough scad, Trachurus lathami, in the southeastern Brazilian Bight. J. Appl. Ichthyol., v. 19, n. 1, p. 21-28, 2003.

KATSURAGAWA, M. et al. Ichthyoplankton distribution and abundance in the northern Todos os Santos and Camamu bays, Bahia state - Brazil. Braz. J. Oceanogr., v. 59, n. 1, p. 97-109, 2011.

KATSURAGAWA, M.; FERRAS, J. D.; LEÃO, C. L. 2008. Ictioplâncton. In: PIRES-VANIN, A. M. Oceanografia de um Ecossistema Subtropical: Plataforma de São Sebastião, SP. 1. ed. São Paulo: EDUSP, v. 01, 2008. p. 273-310. 
KATSURAGAWA, M.; MUELBERT, J. H; DIAS, J. F. O Ictioplâncton na região entre o cabo de São Tomé (RJ) e o Chuí (RS). In: ROSSI-WONGTSCHOWSKI, C.L; MADUREIRA, L. (Org.). O ambiente oceanográfico da plataforma continental e do talude na região sudeste-sul do Brasil. São Paulo: EDUSP, 2006. p. 359 - 446.

KATSURAGAWA, M. et al. Patterns in larval fish assemblages under the influence of the Brazil Current. Cont. Shelf Res., v. 89, p. 103-117, 2014.

KENDAll Jr, A. W.; AHLSTROM, E. H.; MOSER, H. G. 1984. Early Life History Stages of Fishes and Their Characters. In: MOSER, H. G. et al. (Eds.). Ontogeny and Systematics of Fishes. American Society of Ichthyologists and Herpetologists. Special Publication Number 1, 1984. p. 11-22.

KRAUS, L. A. S.; BONECKER, A. C. T. The spawning and early stages o Cetengraulis edentulus (Cuvier, 1824) (Pisces - Engraulidae) in a fixed point in Guanabara Bay. Rev. Brasil. Biol., v. 54, n. 2, p. 199-209, 1994.

LE FRÉVE, J. Aspects of the biology of frontal systems. Adv. Mar. Biol., v. 23, p. 163-299, 1986.

LEGENDRE, L. \& LEGENDRE, P. Ecologie numerique, 2 ed. Tome 2: La structure des donnres Ecologiques. Masson: Paris et les Presses de l'Universit du Qurbec, 1984a.

LEGENDRE, P. Constrained clustering. In: LEGENDRE, P.; LEGENDRE, L. (eds), Developments in numerical ecology. NATO ASI Series, Vol. G 14, Berlin: Springer, 1987. p. 289-307.

LEIS, J. M.; RENNIS D. S. The Larvae of Indo-Pacific Coral Reef Fishes. Honolulu: University of Hawaii Press, 1983.

LEIS, J. M.; TRNSKA, T. The Larvae of Indo-Pacific Shorefishes. Honolulu: University of Hawaii Press, 1989.

LOPIZ, J. K. et al. Early Life History and Fisheries Oceanography New Questions in a Changing World. Oceanography, v. 27, n. 4, p. 26-41, 2014.

LONGHURST, A. R; PAULY, D. Ecologia dos Oceanos Tropicais. São Paulo: EDUSP, 2007.

LOPES, R. M. et al. Zooplankton and ichthyoplankton distribution on the southern Brazilian shelf: an overview. Sci. Mar., v. 70, n. 2, p. 189-202, 2006. 
MAMAYEV, O.L., 1975. Temperature-salinity analysis of world ocean waters. Amsterdam-Oxford-New York: Elsevier Scientific, 1975.

MANN, K. H; LAZIER, J. R. N. Dynamics of Marine Ecosystems. BiologicalOhysical Interactions in the Oceans. Oxford: Blacwell Scientific Publishers, 1991.

MARCOLIN, C. R.; GAETA, S.; LOPES, R. M. Seasonal and interanual variability of zooplankton vertical distribution and biomass size spectra off Ubatuba, Brazil. J. Plankton Res. v. 37, n. 4, 2015.

MATSUURA, Y. 1971. A study of the life history of Brazilian sardine, Sardinella aurita. I. Distribution and abundance of sardine eggs in the region of Ilha Grande, Rio de Janeiro. Bol. Inst. Oceanogr., S. Paulo, v. 20, n. 1, p. 33-60, 1971.

MATSUURA, Y and NAKATANI, K. Ocorrencias de larvas e jovens de peixes na Ilha Anchieta (SP), com algumas anotações sonre a morfologia da Castanha, Umbrina coroides Cuvier, 1830. Bolm. Inst. Oceanogr., S. Paulo, v. 28, n. 1, p. 165-183, 1979.

MATSUURA, Y. Egg development of scaled sardine, Harengula pensacolae Good \& Bean (Pisces, Clupeidae). Bolm. Inst. Oceanogr., S. Paulo, v. 21, p. 129-135, 1972.

MATSUURA, Y. O Ciclo de Vida da Sardinha Verdadeira - Introdução à Oceanografia Pesqueira. Publ. Esp. Inst. Oceanogr., S. Paulo, n. 4, p. 1-146. 1977.

MATSUURA, Y.; NAKATAMI, K.; TAMASSIA, S. T. J. Distribuição Sazonal de Zooplâncton, Ovos e Larvas de Peixes na Região Centro-Sul do Brasil (1975-77). Bol. Inst. oceanogr., São Paulo, v. 29, n. 2, p. 231-235, 1980.

MATSUURA, Y.; SATO, G. Distribution and abundance of scombroid larvae in southern Brazilian waters. Bull. Mar. Sci., v. 31, n. 4, p. 824-32, 1981.

MATSUURA, Y.; SPACH, H. L.; KATSURAGAWA, M. Comparison of spawning patterns of the Brazilian sardine (Sardinella brasiliensis) and anchoita (Engraulis anchoita) in Ubatuba region, southern Brazil during 1985 through 1988. Bolm. Inst. Oceanogr., v. 40, n, p. 101-115, 1992.

MATSUURA, Y. OLIVAR, M. P. Fish Larvae. In: DEMETRIO, B. (Org.) South Atlantic Zooplankton, 1 ed. Leiden: Backhuys Publ. Co., v. 2, 1998. p. 1445-1496.

MATSUURA, Y. Brazilian Sardine (Sardinella brasiliensis) spawning in the Southeast Brazilian Bight over the period 1976 - 1993. Rev. Bras. Oceanogr., v. 46, p. 3343, 1998. 
MELO JUNIOR, M; MARCOLIN R, C.; MIYASHITA, K. L.; LOPES, M. R. Temporal changes in pelagic copepod assemblages off Ubatuba, Brazil. Mar. Ecol. v. 37, n. 4, p. 877-890, 2016.

MELO JUNIOR, M. Produção secundária e aspectos reprodutivos de copépode pelágicos ao largo de Ubatuba (SP, Brasil). Tese de Doutorado - Instituto Oceanográfico, Universidade de São Paulo, São Paulo, 2009.

MESQUITA, H. S. L. Densidade e distribuição do bacterioplâncton nas águas de Ubatuba $\left(23^{\circ} \mathrm{S} 45^{\circ} \mathrm{W}\right)$, Estado de São Paulo. Publ. Esp. Inst. Oceanogr., v. 10, p. 45-63, 1993.

METZLER, P M. Estudo da produtividade primária e características fisiológicas do fitoplâncton na região de Ubatuba, São Paulo, através de curvas de luz-fotossíntese. Dissertação de Mestrado - Instituto Oceanográfico, Universidade de São Paulo, São Paulo, 1991.

MIRANDA, L. B. Análise de massas de água da platarforma continental e da região oceâcnica adjacente: Cabo de São Tomé (RJ) e a Ilha de São Sebastião (SP), Brasil. Tese de Livre Docência - Instituto Oceanografico, Universidade de São Paulo, São Paulo, 1982.

MIRANDA L. B. Forma de correlação T-S de massa de água das regiões costeira e oceânica entre o Cabo de São Tomé (RJ) e a Ilha de São Sebastião (SP), Brasil. Bolm Inst. Oceanogr., S. Paulo, v. 33, n. 2, p. 105-119, 1985.

MIRANDA, L. B.; KATSURAGAWA, M. . Estrutura Térmica Na Região Sudeste do Brasil (Outubro/Novembro de 1988). Pub. Esp. Inst. Oceanogr., S. Paulo, v. 8, p. 1-14, 1991.

MORAES, L. E. D. S. et al. Brazilian sardine (Sardinella brasiliensis Steindachner, 1879) spawning and nursery habitats: spatial-scale partitioning and multiscale relationships with thermohaline descriptors. ICES J. Mar. Sci. , v. 69, n. 939$952,2012$.

MOSER, H. G. \& SMITH, P. E. Larval Fish Assemblages and Oceanic Boundaries. Bull Mar. Sci., v. 53, n. 2, p. 283-289, 1993.

MOSER, H. G. The early stages of fishes in the California current region. La Jolla: California Cooperative Oceanic Fisheries Investigations, Atlas n. 33, 1996. 
NAGELKERKEN, I. et al. The seascape nursery: a novel spatial approach to identify and manage nurseries for coastal marine fauna. Fish Fish., v. 16, n. 2, p. 362-371, 2014.

NAKATAMI, K. Estudos sobre ovos e larvas de Engraulis anchoita (Hubbs Marini, 1935) (Teleostei, Engraulidae) coletados na região entre cabo Frio (23ํ) e cabo de Santa Marta Grande $\left(29^{\circ}\right)$. Dissertação de Mestrado - Instituto Oceanográfico, Universidade de São Paulo, São Paulo, 1982.

NAMIKI, C.; BONECKER, A. C. T.; CASTRO, M. S.. Carapidae (Acanthomorpha, Paracanthopterygii) from the oceanic region of the southwest Atlantic Ocean off Brazil (12-22 ${ }^{\circ}$ S). Deep-Sea. Res. Part I, v. 54, p. 292-295, 2007.

NAMIKI, C.; KATSURAGAWA, M. \& ZANI-TEIXEIRA, M. L. Growth and mortality of larval Myctophum affine (Myctophidae, Teleostei). J. Fish Biol., v. 86, p. 1335-1347, 2015.

NAMIKI, C. Hydrodynamically-driven distribution of lanternfish larvae in the Southeast Brazilian Bight. J. Marine Syst., v. 170, p. 115-133, 2017.

NELSON, J. S.; GRANDE, T. C.; WILSON, M. V. H. Fishes Of The World. Fifth edition. Hoboken, New Jersey: John Willey \& Sons, 2016.

NICHOLLS, R. J.; SMALL, C. Improved estimates of coastal population and exposure to hazards released. Eos Trans. AGU, v. 83, n. 28, p. 301-305, 2002.

OLIVEIRA, A. S. Interações entre sistemas frontais na América do Sul e convecção na Amazônia. Dissertação de Mestrado - Instituto de Pesquisas Espaciais, São José dos Campos, 1986.

OLIVEIRA, G. Q. Análise temporal da concentração de clorofila-a e do campo de ventos na Plataforma Interna de Ubatuba (SP). Trabalho de conclusão de curso Universidade de São Paulo, São Paulo, 2009.

OLSON, D. et al. Life on the edge: marine life and fronts. Oceanography, v. 7, p. 52-60, 1994.

OMORI, M; IKEDA, T. Methods in marine zooplankton ecology. New York, Jhon Wiley \& Sons, 1984 .

OWEN, R.W., 1981. Fronts and eddies in the sea: mechanisms, interactions, and biological effects. In: LONGHURST, A.R. (Ed.), Analysis of Marine Ecosystems. New York: Academic Press, 1981. p. 197-233. 
OWEN, R.W.; GALVÃO-GIANESELLA, S.F.; KUTNER, M.B.B. Discrete, subsurface layers of the autotrophic ciliate Mesodinium rubrum off Brazil. J. Plankton. Res., v. 14, n. 1, p. 97-105, 1992.

PAIVA-FILHO, A. M. et al. Ictiofauna do complexo baia-estuário de santos e são Vicente, sp, brasil. Rel. int. Inst. Oceanogr., S. Paulo, n. 17 p. 1-10, 1987.

PALÓCZY, A. et al. Coastal upwelling off Cape São Tomé $\left(22^{\circ} \mathrm{S}\right.$, Brazil): the supporting role of deep ocean processes. Cont. Shelf Res., v. 89, p. 38-50, $2014 .$.

PAULY, D. Towards sustainability in world fisheries. Nature, v. 418, n. 6898, p. 689-695, 2002.

PEREIRA, E. B. et al. Atlas Brasileiro de Energia solar. Instituto Nacional de Pesquisas Espaciais - INPE. São Jose dos Campos, 2006.

PIRES-VANIN, A. M. S.; MATSUURA, Y. Estrutura e função do ecossistema de plataforma continental da região de Ubatuba, Estado de São Paulo: uma introdução. Publ. esp. Inst. Oceanogr., S. Paulo, v. 10, p. 1-8, 1993.

PIRES-VANIN, A. M. S. A macrofauna bêntica da plataforma continental ao largo de Ubatuba, São Paulo, Brasil. Publ. Esp. Inst. Oceanogr. S Paulo, v. 10. P. 137-158, 1993.

PIRES-VANIN, A. M. S. et al. Estrutura e função do ecossistema de plataforma continental do Atlântico sul brasileiro: síntese dos resultados. Publ. Esp. Inst. Oceanogr. S Paulo, v. 10, p. 217-231, 1993.

PORCARO, R. R. et al. Spatial and temporal distribution patterns of larval sciaenids in the estuarine system and adjacent continental shelf off Santos Southeastern Brazil. Braz. J. Oceanogr., n. 62, v. 2, p. 149-164, 2014.

PRIEDE, I.G. Deep-Sea Fishes: Biology Diversity Ecology and Fisheries. Cambridge: Cambridge University Press, 2017.

RICHARDS, W. J. ed. Early Stages of Atlantic Fishes. An identification guide for the Western Central North Atlantic. CRC Press. Taylor \& Francis. Boca Raton FL. v.1. p. $1-1335,2006 a$.

RICHARDS, W. J. ed. Early Stages of Atlantic Fishes. An identification guide for the Western Central North Atlantic. CRC Press. Taylor \& Francis. Boca Raton FL: v.2, p. 1336-2640, 2006b. 
RYTHER, H. Photosynthesis and fish production from the sea. Science, n. 166, p. 72-80, 1969.

SACCARDO, S. A. M.; KATSURAGAWA, M. Biology of the Rough Scad, Trachurus Lathami, in the Southeastern coast of Brazil. Sci. Mar., v. 58, n. 3-4, p. 265-277, 1995.

SANTOS, G. M. P. P. Influência do campo de ventos e do meandramento da Corrente do Brasil na concentração de clorofila-a e nutrientes ao largo de Ubatuba - SP. Dissertação de Mestrado - Instituto Oceanográfico, Universidade de São Paulo, São Paulo, 2015.

SASSI, R.; KUTNER, M. B. B. Variação sazonal do fitoplâncton na região do

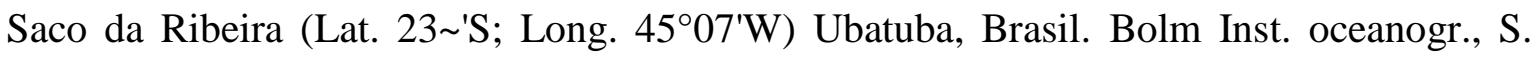
Paulo, n. 31, v, 2, p. 29-42, 1982.

SHEAVES, M. et al. True value of estuarine and coastal nurseries for fish: incorporating complexity and dynamics. Estuaries and Coasts, v. 38, n. 2, p. 401-414, 2015.

SHTOKMAN, W. B. A theory of the T-S curves as a method for studying the mixing of water mases in the sea. J. Mar. Res., v. 6, n. 1, p. 1-24, 1946.

SIMPSON, J. H.; SHARPLER, J. Introduction to the physical and biological oceanography of shelf seas. Cambridge: Cambridge University Press, 2012.

SMETACEK, V. Making sense of ocean biota: How evolution and biodiversity of land organisms differ from that of the plankton. J. Biosci., v. 37, n. 4, p. 589-607, 2012.

SMITH, P. E.; RICHARDSON, S. Standard techniques for pelagic fish egg and larval surveys. FAO Fish. Tech. Paper, p. 8-18, 1977.

SOARES, L. et al. Organização trófica dos peixes. In: PIRES-VANIN, A.M. Oceanografia de um Ecossistema Subtropical: Plataforma de São Sebastião, SP. 1. ed. São Paulo: EDUSP, 2008. p. 405-428.

SOURNIA, A. Pelagic biogeography and fronts. Prog. Oceanogr., v. 34, p. 109$120,1994$.

SOUZA, L. M.; CHAVES, P. T. Atividade reprodutiva de peixes (Teleostei) e o defeso da pesca de arrasto no litoral norte de Santa Catarina, Brasil. Rev. Bras. Zool., v. 24, n. 4, p. 1113-1121, 2007. 
SUSINI-ZILLMANN, S.M. Distribuição do fitoplâncton na radial entre Ilha

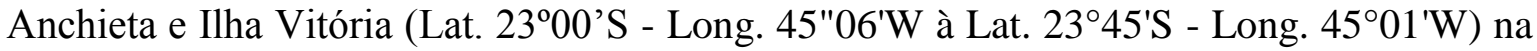
região de Ubatuba, São Paulo. Dissertação de mestrado - Instituto Oceanográfico, Universidade de São Paulo, São Paulo, 1990.

METZLER, P. M. Estudo da produtividade primária e características fisiológicas do fitoplâncton na região de Ubatuba, São Paulo, através de curvas de luz-fotossíntese. Dissertação de mestrado - Instituto Oceanográfico, Universidade de São Paulo, São Paulo, 1991.

TANAKA, S. Stock assessment by means of ichthyoplankton surveys. FAO Fish., v. 122 , p. $33-51,1973$.

TEIXEIRA, C. A influência das variações nictemeral e sazonal sobre as curvas de luz x fotossíntese. Bolm Inst.oceanogr., S Paulo, n, 31, v 1, p. 5-67, 1982.

TEIXEIRA, C. and GAETA, S. A Contribution of picoplankton to primary production in estuarine, coastal and equatorial waters of Brazil. Hydrobiologia, v. 209, p. 117-122, 1991.

TEIXEIRA, C. Daily variation of marine primary production in the Flamengo inlet, Ubatuba region, southern Brazil. In: SIMPÓSIO INTERNACIONAL ALGAS: A ENERGIA DO AMANHÃ, São Paulo, 1982. Anais. Bicudo, C. E. de M.; Teixeira, C. \& Tundisi, J. G., eds Algas: a energia do amanhã. São Paulo, Instituto Oceanográfico da Universidade de São Paulo. P .97-108, 1986.

TURNER, J. T. The importance of small planktonic copepods and their roles in pelagic marine food webs. Zool. Stud., v. 43, p. 255-266, 2004.

TYLER, J.E. The Secchi Disc. Limnol. Oceanogr., v. 13, n. 1, p. 1-6, 1968.

VASCONCELlOS, M. C.; FREIRE, K. F.; CASTELlO, J. P. Distribution patterns and feeding success of anchovy, Engraulis anchoita, larvae off southern Brazil. Sci. Mar., v. 62, n. 4, p. 385-392, 1998.

VIEIRA, A. A. H.; TEIXEIRA, C. Excreção de matéria orgânica dissolvida por populações fitoplanctônicas marinhas em bioensaios com nutrientes. Bolm Inst. oceaoogr., S Paulo, n. 31, v, 1, p. 33-38, 1982.

WELSCHMEYER, N. A. Fluorometric analysis of chlorophyll a in the presence of chlorophyll b and pheopigments. Limnol. Oceanogr., v. 39, n. 8, p. 1985-1992, 1994. 
WOODSON, C.B., LITVIN, S.Y. Ocean fronts drive marine fishery production and biogeochemical cycling. Proc. Natl. Acad. Sci. USA, n. 112, p. 1710-1715, 2015.

WORLD OCEAN REVIEW (WOR) 1. Living with the Oceans - A report on the state of the world's oceans. Maribus, 2010.

YONEDA, N. T. Criação em laboratório de larvas da sardinha-verdadeira, Sardinella brasiliensis, e estudo dos incrementos diários nos otólitos. Dissertação de Mestrado - Instituto Oceanográfico, Universidade de São Paulo, São Paulo, 1987. 